Florida International University

FIU Digital Commons

7-22-2019

\title{
Mechanisms for the Persistence of the Coral Holobiont in the Warming Oceans of the Anthropocene
}

Daniel G. Merselis

Florida International University, dmers001@fiu.edu

Follow this and additional works at: https://digitalcommons.fiu.edu/etd

Part of the Integrative Biology Commons, and the Terrestrial and Aquatic Ecology Commons

\section{Recommended Citation}

Merselis, Daniel G., "Mechanisms for the Persistence of the Coral Holobiont in the Warming Oceans of the Anthropocene" (2019). FIU Electronic Theses and Dissertations. 4287.

https://digitalcommons.fiu.edu/etd/4287

This work is brought to you for free and open access by the University Graduate School at FIU Digital Commons. It has been accepted for inclusion in FIU Electronic Theses and Dissertations by an authorized administrator of FIU Digital Commons. For more information, please contact dcc@fiu.edu. 


\title{
FLORIDA INTERNATIONAL UNIVERSITY
}

Miami, Florida

MECHANISMS FOR THE PERSISTENCE OF THE CORAL HOLOBIONT IN THE

WARMING OCEANS OF THE ANTHROPOCENE

\author{
A dissertation submitted in partial fulfillment of \\ the requirements for the degree of \\ DOCTOR OF PHILOSOPHY \\ in \\ BIOLOGY
}

by

Daniel Garret Merselis

2019 
To: Dean Michael R. Heithaus

College of Arts, Sciences and Education

This dissertation, written by Daniel Garret Merselis, and entitled Mechanisms for the Persistence of the Coral Holobiont in the Warming Oceans of the Anthropocene, having been approved in respect to style and intellectual content, is referred to you for judgment.

We have read this dissertation and recommend that it be approved

Jose M Eirin-Lopez

Jessica Siltberg-Liberles

Diego Lirman

Wensong $\mathrm{Wu}$

$\overline{\text { Mauricio Rodriguez-Lanetty, Major Advisor }}$

Date of Defense: July 22, 2019

The dissertation of Daniel Garret Merselis is approved.

Dean Michael R. Heithaus College of Arts, Sciences and Education

Andrés G. Gil

Vice President for Research and Economic Development and Dean of the University Graduate School

Florida International University, 2019 
C Copyright 2019 by Daniel Garret Merselis

All rights reserved. 


\section{DEDICATION}

I dedicate this dissertation to my parents as its inception and motivation can be traced to their impact on my development.

Thank you for urging me to pursue my passion and providing unwavering support in all that the pursuit requires. I would not have become who I am without your constant encouragement. Your appreciation for nature, the trips to Mayflower Beach, your demonstration of the belief that we should do our part to make the country and world a better place- it shaped the person I aim to be.

For my Father: The tropical fish tank in our living room was a spark in my childhood that triggered my career. You may not have realized it at the time, but by moving that fish tank into my bedroom, you started us down the road for countless hour long (one way) trips to tropical fish stores and the endless conversations we had about the hobby and life. That part of my life is the indirect foundation of this dissertation.

For my Mother: Your insistence that I do my best in school is the main reason I performed above the bare minimum through middle school. Without your persistence it isn't clear that I would have ever realized my love for science, pursued a bachelor's degree, and ultimately gotten exposure to research. Given that I'm currently editing a dissertation, it looks like you won- I will be doing my best as a student my entire career. Thank you! 


\section{ACKNOWLEDGMENTS}

This dissertation wouldn't be possible without the contributions of so many who have helped me along the way!

First I would like to thank my major advisor, Dr. Mauricio Rodriguez-Lanetty. Never before have I worked with or even met someone with such a patient, kindly disposition. He has repeatedly taken risks and demonstrated his trust by investing in side project ideas which fueled my confidence and growth as a scientist. I've never walked out of his office feeling unsupported or unsure of the next steps. There are few people whose scientific and general advice I have come to value so highly.

I am grateful to my committee for their guidance and their valuable expertise! Dr. Wensong $\mathrm{Wu}$ provided statistical advice at numerous junctures throughout this project. Dr. Jessica Siltberg-Liberles challenged me to better understand comparative genomics, consider alternative molecular mechanisms of phenotypic plasticity, and urged me to apply for the DYF. Dr. Diego Lirman brought the critical perspective of an experienced restorationist and field ecologist to the committee and was an invaluable collaborator for Acropora cervicornis work. His rigorous qualifying examination materials and continued feedback have pushed my confidence with experimental design and interpretation. Dr.

Jose M Eirin-Lopez challenged me to approach epigenetics and cell/ molecular biology in general with better appreciate the enormous potential for environmental / epigenetic impact on organismal functions.

I'd also like to thank my lab mates in order of IMaGeS seniority: Dr. Anthony Bellantuono for lending his molecular methodological expertise, zip-tie engineering, and battling my inner curmudgeon to find the features in all the bugs; Dr. Camilla Granados- 
Cifuentes for her ample feedback and attention to detail; Dr. Tanya Brown for her cheerful eagerness in the field and leading by example; Dr. Cynthia Lewis for the excellent conversations, sharing updates from this work's "sister project," and lessons from her extensive field experience; Katherine Dougan for her introduction to QIIME, field support, and support for many projects; Ellen Dow for the field support, mental health check ins, and artwork; Guido Bonthond for collaboration with primer design, dental expertise, and professionally played matches of ping-pong; Dr. Thangadurai Thinesh for his unique perspective and interesting conversation; Patty Waikel for field support, patience, and realism; Hiram Duarte for maintaining sanity, preventing disaster, and his unreasonable insistence to pay; Riley Hatch for his feedback and cheerful disposition; and Vanessa Russnak for rolling with the punches, substantial photophysiology expertise, and dedication.

To my undergraduate assistants- your help was and continues to be invaluable: Christine Rojas, Zacharia Abdulla, Emely Garcia, Cpt. Emmanuel Medrano, Cpt. Gabriel Arias, Cpt. Danny " anemone nanny" Quintero, Alex Dieguz, Alex Ladron De Guevera, Kathan Soni, Hiram Duarte, Brian Kamel, Pakrat Rasamikomen, Laura Carvajal, Gabriel Leiva-Gomez, Taidiana Gonzalez-Santander, Dino Fanfan, Daniel Cambron, Pablo Puentes, Jans Dorta, Genesis De La Vera, Matthew Rodriguez, Emmanuel Mijares, Mariolga Aymat, and Miguel Alcrudo De Jesus all contributed to my success at FIU.

Thanks to Dr. James Fourqurean, Roger Garcia, Otto Rutten at Aquarius, Bill Todd, Kelsey Young and Trevor Graft with NEEMO, Stephanie Schopmeyer, Dalton Hesley, and Ford Drury with Rescue a Reef / Lirman laboratory, Ken Nedimyer at CRF/ 
Reef Renewals, Erich Bartels and Cory Walters at Mote Marine Laboratory and all the others involved in nursery logistics!

My dissertation benefited from the editing of Dean Donnelly--Thanks!

To my family, thanks for your patience and support over the last six years. I look forward to seeing you more often and getting to know my nephews in the near future.

This milestone in my life could not have been accomplished without my wife Leidy! Without her, my life outside of the lab would be non-existent. She's my reason to go home at the end of the day and the primary bulwark mostly preventing my descent into madness (kidding- kind of). Not only is she an emotional bedrock of support, but as a fellow biologist, she provides a second opinion and cross-disciplinary pollination. More specifically, we all owe her a debt of gratitude for saving us from my aesthetic incompetence by guiding me away from color schemes that lab mates and advisor alike have described as hideous.

My dissertation was made possible through the support of a TAship through the Biology department, a semester-long RAship under the support of Dr. James Fourqurean, and an FIU Dissertation Year Fellowship. I got paid to pursue my passion, earn a PhD, and learn to teach. This research was supported by NSF grants RAPID 1503483 and CAREER 1453519 awarded to Dr. Mauricio Rodriguez-Lanetty. 


\title{
ABSTRACT OF THE DISSERTATION \\ MECHANISMS FOR THE PERSISTENCE OF THE CORAL HOLOBIONT IN THE WARMING OCEANS OF THE ANTHROPOCENE
}

\author{
by \\ Daniel Garret Merselis \\ Florida International University, 2019 \\ Miami, Florida \\ Professor Mauricio Rodriguez-Lanetty, Major Professor
}

Coral Reefs are rapidly deteriorating in response to an onslaught of humanmediated stressors. Just one stressor alone, climate change, may extirpate coral reef ecosystems within a human lifetime, threatening societal and ecological catastrophe. Reef-derived ecosystem services are crucial for sustenance, coastal protection, and economic prosperity in over 100 countries. Near-term human decisions will determine whether reef-corals, the ecosystems they engineer, the $25 \%$ of marine biodiversity they support, and the human communities that depend upon them can be protected. My dissertation aims to characterize the potential for corals' adaptive mechanisms to facilitate their continued survival- information which will only represent hope if society takes decisive action on numerous environmental concerns.

Even with swift action to curb carbon emissions, most of the world's reefs will come to experience annual hyperthermal stress beyond their current tolerances. Rapid warming necessitates improvement of physiological limits to prevent mass coral bleaching and disease. Bleaching metabolically deprives corals by terminating their 
obligate nutritional mutualism with symbiodiniacid dinoflagellates, while outbreaks of coral disease result in direct mortality.

Using common garden experiments and coral species with disparate adaptive strategies, my dissertation appraises the feasibility of corals' adaptive mechanisms to facilitate survival under hyperthermal stress and environmental variability along a depthcline. I characterized and monitored Symbiodiniaceae to detect adaptive changes in community identity, appraised the intrinsic capacity for corals to acclimatize, and estimated the potential for adaptation through coral evolution by comparing genotypes within the same species. Monitoring the dynamics of mass bleaching and disease outbreaks further enabled me to disentangle the frequently confounded effects of bleaching and thermal stress on an individual colony's risk of disease.

Surprising results suggest that some bleaching may represent a mechanism of immune-activation by corals preparing to fight disease. I detected limited responsiveness of Symbiodiniaceae community rearrangement and no effect of innate acclimatization under the thermal stress, depth environments, and coral species investigated here. By contrast, variation between coral genotypes was a strong and highly significant predictor of all measurements made throughout this project. My dissertation provides recommendations for leveraging variability in host genotype performance and facilitating enormous evolutionary potential within a restoration framework. 


\section{TABLE OF CONTENTS}

CHAPTER

PAGE

CHAPTER 1: Coral Reef Collapse and Mechanisms of Resistance ..................................

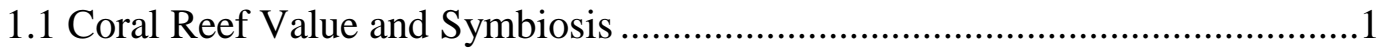

1.2 Threats to Corals and their Mechanisms of Action ..........................................1

1.3 Adaptive Mechanisms of Reef Building Corals .............................................5

1.4 Dissertation Questions, Hypotheses, and Organization ................................11

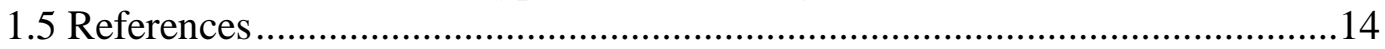

CHAPTER 2: Coral Host Identity, Not Symbiont Identity or Prior Bleaching History Predict the Bleaching Response of the Symbiont Specifist Coral, Acropora

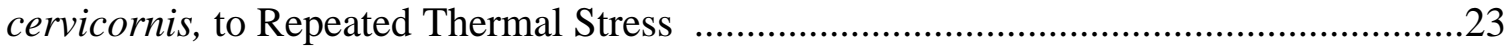

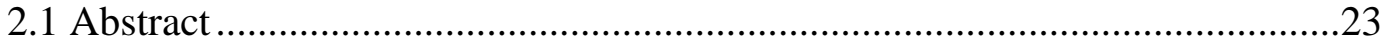

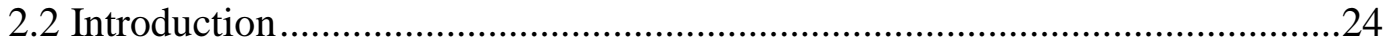

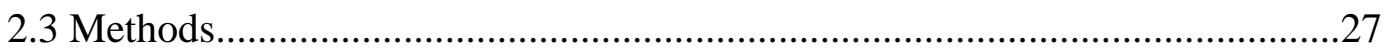

2.3.1 Common Garden Site and Distribution of Corals...........................27

2.3.2 Monitoring of Acropora cervicornis Bleaching and Elucidation of Inter-Annual Acclimatization .................................................................22

2.3.3 Monitoring and Relating Symbiodiniaceae Assemblage to Repetitive Bleaching Response........................................................29

2.3.4 Determining the Role of Host Identity in Repetitive Bleaching

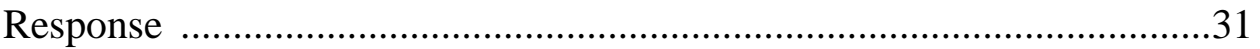

2.4 Results

2.4.1 Inter-annual Dynamism of Coral Ramets' Bleaching Response

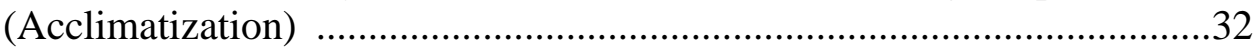

2.4.2 Relationship Between Symbiodiniaceae Assemblage and

Repetitive Bleaching Response

2.4.3 Host Genetic Identity is a Highly Significant Factor Structuring

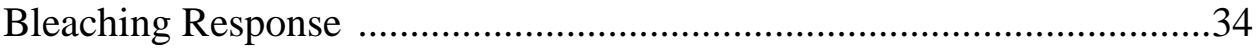

2.5 Discussion:

2.5.1 Initial Bleaching Response did not Improve Response to a Second

Bleaching Event 34

2.5.2 Minute Thermal Stress-driven Symbiodiniaceae Community

Dynamism is not Relevant to Bleaching Response

2.5.3 Coral Genetic Identity Structures Bleaching Response and

Represents an Important Conservation Resource

2.5.4 Conclusions and Recommendations ..............................................40

2.6 Figures

2.7 References

Chapter 3: Adaptative Mechanisms Fuel Competitive Ability, Growth, and Survivorship Across a Depth Cline in Symbiont and Depth Generalists Orbicella annularis and Orbicella faveolata .56

3.1 Abstract .56 


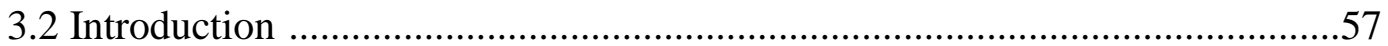

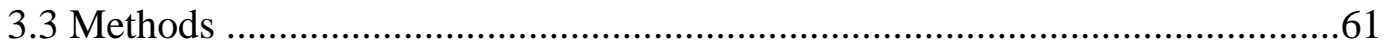

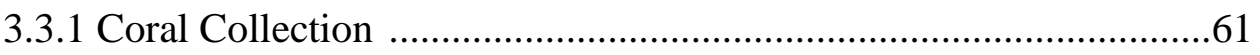

3.3.2 Depth Transplantation Experiment …………………………….....62

3.3.3 Symbiodiniaceae Community Characterization via Amplicon

Sequencing of the Chloroplast 23S ........................................................63

3.3.4 Measuring Orbicella Ramet Survivorship and Growth Over One

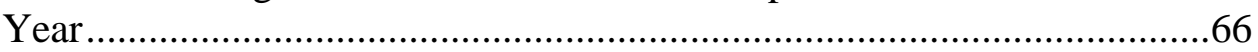

3.3.5 Characterization of Spatial Competitive Interactions .......................66

3.3.6 Suitability of Data Collected from the 8m Nursery .........................67

3.3.7 Determining the Role of Host Identity in Growth, Competition, and Survivorship ................................................................................68

3.3.8 Parity amongst Survivorship, Competitive Ability, and Growth......69

3.3.9 Influence of Symbiodiniaceae Assemblage on Survivorship and

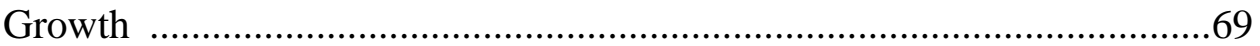

3.3.10 Influence of Depth and Host Identity on Symbiodiniaceae

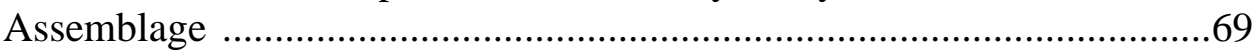

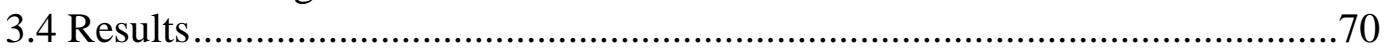

3.4.1 Symbiodiniaceae Assemblage of Orbicella Ramets After One

Year at Eight, 20, or 30m ...................................................................70

3.4.2 Depth and Host Identity as Structuring Factors of

Symbiodiniaceae Assemblage ...............................................................72

3.4.3 Survivorship, Growth and Spatial Competition of Orbicella

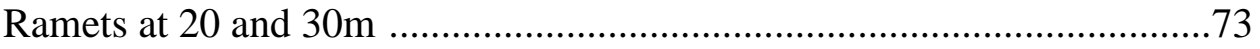

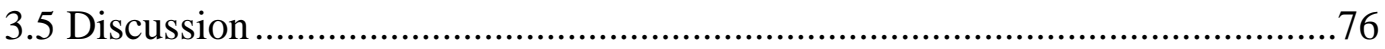

3.5.1 Symbiodiniaceae Community Structure Affects Growth, but not

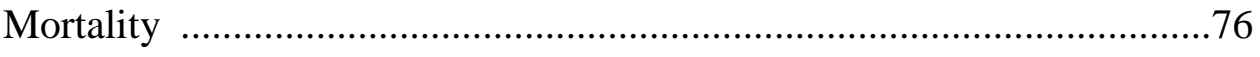

3.5.2 Symbiodiniaceae Community is Structured by Coral Host

Identity, but not Depth ........................................................................78

3.5.3 Depth Significantly Determines Competitive Ability, but not

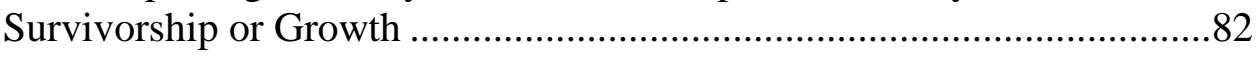

3.5.4 Coral Species and Genet Strongly Shape Competitive Ability,

Growth, and Survival ..............................................................................83

3.5.5 Study Limitations and Future Directions ..........................................8

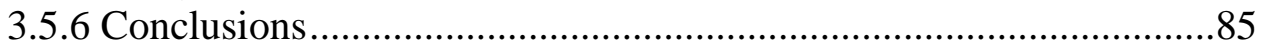

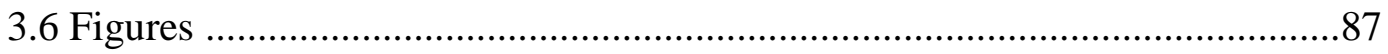

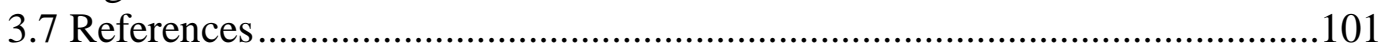

CHAPTER 4: Symbiotic Immuno-suppresion: is Disease Susceptibility the Price of

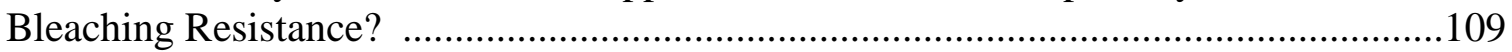

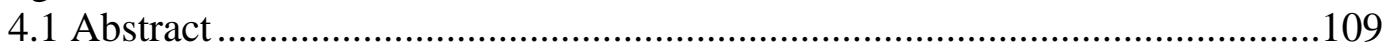

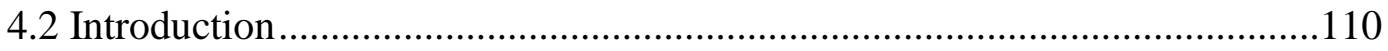

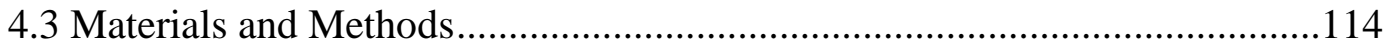

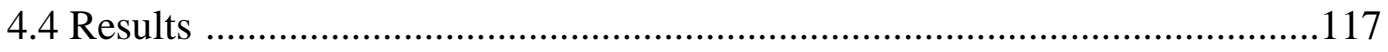

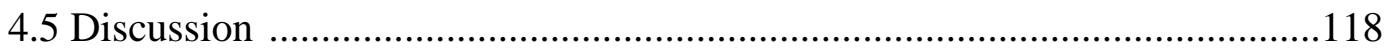




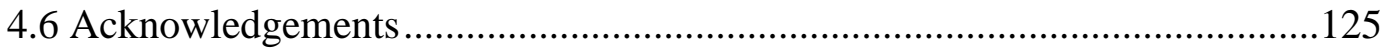

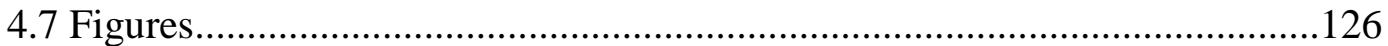

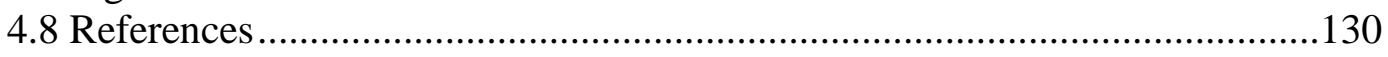

4.9 Additional Analyses since Publication ...................................................137

CHAPTER 5: Overall Conclusions and Synthesis ....................................................138

5.1 Symbiodiniaceae Assemblage Structuring Factors....................................138

5.2 Adaptive Mechanisms: Conclusions, Limitations, and Future Directions ....140

5.3 Applications in Restoration and Conservation ...........................................144

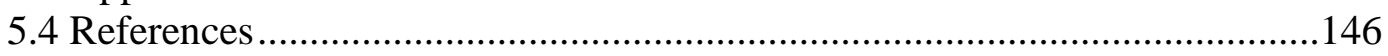

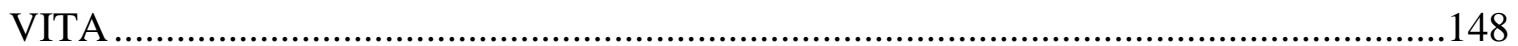




\section{LIST OF FIGURES}

CHAPTER-FIGURES

PAGE

2.1 Acropora cervicornis Mortality Prior to 2015 Bleaching .42

2.2 Repetitive Bleaching Outcomes for Acropora cervicornis following the 2014 / 2015 Mass Bleaching Events

2.3 Symbiodiniaceae Community through 2014 / 2015 Mass Bleaching Events

2.4 Ramets Categorized by Symbiodiniaceae Community Identity through Time

2.5 Ramets' Symbiodiniaceae Communities Ordinated through Non-metric Multi-

Dimensional Scaling (nMDS) .46

2.6 Bleaching Resistance by Host Genet in 2014 and 2015

2.7 Ramet Membership in Repetitive Bleaching Response Categories by Genet .48

3.1 Coral Deployment Workflow

3.2 Coral Tree Layout

3.3 Principle Component Analysis of Symbiodiniaceae Community Redundancy

Analysis including all Depths

3.4 Relative Abundance of Symbiodiniaceae Taxa by Orbicella spp, Depth, and Genet .90

3.5 Percent Symbiodiniaceae Community Variation explained by each of Species,

Genet, and Depth

3.6 Survivorship of Orbicella Ramets after One Year at 20 or 30m .... .95

3.7 Examples of Orbicella Growth and Competition After One Year at 20 or 30m .96

3.8 Growth of Orbicella Ramets after One Year at 20 or 30m .96

3.9 PCA of the Symbiodiniaceae RDA to Determine Factors Governing Growth

3.10 Outcomes of Interactions between Orbicella Ramets and Competing Benthic Organisms .98

3.11 Linear Regression between Growth and Competitive Ability. .99 
3.12 Linear Regression between Genet-wide Survivorship and Competitive Ability .......99

3.13 Linear Regression between Genet-wide Growth and Survivorship........................100

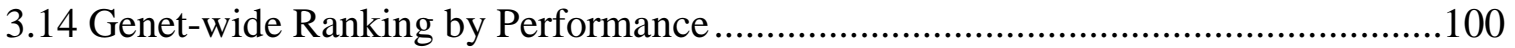

4.1 Monthly prevalence of bleached and diseased coral ramets of Acropora cervicornis between September 2014 and March 2015 in the "North Nursery" at Biscayne Bay (N 25.488;W80.109).

4.2 Images of bleaching and diseased colonies of Acropora cervicornis within the North Nursery

4.3 Frequency of health status in Acropora cervicornis corals as a function of genet identity

4.4 Predicted relative immunological vulnerability assuming Symbiodinium have an immuno-suppressive effect on the coral host. 


\section{Chapter 1: Coral Reef Collapse and Mechanisms of Resistance}

\subsection{Coral Reef Value and Symbiosis}

Coral reefs support greater than $30 \%$ of all marine biodiversity despite occupying less than $0.2 \%$ of the oceans (Reaka-Kudla 2005). They are foundational to tourism (Spalding et al. 2017), coastal protection (Ferrario et al. 2014), and fisheries (Rogers et al. 2018) with estimated annual value over ten trillion dollars (Groot et al. 2012). Such economic benefits are possible through the complex coral reef structure, which resists waves and provides habitat to innumerable species.

Reef formation and maintenance is driven by metabolically expensive calcification dependent on the nutritional symbiosis corals share with dinoflagellates in the family Symbiodiniaceae (Muscatine et al. 1984; Colombo-Pallotta et al. 2010; LaJeunesse et al. 2018). Carbohydrates and lipids from symbiotic dinoflagellate photosynthesis compose up to $95 \%$ of coral host's total energy budget (Muscatine and Porter 1977; Burriesci et al. 2012), while host nitrogen waste is returned by symbionts to the host in the form of amino acids (Wang and Douglas 1999; Pernice et al. 2012). In exchange for energetic subsidy, symbionts reside in nutrient enriched oases in the midst of marine nutrient deserts.

\subsection{Threats to Corals and their Mechanisms of Action}

Coral reefs are rapidly collapsing under the pressures of myriad anthropogenic stressors acting at both local and global scales. Local stressors play important roles in 
reef decline (Pandolfi et al. 2003; Pandolfi et al. 2005). Dynamite and cyanide fishing used in certain regions of the developing world directly destroys reef structure and results in the indiscriminate killing of reef fauna. Sedimentation results in the irritation or even complete burial and mortality of corals and other benthic organisms (Cunning et al. 2019).

Nutrient enrichment has complex direct and indirect effects on corals and coral reefs, sensitizing corals to other stressors (Vega Thurber et al. 2014; Hall et al. 2018; Lapointe et al. 2019). Nutrient enrichment from run off or sewage discharge directly destabilizes the mutualism between corals and Symbiodiniaceae by releasing endosymbionts from nutrient limitation critical to sustain the release of fixed carbon from the symbiont to the coral animal (Cui et al. 2019; reviewed in Morris et al. 2019). With replete nitrogen and phosphorous, Symbiodiniaceae are able to invest excess carbon into cell division rather than subsidizing their hosts' energetic budget. Growing symbiont populations increase susceptibility to bleaching (Cunning and Baker 2012). Increased symbiont load may also increase the risk of coral disease (Mansfield and Gilmore 2018; Merselis et al. 2018). At a community scale, eutrophied coral reefs can become dominated by algal communities which may smother corals and prevent coral recruitment (Vermeij et al. 2010; Speare et al. 2019). Algal contact may induce bleaching responses within proximal coral tissues (Jompa and McCook 2003) and introduce numerous potential pathogens to the coral microbiome, increasing the chance and severity of disease (Bruno et al. 2003; Morrow et al. 2017; Pratte et al. 2018).

Overfishing, particularly through the removal of key herbivores, may also facilitate the release of algae from trophic control and may interact with nutrient 
enrichment to shape algal growth rates and competitive ability (Jackson et al. 2001; Vermeij et al. 2010). Local stressors such as nutrient enrichment and overfishing may increase the destructive potential of global stressors like climate change (Carilli et al. 2009; Lapointe et al. 2019).

The deliberate destruction of coral reefs associated with construction, dredging (Cunning et al. 2019), and island building/ land reclamation (Hughes et al. 2013) is ongoing in both the developed and developing world. Although local stressors may pose dire threats to the reefs they effect, their impact can be alleviated at local scales if sustainability is realized at local or regional scales.

However, global stressors affect even the most remote reefs, threatening the persistence of the ecosystem as a whole (Lesser 2007; Hoegh-Guldberg 2011). Global stressors are also difficult to mitigate through local or even global action. Carbon dioxide enrichment of the atmosphere results in both ocean acidification and climate change (Hoegh-Guldberg et al. 2007). The dissolution of two thirds of atmospheric carbon dioxide emissions into water forms carbonic acid which continues to measurably decrease the $\mathrm{pH}$ of the ocean. Carbon dioxide remaining in the atmosphere increases the atmospheric absorption of infrared radiation, decreasing the rate at which thermal energy leaves the Earth. Global action on carbon emissions may slow or completely halt the addition of carbon to the atmosphere, but would merely halt acidification at present day, decreased $\mathrm{pH}$ while merely slowing climate change (Donner 2009). In order to arrest and eventually reverse the effects of industrial carbon emissions, carbon must be removed from the atmosphere. 
While ocean acidification may impair coral health and reproduction (Albright et al. 2010; Albright and Langdon 2011), climate change- by increasing the severity and frequency of coral bleaching and disease outbreaks- threatens the persistence of coral reef ecosystem functionality within a human life-time (Donner 2009; Hoegh-Guldberg 2011; Van Hooidonk et al. 2013; Manzello 2015). Most coral reefs around the world exist within 2 degrees Celsius of their upper thermal tolerances (Berkelmans and Willis 1999) such that small increases in thermal maxima devastate coral reefs.

The same symbiosis that has driven the formation of coral reefs also represents its vulnerability to hyperthermal stress. When temperatures exceed normal summer maxima, symbiont photosynthesis malfunctions, failing to deliver usable photosynthate and poisoning both host and symbiont through the generation of toxic reactive oxygen species (ROS; Lesser 1997; Jones et al. 1998; Warner et al. 1999). Corals then eject or digest their symbionts, leaving live transparent host tissue over white skeleton in a process known as "coral bleaching" (Glynn 1983; reviewed in Lesser 2011)

It may take several years to facilitate full recovery from a bleaching event (Szmant and Gassman 1990; Levitan et al. 2014; Schoepf et al. 2015). During recovery, bleached corals suffer decreased growth, compromised wound recovery (Meesters et al. 1993), depleted energy stores (Schoepf et al. 2015), lower fecundity (Szmant and Gassman 1990; Levitan et al. 2014), and increased risk of mortality (Baird and Marshall 2002; Ward et al. 2002; Anthony et al. 2009). Even with immediate unprecedented action on emissions, climate change is expected to trigger annual bleaching on most reefs by 2060 and for nearly all reefs by 2100 (Donner 2009; Van Hooidonk et al. 2013). In Florida, annual bleaching may commence as soon as 2028 (Manzello 2015). However, 
with small increases in thermal tolerance, annual bleaching can be substantially delayed, allowing time for humans to reverse carbon emissions (Donner et al. 2005).

Thermal stress not only drives bleaching events, but also increasingly frequent and damaging outbreaks of coral tissue-loss diseases either by increasing bacterial growth or damaging coral immunity (Harvell et al. 2001; Bruno et al. 2007; Brandt and Mcmanus 2009; Ruiz-Moreno et al. 2012). Coral diseases are diverse and include advancing bands or zones of tissue lysis, bleaching inducing and animal cell lysing pathogen infections, and/or unexplained sloughing of live coral tissue from skeletons (Rosenberg and Ben Haim 2002; Lesser et al. 2007; Bourne et al. 2009). Coral diseases have had devastating impact on coral cover in recent decades. Disease outbreaks have often occurred during and following thermal stress events accounting for the majority of thermal stress related mortality (Patterson et al. 2002; Aronson and Precht 2006; Muller et al. 2008; Precht et al. 2016; Lewis et al. 2017).

\subsection{Adaptive Mechanisms of Reef Building Corals}

Only increased resistance to disease and bleaching will allow the persistence of coral reefs, although increased bleaching and disease resistance will do little without decisive action on climate change and other pressing environmental concerns (Donner 2009; Van Hooidonk et al. 2013; Maynard et al. 2015). Increased resistance is possible through a number of mechanisms including symbiont community identity change (Baker 2001; Berkelmans and van Oppen 2006; Hume et al. 2013), host adaptation (evolution; Fine et al. 2013; Palumbi et al. 2014), or acclimatization based upon prior experience 
(Brown et al. 2002; Bellantuono et al. 2012; Brown and Rodriguez-Lanetty 2015). Understanding adaptation and acclimatization will enable and guide our attempts to halt the collapse of coral reef ecosystems.

Corals and their associated symbionts compose a holobiont whose members are under the pressures of selection (Reshef et al. 2006) and who collectively house a hologenome which is also under selection (Rosenberg et al. 2007). Holobionts may increase thermal tolerance through the process of "adaptive bleaching," whereby coral bleaching removes thermally susceptible symbionts, allowing recolonization by symbiont species resistant to thermal stress (Buddemeier and Fautin 1993; LaJeunesse et al. 2009; Silverstein et al. 2014). However, certain coral species have a limited capacity to host diverse Symbiodiniaceae--hosting few or even a single species (Baker 2003; Van Oppen et al. 2005; Stat et al. 2009; Thomas et al. 2014). The "flexibility" of coral species specificity is further winnowed by environmental parameters such as light intensity and thermal regime (Cooper et al. 2011; Bongaerts et al. 2015; Bonthond et al. 2018).

Besides the potential for coral bleaching to foster Symbiodiniaceae change, bleaching has also been implicated as a risk factor in coral disease as evidenced by frequent disease outbreaks following bleaching events (Muller et al. 2008; Brandt and Mcmanus 2009; Cróquer and Weil 2009). However, the population-level observations do not necessarily support causality, because they do not confirm that bleached individuals are more likely to become diseased than their unbleached counterparts--only that disease outbreaks coincide with or follow mass bleaching events. Such a pattern of co-occurrence is expected even in the case of their mechanistic independence, as they are both promoted by thermal stress (Bruno et al. 2007). 
Symbiodiniaceae are universally recognized as obligate symbionts of reef building corals but hosting them comes at a cost. Losing symbionts through bleaching may be accompanied by gains in certain measures of performance. It has been widely reported that Symbiodiniaceae hosting cnidarians have suppressed expression of genes important for critical immunological functions such as cell death, endocytosis, and immune-activating transcription factors (Rodriguez-Lanetty et al. 2006; Mansfield et al. 2019; Medrano et al. 2019), in addition to modified vesicle trafficking (Medrano et al. 2019), and lysosomal maturation (Chen et al. 2004; Chen et al. 2005). Host immunesuppression may be a consequence of Symbiodiniaceae-origin miRNAs recovered interacting with cnidarian animal proteins within cnidarian nuclei (Baumgarten et al. 2018). Such symbiont-derived examples of immune-suppression confirm that immunetolerance is necessary to facilitate evolutionarily diverse intracellular symbioses (e.g., Fytrou et al. 2006; Zheng et al. 2014).

Symbiont enforced immune tolerance have important organismal effects on immunological capacity. More specifically, Mansfield et al., (2019) detected significantly higher mortality of Symbiodiniaceae hosting anemones in disease challenges than for anemones that were maintained without Symbiodiniaceae across numerous anemone strains. The same study also confirmed that Symbiodiniaceae suppressed important components of the innate immune system in Exaiptasia.

Different Symbiodiniaceae species have differential capacity to modulate their host's immunological tolerance. The thermally tolerant Durusdinium trenchii fails to suppress host anemone and coral immune systems as effectively as more co-evolved homologous symbionts (Mansfield et al. 2019; Medrano et al. 2019; Sproles et al. 2019), 
potentially explaining decreased disease susceptibility amongst its coral hosts (RuizMoreno et al. 2012). Acknowledging that symbioses come with trade-offs hints at interconnections amongst bleaching and disease and reveals a potential role for Symbiodiniaceae switching to increase disease resistance. While the molecular evidence seems very clear, further work is needed to verify the existence of disease resistance through bleaching.

Independent of switching symbiont partners or any hypothetical immunological boost resultant from bleaching, corals have an ability to increase bleaching resistance on the basis of prior priming experience (Middlebrook et al. 2008; Bellantuono et al. 2012; Palumbi et al. 2014; Bay and Palumbi 2015). Exposure to high sub-stress temperatures or large thermal variance may increase bleaching resistance, while prior bleaching has been associated with both increased thermal tolerance (Brown et al. 2002; Gintert et al. 2018) and decreased thermal tolerance (Grottoli et al. 2014; Hughes et al. 2017) in response to future hyperthermal events. Similarly, symbiotic Exaiptasia pallida may also increase their capacity to resist infection based upon a priming challenge by that same pathogen despite lacking an adaptive immune system (Brown and Rodriguez-Lanetty 2015).

No study has previously identified an inter-annual effect for coral acclimatization without possible or detected confounding by symbiont identity or coral mortality. Addressing the knowledge gap should reveal whether innate acclimatization (acclimatization without change in coral or Symbiodiniaceae identity) could facilitate increased anthropogenic resistance under annually repetitive hyperthermal stress. 
The molecular mechanisms underpinning an acquired stress tolerant phenotype and mediating its longevity likely include epigenetic modification of coral or Symbiodiniaceae chromatin. Modifications may include direct methylation of cytosine and possibly adenine DNA nucleotides or post translational modifications of histone proteins including methylation, acetylation, and phosphorylation (reviewed in: Torda et al. 2017; Eirin-Lopez and Putnam 2018). Such epigenetic alterations have demonstrated relevance in the stress response of reef-building corals (Dixon et al. 2014; Dimond and Roberts 2016; Rodriguez-Casariego et al. 2018) and trans-generational inheritance of parent colony epigenetics seems likely (Putnam and Gates 2015; Wall et al. 2018). Epigenetic modifications alter the charge environment of chromatin changing the likelihood for DNA to be organized as euchromatin or heterochromatin and thusly modifying the accessibility of DNA for numerous processes including RNA transcription. The exchange of canonical histone variants for alternative variants may further modulate chromatin accessibility and the probability of gene expression and aiding in processes such as DNA repair. Better understanding the longevity of epigenetically mediated thermal tolerance would reveal whether thermal priming mechanism might endure cooler winters free and foster increased bleaching resistance.

Epigenetic mechanisms play a pivotal role in innate acclimatization where there is no change in hologenome composition, but it should be noted that epigenetics plays a role in the other mechanisms under study as well. Epigenetic mechanisms interact with all organismal functions such as transcription from every genomic locus by regulating the conformation of chromatin. With such a pervasive role in cellular biology, it seems 
inevitable that epigenetic processes play a role in mediating differences amongst coral genotypes and facilitating transitions in symbiont community.

In addition to symbiont community composition and environmental experience, coral genetic identity also shapes bleaching and disease resistance (Vollmer and Kline 2008; Bay and Palumbi 2014; Hughes et al. 2017). To sustain coral reefs, "super-tolerant" genotypes must have tremendous success interbreeding with other, "weaker," genotypes to prevent the collapse of genetic variability essential to confront ongoing environmental change (van Oppen et al. 2017). Existent coral restoration organizations and evolving techniques will help reduce the maturation time of certain species from 20 years to as few as five years (Forsman et al. 2015; Page et al. 2018) and generate new "super-tolerant" genotypes though selective breeding (van Oppen et al. 2015).

Studying adaptation and acclimatization amongst several partners requires careful wording. Through Symbiodiniaceae change, selection occurs with one or more symbiont species being favored over others by environmental conditions within the coral host habitat. Engaging in symbiosis with a new partner is clearly an example of acclimatization strictly from the coral animal's perspective, but selection has occurred from the holobiont perspective with a change in genomic content. Thusly, symbiont change cannot be considered purely acclimatization. Therefore I will use the terms acclimatization or innate acclimatization to describe phenotypic plasticity arising from environment without any change in holobiont identity and refer to partner changing as Symbiodiniaceae community change. 
Likewise, "adaptive mechanisms" has been used broadly to refer to mechanisms underlying adjustment to an environmental condition rather than within the strict sense of adaptation, meaning evolution where variation in genetic composition arises and is then selected on by the environment. To prevent confusion I will use the term mechanisms of adaptation and acclimatization. Further, because adaptation is a multi-generational process and corals have generation times measured in years or decades, my dissertation appraises the potential for adaptation by measuring differences amongst coral genotypes upon which selection may act and was not able to measure evolution itself.

\subsection{Dissertation Questions, Hypotheses, and Organization}

My dissertation aimed to identify the role of Symbiodiniaceae identity, holobiont experience / acclimatization, and host genetic identity in determining four critical measures of success for corals in the anthropocene- bleaching resistance, growth, survival, and disease resistance. I further tried to determine the inter-relationship between bleaching and disease.

Chapter 2: Do symbiont identity, bleaching experience, and/or host genotype determine bleaching resistance in repeatedly heat stressed Acropora cervicornis?

Hypothesis: Symbiodiniaceae community composition plays a substantial role in bleaching resistance, but Acropora cervicornis, a symbiont specialist, may not transition to hosting thermally tolerant symbionts except after substantial disturbance (i.e., severe bleaching). Therefore, bleaching experience and Symbiodiniaceae community composition may interact to facilitate increased bleaching resistance. Bleaching 
experience without a change in symbiont community structure will not facilitate acclimatization but may weaken bleaching resistance. Host genetic identity will have a strong deterministic role in shaping bleaching resistance in concordance with literature on a large number of physiological parameters (e.g., Willis and Ayre 1985; Vollmer and Kline 2008; Lirman et al. 2014; Ladd et al. 2017).

Chapter 3: Do symbiont identity, depth, and/or host identity influence the growth and survival of Orbicella spp.?

Hypothesis: As a symbiont generalist, Orbicella spp. inhabiting different depths will have their broad symbiont specificity winnowed to a particular symbiont community structure favored by each depth. Symbiodiniaceae identity and experience (acclimation to depth) will act concordantly in shaping growth and survival. Host genotype and species $(O$. faveolata or O. annularis) will both strongly influence outcomes for Orbicella with interactions by experience (depth) to which certain genotypes will be better adapted.

Chapter 4: Do Symbiodiniaceae identity, bleaching experience, or host genotype influence disease susceptibility in Acropora cervicornis?

Hypothesis: The obligate symbiosis between reef building corals and Symbiodiniaceae species provides nutrition essential to maintenance of physiological well-being- including immune activity. Bleaching, by interrupting the vital mutualism will therefore predispose bleached corals to disease relative to their unbleached counterparts. Differential 
Symbiodiniaceae community composition, if present in the monitored Acropora cervicornis, will modulate disease susceptibility either directly or through differential nutritional benefit to their hosts. Host genotype will also play an important role in determining disease susceptibility as in many other phenotypes.

\subsection{References}

Albright R, Langdon C (2011) Ocean acidification impacts multiple early life history processes of the Caribbean coral Porites astreoides. Glob Chang Biol 17:24782487. doi: $10.1111 / \mathrm{j} .1365-2486.2011 .02404 . x$

Albright R, Mason B, Miller M, Langdon C (2010) Ocean acidification compromises recruitment success of the threatened Caribbean coral Acropora palmata. Proc Natl Acad Sci 107:20400-20404. doi: 10.1073/pnas.1007273107

Anthony KRN, Hoogenboom MO, Maynard JA, et al. (2009) Energetics approach to predicting mortality risk from environmental stress: a case study of coral bleaching. Funct Ecol 23:539-550. doi: 10.1111/j.1365-2435.2008.01531.x

Aronson RB, Precht WF (2006) Conservation, precaution, and Caribbean reefs. Coral Reefs 25:441-450. doi: 10.1007/s00338-006-0122-9

Baird A, Marshall P (2002) Mortality, growth and reproduction in scleractinian corals following bleaching on the Great Barrier Reef. Mar Ecol Prog Ser 237:133-141. doi: $10.3354 /$ meps 237133

Baker A (2003) Flexibility and Specificity in Coral-Algal Symbiosis: Diversity, Ecology, and Biogeography of Symbiodinium. Annu Rev Ecol Evol Syst 34:661-689. doi: $10.1146 / 132417$

Baker AC (2001) Reef corals bleach to survive change. Nature 411:765-766.

Baumgarten S, Cziesielski MJ, Thomas L, et al. (2018) Evidence for miRNA-mediated modulation of the host transcriptome in cnidarian-dinoflagellate symbiosis. Mol Ecol 403-418. doi: $10.1111 / \mathrm{mec} .14452$

Bay RA, Palumbi SR (2015) Rapid acclimation ability mediated by transcriptome changes in reef-building corals. Genome Biol Evol 7:1602-1612. doi: 10.1093/gbe/evv085 
Bay RA, Palumbi SR (2014) Multilocus adaptation associated with heat resistance in reef-building corals. Curr Biol 24:2952-2956. doi: 10.1016/j.cub.2014.10.044

Bellantuono AJ, Hoegh-Guldberg O, Rodriguez-Lanetty M (2012) Resistance to thermal stress in corals without changes in symbiont composition. Proc Biol Sci 279:1100-7. doi: $10.1098 / \mathrm{rspb} .2011 .1780$

Berkelmans R, van Oppen MJH (2006) The role of zooxanthellae in the thermal tolerance of corals: a "nugget of hope" for coral reefs in an era of climate change. Proc Biol Sci 273:2305-12. doi: 10.1098/rspb.2006.3567

Berkelmans R, Willis BL (1999) Seasonal and local spatial patterns in the upper thermal limits of corals on the inshore Central Great Barrier Reef. Coral Reefs 18:219-228. doi: $10.1007 / \mathrm{s} 003380050186$

Bongaerts P, Carmichael M, Hay KB, et al. (2015) Prevalent endosymbiont zonation shapes the depth distributions of scleractinian coral species. R Soc Open Sci. doi: 10.1098/rsos.140297

Bonthond G, Merselis DG, Dougan KE, et al. (2018) Inter-domain microbial diversity within the coral holobiont Siderastrea siderea from two depth habitats. PeerJ 6:e4323. doi: $10.7717 /$ peerj.4323

Bourne DG, Garren M, Work TM, et al. (2009) Microbial disease and the coral holobiont. Trends Microbiol 17:554-562. doi: 10.1016/j.tim.2009.09.004

Brandt ME, Mcmanus JW (2009) Disease incidence is related to bleaching extent in reefbuilding corals. Ecology 90:2859-2867. doi: 10.1890/08-0445.1

Brown BE, Dunn RP, Goodson MS, Douglas AE (2002) Experience shapes the susceptibility of a reef coral to bleaching. 119-126. doi: 10.1007/s00338-002-0215-z

Brown T, Rodriguez-Lanetty M (2015) Defending against pathogens-immunological priming and its molecular basis in a sea anemone, cnidarian. Sci Rep 5:1-14. doi: $10.1038 /$ srep 17425

Bruno JF, Petes LE, Harvell CD, Hettinger A (2003) Nutrient enrichment can increase the severity of coral diseases. Ecol Lett 6:1056-1061. doi: 10.1046/j.14610248.2003.00544.x

Bruno JF, Selig ER, Casey KS, et al. (2007) Thermal stress and coral cover as drivers of coral disease outbreaks. PLoS Biol 5:e124. doi: 10.1371/journal.pbio.0050124 
Buddemeier R, Fautin D (1993) Coral bleaching as an adaptive mechanism. Bioscience 43:320-326.

Burriesci MS, Raab TK, Pringle JR (2012) Evidence that glucose is the major transferred metabolite in dinoflagellate-cnidarian symbiosis. J Exp Biol 215:3467-3477. doi: $10.1242 /$ jeb. 070946

Carilli JE, Norris RD, Black B a, et al. (2009) Local stressors reduce coral resilience to bleaching. PLoS One 4:e6324. doi: 10.1371/journal.pone.0006324

Chen M-C, Hong M-C, Huang Y-S, et al. (2005) ApRab11, a cnidarian homologue of the recycling regulatory protein Rab11, is involved in the establishment and maintenance of the Aiptasia-Symbiodinium endosymbiosis. Biochem Biophys Res Commun 338:1607-16. doi: 10.1016/j.bbrc.2005.10.133

Chen MC, Cheng YM, Hong MC, Fang LS (2004) Molecular cloning of Rab5 (ApRab5) in Aiptasia pulchella and its retention in phagosomes harboring live zooxanthellae. Biochem Biophys Res Commun 324:1024-1033. doi: 10.1016/j.bbrc.2004.09.151

Colombo-Pallotta MF, Rodríguez-Román A, Iglesias-Prieto R (2010) Calcification in bleached and unbleached Montastraea faveolata: Evaluating the role of oxygen and glycerol. Coral Reefs 29:899-907. doi: 10.1007/s00338-010-0638-x

Cooper TF, Berkelmans R, Ulstrup KE, et al. (2011) Environmental factors controlling the distribution of Symbiodinium harboured by the coral Acropora millepora on the great barrier reef. PLoS One 6:1-16. doi: 10.1371/journal.pone.0025536

Cróquer A, Weil E (2009) Changes in Caribbean coral disease prevalence after the 2005 bleaching event. Dis Aquat Organ 87:33-43. doi: 10.3354/dao02164

Cui G, Liew YJ, Li Y, et al. (2019) Host-dependent nitrogen recycling as a mechanism of symbiont control in Exaiptasia. PLOS Genet 15:e1008189. doi: 10.1371/journal.pgen.1008189

Cunning R, Baker AC (2012) Excess algal symbionts increase the susceptibility of reef corals to bleaching. Nat Clim Chang 3:259-262. doi: 10.1038/nclimate1711

Cunning R, Silverstein RN, Barnes BB, Baker AC (2019) Extensive coral mortality and critical habitat loss following dredging and their association with remotely-sensed sediment plumes. Mar Pollut Bull 145:185-199. doi:

10.1016/J.MARPOLBUL.2019.05.027

Dimond JL, Roberts SB (2016) Germline DNA methylation in reef corals: Patterns and potential roles in response to environmental change. Mol Ecol 25:1895-1904. doi: $10.1111 / \mathrm{mec} .13414$ 
Dixon GB, Bay LK, Matz M V. (2014) Bimodal signatures of germline methylation are linked with gene expression plasticity in the coral Acropora millepora. BMC Genomics 15:1-11. doi: 10.1186/1471-2164-15-1109

Donner SD (2009) Coping with commitment: projected thermal stress on coral reefs under different future scenarios. PLoS One 4:e5712. doi: 10.1371/journal.pone.0005712

Donner SD, Skirving WJ, Little CM, et al. (2005) Global assessment of coral bleaching and required rates of adaptation under climate change. Glob Chang Biol 11:22512265. doi: $10.1111 /$ j.1365-2486.2005.01073.x

Eirin-Lopez JM, Putnam HM (2018) Marine Environmental Epigenetics. Ann Rev Mar Sci 11:335-368. doi: 10.1146/annurev-marine-010318-095114

Ferrario F, Beck MW, Storlazzi CD, et al. (2014) The effectiveness of coral reefs for coastal hazard risk reduction and adaptation. Nat Commun 5:1-9. doi: $10.1038 /$ ncomms 4794

Fine M, Gildor H, Genin A (2013) A coral reef refuge in the Red Sea. Glob Chang Biol 19:3640-7. doi: $10.1111 / \mathrm{gcb} .12356$

Forsman ZH, Page CA, Toonen RJ, Vaughan D (2015) Growing coral larger and faster: micro-colony-fusion as a strategy for accelerating coral cover. PeerJ 3:e1313. doi: 10.7717/peerj.1313

Fytrou A, Schofield PG, Kraaijeveld AR, Hubbard SF (2006) Wolbachia infection suppresses both host defence and parasitoid counter-defence. Proc R Soc B Biol Sci 273:791-796. doi: 10.1098/rspb.2005.3383

Gintert BE, Manzello DP, Enochs IC, et al. (2018) Marked annual coral bleaching resilience of an inshore patch reef in the Florida Keys: A nugget of hope, aberrance, or last man standing? Coral Reefs 37:533-547. doi: 10.1007/s00338-018-1678-X

Glynn P (1983) Extensive" bleaching" and death of reef corals on the Pacific coast of Panama. Environ Conserv 10:149-154.

Groot R De, Brander L, Ploeg S Van Der, et al. (2012) Global estimates of the value of ecosystems and their services in monetary units. Ecosyst Serv 1:50-61. doi: 10.1016/j.ecoser.2012.07.005

Grottoli AG, Warner ME, Levas SJ, et al. (2014) The cumulative impact of annual coral bleaching can turn some coral species winners into losers. Glob Chang Biol 1-11. doi: $10.1111 /$ gcb.12658 
Hall ER, Muller EM, Goulet T, et al. (2018) Eutrophication may compromise the resilience of the Red Sea coral Stylophora pistillata to global change. Mar Pollut Bull 131:701-711.

Harvell D, Kim K, Quirolo C, et al. (2001) Coral bleaching and disease: contributors to 1998 mass mortality in Briareum asbestinum (Octocorallia, Gorgonacea). Ecol Etiol New Emerg Mar Dis 460:97-104. doi: 10.1023/A:1013169331913

Hoegh-Guldberg O (2011) Coral reef ecosystems and anthropogenic climate change. Reg Environ Chang 11:215-227. doi: 10.1007/s10113-010-0189-2

Hoegh-Guldberg O, Mumby PJ, Hooten a J, et al. (2007) Coral reefs under rapid climate change and ocean acidification. Science 318:1737-42. doi:

10.1126/science. 1152509

Hughes TP, Huang H, Young MAL (2013) The Wicked Problem of China's

Disappearing Coral Reefs. Conserv Biol 27:261-269. doi: 10.1111/j.15231739.2012.01957.x

Hughes TP, Kerry JT, Álvarez-Noriega M, et al. (2017) Global warming and recurrent mass bleaching of corals. Nature 543:373-377. doi: 10.1038/nature21707

Hume B, D’Angelo C, Burt J, et al. (2013) Corals from the Persian/Arabian Gulf as models for thermotolerant reef-builders: Prevalence of clade C3 Symbiodinium, host fluorescence and ex situ temperature tolerance. Mar Pollut Bull 72:313-22. doi: 10.1016/j.marpolbul.2012.11.032

Jackson JBC, Kirby MX, Berger WH, et al. (2001) Historical Overfishing and the Recent Colllapse of Coastal Ecosystems. Science (80- ) 293:629-638. doi:

10.1126/science.1059199

Jompa J, McCook LJ (2003) Coral-algal competition: Macroalgae with different properties have different effects on corals. Mar Ecol Prog Ser 258:87-95. doi: $10.3354 /$ meps 258087

Jones R, Hoegh-Guldberg O, Larkum A, Schreiber U (1998) Temperature induced bleaching of corals begins with impairment of the $\mathrm{CO} 2$ fixation mechanism in zooxanthellae. Plant Cell Environ 21:1219-1230.

Ladd M, Shantz A, Bartels E, Burkepile D (2017) Thermal stress reveals a genotypespecific tradeoff between growth and tissue loss in restored Acropora cervicornis.

LaJeunesse TC, Parkinson JE, Gabrielson PW, et al. (2018) Systematic revision of Symbiodiniaceae highlights the antiquity and diversity of coral endosymbionts. Curr Biol 1-11. doi: 10.1016/j.cub.2018.07.008 
LaJeunesse TC, Smith RT, Finney J, Oxenford H (2009) Outbreak and persistence of opportunistic symbiotic dinoflagellates during the 2005 Caribbean mass coral "bleaching" event. Proc Biol Sci 276:4139-48. doi: 10.1098/rspb.2009.1405

Lapointe BE, Brewton RA, Herren LW, et al. (2019) Nitrogen enrichment, altered stoichiometry, and coral reef decline at Looe Key, Florida Keys, USA: a 3-decade study. Springer Berlin Heidelberg

Lesser MP (2007) Coral reef bleaching and global climate change: Can corals survive the next century? Proc Natl Acad Sci 104:5259-5260. doi: 10.1073/pnas.0700910104

Lesser MP (1997) Oxidative stress causes coral bleaching during exposure to elevated temperatures. Coral Reefs 16:187-192. doi: 10.1007/s003380050073

Lesser MP (2011) Coral Bleaching: Causes and Mechanisms. Coral Reefs: An Ecosystem in Transition. Springer Netherlands, Dordrecht, pp 405-419

Lesser MP, Bythell JC, Gates RD, et al. (2007) Are infectious diseases really killing corals? Alternative interpretations of the experimental and ecological data. J Exp Mar Bio Ecol 346:36-44. doi: 10.1016/j.jembe.2007.02.015

Levitan D, Boudreau W, Jara J, Knowlton N (2014) Long-term reduced spawning in Orbicella coral species due to temperature stress. Mar Ecol Prog Ser 515:1-10. doi: $10.3354 /$ meps 11063

Lewis CL, Neely KL, Richardson LL, Rodriguez-Lanetty M (2017) Temporal dynamics of black band disease affecting pillar coral (Dendrogyra cylindrus) following two consecutive hyperthermal events on the Florida Reef Tract. Coral Reefs 36:427-431. doi: $10.1007 / \mathrm{s} 00338-017-1545-1$

Lirman D, Schopmeyer S, Galvan V, et al. (2014) Growth dynamics of the threatened Caribbean staghorn coral Acropora cervicornis: influence of host genotype, symbiont identity, colony size, and environmental setting. PLoS One 9:e107253. doi: 10.1371/journal.pone.0107253

Mansfield KM, Cleaves PA, Van Vlack E, et al. (2019) Varied effects of algal symbionts on transcription factor NF-kB.

Mansfield KM, Gilmore TD (2018) Innate immunity and cnidarian-Symbiodiniaceae mutualism. Dev Comp Immunol. doi: 10.1016/j.dci.2018.09.020

Manzello DP (2015) Rapid recent warming of coral reefs in the Florida Keys. Sci Rep 5:16762. doi: $10.1038 /$ srep 16762 
Maynard J, Van Hooidonk R, Eakin CM, et al. (2015) Projections of climate conditions that increase coral disease susceptibility and pathogen abundance and virulence. Nat Clim Chang 5:688-694. doi: 10.1038/nclimate2625

Medrano E, Merselis DG, Bellantuono AJ, Rodriguez-Lanetty M (2019) Proteomic Basis of Symbiosis: A Heterologous Partner Fails to Duplicate Homologous Colonization in a Novel Cnidarian-Symbiodiniaceae Mutualism. Front Microbiol 10:1-15. doi: 10.3389/fmicb.2019.01153

Meesters EH, Bak RPM, Meesters EH, Bäk RPM (1993) Effects of coral bleachin potential and colony survival. 96:189-198.

Merselis DG, Lirman D, Rodriguez-Lanetty M (2018) Symbiotic immuno-suppression: is disease susceptibility the price of bleaching resistance? PeerJ 6:e4494. doi: $10.7717 /$ peerj. 4494

Middlebrook R, Hoegh-Guldberg O, Leggat W (2008) The effect of thermal history on the susceptibility of reef-building corals to thermal stress. J Exp Biol 211:1050-6. doi: $10.1242 /$ jeb.013284

Morris LA, Voolstra CR, Quigley KM, et al. (2019) Nutrient Availability and Metabolism Affect the Stability of Coral-Symbiodiniaceae Symbioses. Trends Microbiol 27:678-689. doi: 10.1016/j.tim.2019.03.004

Morrow KM, Bromhall K, Motti CA, et al. (2017) Allelochemicals Produced by Brown Macroalgae of the Lobophora Genus Are Active against Coral Larvae and Associated Bacteria, Supporting Pathogenic Shifts to Vibrio Dominance. 83:1-19.

Muller EM, Rogers CS, Spitzack a. S, van Woesik R (2008) Bleaching increases likelihood of disease on Acropora palmata (Lamarck) in Hawksnest Bay, St John, US Virgin Islands. Coral Reefs 27:191-195. doi: 10.1007/s00338-007-0310-2

Muscatine L, Falkowski PG, Porter JW, Dubinsky Z (1984) Fate of photosynthetic fixed carbon in light and shade-adapted colonies of the symbiotic coral, Stylophora pistillata. Proc R Soc B Biol Sci 222:181-202.

Muscatine L, Porter J (1977) Reef corals: mutualistic symbioses adapted to nutrient-poor environments. Bioscience 27:454-460.

Oster CN, Kenyon RH, Pedersen CEJ (1978) Suppression of cellular immune responses in guinea pigs infected with spotted fever group rickettsiae. Infect Immun 22:411417. 
Page CA, Muller EM, Vaughan DE (2018) Microfragmenting for the successful restoration of slow growing massive corals. Ecol Eng 123:86-94. doi: 10.1016/j.ecoleng.2018.08.017

Palumbi SR, Barshis DJ, Traylor-Knowles N, Bay RA (2014) Mechanisms of reef coral resistance to future climate change. Science (80- ) 344:895-898. doi: 10.1071/MF99078

Pandolfi JM, Bradbury RH, Sala E, et al. (2003) Global trajectories of the long-term of coral reef ecosystems. Science (80- ) 301:955-958. doi: 10.1126/science.1085706

Pandolfi JM, Jackson JBC, Baron N, et al. (2005) Are U.S. coral reefs on the slippery slope to slime? Science (80- ) 307:1725 LP-1726.

Patterson KL, Porter JW, Ritchie KB, et al. (2002) The etiology of white pox, a lethal disease of the Caribbean elkhorn coral, Acropora palmata. Proc Natl Acad Sci U S A 99:8725-30. doi: 10.1073/pnas.092260099

Pernice M, Meibom A, Heuvel A Van Den, et al. (2012) A single-cell view of ammonium assimilation in coral - dinoflagellate symbiosis. ISME J 6:1314-1324. doi: 10.1038/ismej.2011.196

Pratte ZA, Longo GO, Burns AS, et al. (2018) Contact with turf algae alters the coral microbiome: contact versus systemic impacts. Coral Reefs 37:1-13. doi: $10.1007 / \mathrm{s} 00338-017-1615-4$

Precht WF, Gintert BE, Robbart ML, et al. (2016) Unprecedented disease-related coral mortality in southeastern florida. Sci Rep 6:31374. doi: 10.1038/srep31374

Putnam HM, Gates RD (2015) Preconditioning in the reef-building coral Pocillopora damicornis and the potential for trans-generational acclimatization in coral larvae under future climate change conditions. J Exp Biol 218:2365-2372. doi: 10.1242/jeb.123018

Reaka-Kudla ML (2005) Biodiversity of caribbean coral reefs. Caribb Mar Biodivers Known Unkn 259-276.

Reshef L, Koren O, Loya Y, et al. (2006) The coral probiotic hypothesis. Environ Microbiol 8:2068-73. doi: 10.1111/j.1462-2920.2006.01148.x

Rodriguez-Casariego JA, Ladd MC, Shantz AA, et al. (2018) Coral epigenetic responses to nutrient stress: Histone H2A.X phosphorylation dynamics and DNA methylation in the staghorn coral Acropora cervicornis. Ecol Evol 8:12193-12207. doi: 10.1002/ece 3.4678

Rodriguez-Lanetty M, Phillips WS, Weis VM (2006) Transcriptome analysis of a cnidarian-dinoflagellate mutualism reveals complex modulation of host gene expression. BMC Genomics 7:23. doi: 10.1186/1471-2164-7-23

Rogers A, Blanchard JL, Mumby PJ (2018) Fisheries productivity under progressive 
coral reef degradation. J Appl Ecol 55:1041-1049. doi: 10.1111/1365-2664.13051

Rosenberg E, Ben Haim Y (2002) Microbial disease of corals and global warming. Environ Microbiol 4:318-326. doi: 10.1046/j.1462-2920.2002.00302.x

Rosenberg E, Koren O, Reshef L, et al. (2007) The role of microorganisms in coral health, disease and evolution. Nat Rev Microbiol 5:355-62. doi: 10.1038/nrmicro1635

Ruiz-Moreno D, Willis BL, Page a C, et al. (2012) Global coral disease prevalence associated with sea temperature anomalies and local factors. Dis Aquat Organ 100:249-61. doi: 10.3354/dao02488

Schoepf V, Grottoli AG, Levas SJ, et al. (2015) Annual coral bleaching and the long-term recovery capacity of coral. Proc R Soc B Biol Sci. doi: 10.1098/rspb.2015.1887

Silverstein RN, Cunning R, Baker AC (2014) Change in algal symbiont communities after bleaching, not prior heat exposure, increases heat tolerance of reef corals. Glob Chang Biol 1-14. doi: 10.1111/gcb.12706

Spalding M, Burke L, Wood SA, et al. (2017) Mapping the global value and distribution of coral reef tourism. Mar Policy 82:104-113. doi: 10.1016/j.marpol.2017.05.014

Speare K, Duran A, Miller M, Burkepile D (2019) Sediment associated with algal turfs inhibits the settlement of two endangered coral species.

Sproles AE, Oakley CA, Matthews JL, et al. (2019) Proteomics quantifies protein expression changes in a model cnidarian colonised by a thermally tolerant but suboptimal symbiont. ISME J. doi: 10.1038/s41396-019-0437-5

Stat M, Pochon X, Cowie R, Gates R (2009) Specificity in communities of Symbiodinium in corals from Johnston Atoll. Mar Ecol Prog Ser 386:83-96. doi: $10.3354 /$ meps 08080

Szmant A, Gassman N (1990) The effects of prolonged "bleaching" on the tissue biomass and reproduction of the reef coral Montastrea annularis. Coral reefs 8:217-224.

Thomas L, Kendrick G a., Kennington WJ, et al. (2014) Exploring Symbiodinium diversity and host specificity in Acropora corals from geographical extremes of Western Australia with 454 amplicon pyrosequencing. Mol Ecol 23:3113-3126. doi: $10.1111 / \mathrm{mec} .12801$

Torda G, Donelson JM, Aranda M, et al. (2017) Rapid adaptive responses to climate change in corals. Nat Clim Chang 7:627-636. doi: 10.1038/nclimate3374

Van Hooidonk R, Maynard JA, Planes S (2013) Temporary refugia for coral reefs in a warming world. Nat Clim Chang 3:508-511. doi: 10.1038/nclimate1829

van Oppen MJH, Gates RD, Blackall LL, et al. (2017) Shifting paradigms in restoration of the world's coral reefs. Glob Chang Biol 23:3437-3448. doi: 10.1111/gcb.13647 
Van Oppen MJH, Mahiny AJ, Done TJ (2005) Geographic distribution of zooxanthella types in three coral species on the Great Barrier Reef sampled after the 2002 bleaching event. Coral Reefs 24:482-487. doi: 10.1007/s00338-005-0487-1

van Oppen MJH, Oliver JK, Putnam HM, Gates RD (2015) Building coral reef resilience through assisted evolution. Proc Natl Acad Sci 112:2307-2313. doi: 10.1073/pnas. 1422301112

Vega Thurber RL, Burkepile DE, Fuchs C, et al. (2014) Chronic nutrient enrichment increases prevalence and severity of coral disease and bleaching. Glob Chang Biol 20:544-554. doi: 10.1111/gcb.12450

Vermeij MJA, van Moorselaar I, Engelhard S, et al. (2010) The effects of nutrient enrichment and herbivore abundance on the ability of turf algae to overgrow coral in the Caribbean. PLoS One 5:1-8. doi: 10.1371/journal.pone.0014312

Vollmer S V., Kline DI (2008) Natural disease resistance in threatened staghorn corals. PLoS One 3:1-5. doi: 10.1371/journal.pone.0003718

Wall CB, Ricci CA, Foulds GE, et al. (2018) The effects of environmental history and thermal stress on coral physiology and immunity. Mar Biol. doi: 10.1007/s00227$018-3317-\mathrm{Z}$

Wang J, Douglas AE (1999) Essential amino acid synthesis and nitrogen recycling in an alga-invertebrate symbiosis Essential amino acid synthesis and nitrogen recycling in an alga - invertebrate symbiosis. Mar Biol 135:219-222. doi:

$10.1007 / \mathrm{s} 002270050619$

Ward S, Harrison P, Hoegh-Guldberg O (2002) Coral bleaching reduces reproduction of scleractinian corals and increases susceptibility to future stress. Proc 9th Int Coral Reef Symp 1123-1128.

Warner ME, Fitt WK, Schmidt GW (1999) Damage to photosystem II in symbiotic dinoflagellates: A determinant of coral bleaching. Proc Natl Acad Sci U S A 96:8007-12.

Willis BL, Ayre DJ (1985) Asexual reproduction and genetic determination of growth form in the coral Pavona cactus: Biochemical genetic and immunogenic evidence. Oecologia 65:516-525.

Zheng H, Tan Z, Xu W (2014) Immune evasion strategies of pre-erythrocytic malaria parasites. Mediators Inflamm. doi: 10.1155/2014/362605 


\section{CHAPTER 2: Coral Host Identity, Not Symbiont Identity or Prior Bleaching History Predict the Bleaching Response of the Symbiont Specifist Coral, Acropora cervicornis, to Repeated Thermal Stress}

\subsection{Abstract:}

Coral bleaching will affect the majority of the world's reefs on an annual basis or even extirpate reef building corals within a human lifetime as a result of anthropogenic climate change. Because recovery from bleaching requires multiple years, enhancement of bleaching resistance in restoration corals is necessary if they are to endure as ecosystem engineers of coral reefs. I investigated the natural mechanisms underlying bleaching resistance in order to determine their relative potential as tools of physiological enhancement in coral restoration programs.

Using Acropora cervicornis, the "flagship" species for Atlantic coral restoration, I assessed the role of prior bleaching experience without change in host or symbiont identity (holobiont acclimatization), Symbiodiniaceae community composition change (symbiont dynamics / adaptive bleaching), and differential performance between host genetic identities as a proxy of the potential for host adaptation (host evolution). Using a common garden experimental approach during two repeated bleaching events in 2014 and 2015, I determined the role of: holobiont acclimatization by repeated bleaching assessment; symbiont dynamics/ adaptive bleaching by amplicon sequencing; potential for host evolution by relating our repeated assessment to the 21 biologically replicated genetic identities (genets). 
I report limited changes in bleaching resistance as a function of previous bleaching history and very limited but responsive Symbiodiniaceae community dynamism and furthermore characterize Acropora cervicornis as a symbiont specialisteven on the order of cryptic diversity. Despite observations of symbiont community dynamism and plastic bleaching response, results demonstrated that of the examined mechanisms, only coral host genotype played a substantial role in structuring response to the repeated mass bleaching events of 2014 and 2015. With coral host identity overwhelmingly explaining bleaching response, I suggest that work to enhance bleaching resistance in Acropora cervicornis should leverage the differential potential of diverse host genotypes.

\subsection{Introduction:}

Coral reefs are collapsing as a consequence of myriad stressors acting at local and global scales (Pandolfi et al. 2005; Hoegh-Guldberg 2011; De'ath et al. 2012; Hughes et al. 2017). Notably, rapid ocean warming has resulted in increasingly common and severe mass coral bleaching. Hyperthermal mass bleaching deals a devastating blow to reef building corals by terminating the relationship corals share with their obligate nutritional endosymbionts of the family Symbiodiniaceae (Glynn 1983; Weis 2008; Lesser 2011). These endosymbionts provide up to 95\% of their coral host's energy, facilitating coral calcification responsible for building reef structure (Muscatine and Porter 1977). Bleaching recovery is possible, but may take several years and is accompanied by limited survivorship (Hughes et al. 2017), impaired reproduction (Szmant and Gassman 1990; 
Levitan et al. 2014), depletion of energetic stores (Rodrigues and Grottoli 2007; Anthony et al. 2009), and decreased growth (Baird and Marshall 2002).

Intensifying climate change is predicted to induce the onset of annual mass bleaching events for the majority or even all of the world's coral reefs within a human lifetime, casting doubt on prospects for the multi-year bleaching recovery process and the endurance of reef structure habitat (Van Hooidonk et al. 2013; Manzello 2015). Annual bleaching threatens the tremendous biodiversity represented by reef building corals and all the species dependent upon them as the primary engineers of coral reefs. Further, the reef structure is invaluable to human society for well known economic, cultural, and security reasons (Groot et al. 2012; Costanza et al. 2014). Devastating instances of annually repetitive mass bleaching have already occurred in South Florida (Lewis et al. 2019; Manzello et al. 2019) and elsewhere (Hughes et al. 2017; Hughes et al. 2018).

It is necessary for coral conservation and restoration programs to consider interventions to physiologically prepare coral populations for the unavoidable intensification of thermal stress and mass bleaching. As drivers of bleaching resistance, Symbiodiniaceae community composition (Berkelmans and van Oppen 2006; Lewis et al. 2019), thermal environment (Bellantuono et al. 2012; Howells et al. 2013; Palumbi et al. 2014), bleaching history (Brown et al. 2002; McClanahan 2017), and coral host genetics (Merselis et al. 2018; Morikawa and Palumbi 2019) are all candidate mechanisms for interventions to leverage (reviewed in: Torda et al. 2017; van Oppen et al. 2017). Adaptation, Symbiodiniaceae community change, and acclimatization may be leveraged by restorationists through Symbiodiniaceae inoculation, exposure to stress or sub-stress challenges, and use of selective breeding, assisted gene flow, or even genetic 
modification in order to leverage or manufacture differences in host genetic bleaching resistance (van Oppen et al. 2015; van Oppen et al. 2017).

The 2014 and 2015 coral mass bleaching events in South Florida were triggered by ENSO-related hyperthermal stress (Merselis et al. 2018; Lewis et al. 2019; Manzello et al. 2019). These back-to-back bleaching events provided a rare opportunity to determine how sources of bleaching resistance operate under predicted annually repetitive hyperthermal conditions. I hypothesized that as a symbiont specialist coral species, Acropora cervicornis would not initially uptake exogenous, thermally tolerant symbionts, but that exposure to multiple bleaching events might facilitate acquisition and hosting of thermally tolerant symbionts. I anticipated that coral host bleaching history would facilitate dynamism in bleaching response, either weakening bleaching resistance through energetic deprivation, or preparing the coral for subsequent bleaching events. Finally, I predicted that host genotype would be a strong driver of bleaching resistance as genetic identity structures numerous holobiont phenotypes (e.g., Vollmer and Kline 2008; Lirman et al. 2014; Kuffner et al. 2017; Ladd et al. 2017; Merselis et al. 2018). Comparing mechanisms of bleaching resistance allowed us to evaluate their relative utility in conservation / restoration efforts. My study was conducted in a coral restoration nursery, allowing for replicated (clonal) examination of host genetic identity within a preestablished common garden. Because of the asexual fragmentation used to propagate corals, nurseries contain many clonal replicates (ramets) for each of many coral genotypes (genets). The coral genets in our study nursery have previously been characterized using micro-satellites as in Baums et al. (2009). 


\subsection{Methods:}

\subsubsection{Common Garden Site and Distribution of Corals}

All Acropora cervicornis corals within my study were propagated within the in situ University of Miami "North Nursery" at N 25.488; W 80.109 since 2007. These corals were monitored by one observer during September and November 2014, January, March, September, October 2015, and March 2016. The nursery contains multiple ramets (individual clones) of many genets (clonal populations, frequently referred to as "genotypes"). Ramets belonging to the same genet grow on individual pedestals raised off of a common cement block. Each block sits on a sand bottom at a depth of approximately 7 meters and within 100 meters of all other genets. No monitored ramets were in physical contact for the duration of the study such that monitoring efforts could consider each ramet a biologically independent experimental replicate.

\subsubsection{Monitoring of Acropora cervicornis Bleaching and Elucidation of Inter-Annual Acclimatization}

To detect acclimatization of independent ramets during the repeated bleaching events, ramets representing 21 A. cervicornis genets were tracked. Because all monitored genets had been in the nursery since 2007 , it was assumed that they were equally acclimatized to the environmental conditions. The most recent bleaching event occurred in 2010, after corals were brought to the common garden, so it was assumed that no coral genet experienced substantially differential environmental conditions that would have confounded our analyses. During every time point, each ramet was photographed and 
scored for presence or absence of bleaching using a colorimetric card as a reference (Siebeck et al. 2006).

To understand whether bleaching resistance or susceptibility in 2014 influenced bleaching response in 2015 (acclimatization) or if prior response to bleaching was a predictor of subsequent bleaching response (static response), ramets were categorized as either "weakened" (resisted bleaching the first year, but bleached the second), "acclimatized" (bleached the first year, but resisted the second), "susceptible" (bleached both years), or "resistant" (resisted bleaching both years). A Chi-square test for independence was employed using only ramets that survived both years. Expected values were calculated for each category following the null hypothesis that bleaching response in 2014 had no effect on bleaching response in 2015 as follows:

OB'14 = observed proportion of ramets bleached in 2014

OB'15 = observed proportion of ramets bleached in 2015

Expected "Susceptible" $=$ OB'14 $* \mathrm{OB}^{\prime} 15 *$ total ramets

Expected "Resistant" = OR'14 * OR'15 * total ramets

Expected "Weakened" = OR'14* O B'15* total ramets

Expected "Acclimated" = OB'14 * OR'15 * total ramets 


\subsubsection{Monitoring and Relating Symbiodiniaceae Assemblage to Repetitive Bleaching Response}

To identify and determine the relative abundances of Symbiodiniaceae populations within ramets, small $(\leq 1 \mathrm{~cm})$ samples were taken of $(3+)$ ramets within each genet during September 2014, March 2015, September 2015, and March 2016. To ensure samples were representative of the ramet as a whole, the lighter pigmented, sparsely Symbiodiniaceae-colonized apical tip of the sampled branch was first cut off and discarded prior to sampling a sub-apical piece of the branch. If ramets within genets showed dissimilar bleaching histories (i.e., several ramets from the same genet bleached while several did not), three ramets within each of the two distinctly responding groups of ramets within that genet were sampled. The genet $\mathrm{x}$ response sampling regime continued for the remainder of the study, including following recovery when bleaching history was no longer visibly apparent. Samples were preserved within CHAOS lysis buffer for at least 24 hours before DNA was extracted.

The CHAOS buffer/ lysed coral tissue mixture was added to a silica spin filter, centrifuged at 6,000 $\mathrm{g}$ for one minute to bind DNA to the silica filter. The filter was subsequently triple washed with $700 \mu \mathrm{L}$ of a protein wash buffer and then double washed with an ethanol / GITC wash buffer before being centrifuged dry. The purified DNA was eluted in a new tube via the addition of $50^{\circ} \mathrm{C} 0.1 \times \mathrm{TE}$ buffer and centrifugation. An approximately 480bp region of the Symbiodiniaceae chloroplast 23S (cp23S) gene was amplified with the primers primers F: AATAACGACCTGCATGAAAC, R: GCCTGTTATCCGTAGAGTAGC designed for universal complimentarity with Symbiodiniaceae using GoTaq polymerase. The PCR reactions were composed of $10 \mu \mathrm{L}$ 
of 2x GoTaq master mix, $1 \mu \mathrm{L}$ of template, $0.5 \mu \mathrm{L}$ of each the Forward and Reverse primers $(10 \mu \mathrm{M})$, and $8 \mu \mathrm{L}$ of molecular water. The PCR program started with an initial denaturation at $95^{\circ} \mathrm{C}$ for 3 minutes, 35 cycles of $95^{\circ} \mathrm{C}$ for 30 s, annealing at $55^{\circ} \mathrm{C}$ for $30 \mathrm{~s}$, and with $72^{\circ} \mathrm{C}$ extension for 30s. The PCRs concluded with a final extension at $72^{\circ} \mathrm{C}$ for five minutes. The PCR products were sent for high throughput amplicon sequencing at MRDNA in Shallowater, Texas for samples from September 2014, March 2015 and September 2015 where they were purified, index-barcoded, purified again, and sequenced. Raw sequence data were processed using the MR DNA pipeline. Forward and Reverse reads were joined after quality control (Q25) barcode index removal, and removal of sequences with $<150$ base pair overlap. Remaining sequences were denoised, OTUs were generated, and chimeras were discarded. Clustering of OTUs was determined at $97 \%$ similarity across samples. Resulting OTUs were taxonomically classified using BLASTn against a selected database created from chloroplast 23S Symbiodiniaceae sequence data from NCBI.

To determine the role of Symbiodiniaceae identity in bleaching resistance, quantitative summaries of Symbiodiniaceae community compositions of each coral were ordinated on an nMDS and resultant patterns corresponding with bleaching outcomes were further explored using MANCOVA. Categorical data concerning the presence / absence of particular symbionts and correlation with bleaching outcome were analyzed using Bonferroni corrected Chi-square tests for independence on each of the Symbiodiniaceae species identified. Repeated measures MANCOVA was employed to reveal whether the March 2016 sampled corals shifted towards a more thermally tolerant community after two mass bleaching events. 


\subsubsection{Determining the Role of Host Identity in Repetitive Bleaching Response}

Genetic identity (genet) was established through previous microsatellite marker work following Baums et al. (2005 \& 2009) and Lirman et al. (2014), confirming that all genets were unique. Genetic disparity must be confirmed as Acropora cervicornis reproduces readily through asexual fragmentation during storms and mechanical damage giving rise to "thickets" typically composed of numerous clonal individuals.

To assess whether bleaching resistance varies by host genetic identity, I performed a Fisher's exact test and post-hoc Benjamini-Hochberg corrected Fisher's pairwise test comparing proportion of ramets bleached vs unbleached by genet using the Rcompanion package within R (R Core Team 2017; Mangiafico 2019).

\subsection{Results:}

From 2014 through 2017, repetitive hyperthermal anomaly provoked continuous mass bleaching events around the world and constituted a sizable blow to the planet's coral reef ecosystems. On the great barrier reef for example, more than $30 \%$ of live coral died in 2016 (Hughes et al. 2018). In South Florida, substantial mass bleaching was observed in late summers 2014 and 2015, affecting the University of Miami "North nursery". In 2014, $9 \%$ of monitored ramets bleached, while in 2015, $28 \%$ bleached. 


\subsubsection{Inter-annual Dynamism of Coral Ramets' Bleaching Response (Acclimatization)}

Considerable whole-ramet coral mortality had occurred by March 2015 (prior to bleaching in September 2015), preventing observation of a second bleaching response for 39 ramets and therefore preventing us from classifying ramets into a repetitive bleaching category (Fig. 2.1). Of the surviving ramets, 5.8\% were categorized as susceptible (bleached both years), 22.1\% were weakened (resisted bleaching in 2014, but bleached in 2015), 3.5\% were "acclimatized" (bleached in 2014, but not in 2015), and 68.6\% were resistant (did not bleach either year; Fig. 2.2).

Resistance or susceptibility to bleaching in 2014 was not associated with either an improved or degraded bleaching resistance in 2015; A Chi-square test for independence did not detect significant deviation from a null hypothesis of independence between bleaching in 2014 and bleaching in 2015. Further, ramets that bleached in 2014 were twice as likely to bleach in 2015 as they were to resist and were also more likely to bleach in 2015 than those corals that bleached in 2014. The few ramets classified as acclimatized suffered severe partial mortality recognized by loss of live tissue effecting the majority of the ramet. 


\subsubsection{Relationship Between Symbiodiniaceae Assemblage and Repetitive Bleaching Response}

Amplicon sequencing of the cp23S revealed that all monitored Acropora cervicornis ramets were dominated by type A3 Symbiodiniaceae (Symbiodinium "fitti," nomen novum) for the duration of the study. Symbiodinium fitti is the canonical symbiont for Acropora in the greater Caribbean, although the presence of both Breviolum psygmophilium (B2), and Durusdinium trenchii (D1a) Symbiodiniaceae were also detected. The abundance of both of cryptic symbionts remained extremely low in both bleached and unbleached corals, never exceeding $1.0 \%$ of the total Symbiodiniaceae community, although heterologous symbionts increased in both prevalence and abundance (Fig. 2.3, 2.4). Assuming corals were hosting approximately one million algal symbionts per $\mathrm{cm}^{2}$, the ramet with the greatest density of heterologous symbiont population at each time point was about 45 cells per $\mathrm{cm}^{2}$ in September 2014, 80 cells per $\mathrm{cm}^{2}$ in March 2015, and 7,000 cells per $\mathrm{cm}^{2}$ in October 2015.

The absolute presence or absence of any of the detected symbiont species was not associated with the bleaching response. The non-metric multi-dimensionally scaled (nMDS) plot (Fig. 2.5) did not recover any apparent patterns of clustering of Symbiodiniaceae communities according to repetitive bleaching category. Further, no apparent clustering of repetitive bleaching categories was apparent with an NMDS including only rare abundance OTUs (less than $1.0 \%$ relative abundance). 


\subsubsection{Host Genetic Identity is Highly Correlated with Bleaching Response}

Bleaching prevalence and repetitive bleaching category classification varied drastically amongst monitored genets. While some genets never had a single ramet bleach or suffer partial mortality (i.e., genets L or M, Fig. 2.6), other genets saw bleaching of most ramets accompanied by a loss of most of that genets' biomass (genet W), and all nine ramets of genet B were dead prior to the second bleaching event in 2015. Pair-wise Fisher's exact tests revealed both significant differences between genets' ability to resist bleaching ( $<<1 \times 10^{-12}$; Fig. 2.6) and significant differences in repetitive bleaching category classification ( $\mathrm{p}<1 \times 10^{-18}$; Fig. 2.7).

\subsection{Discussion:}

\subsubsection{Initial Bleaching Response did not Improve Response to a Second Bleaching Event}

The statistical independence between bleaching response in 2014 and bleaching response in 2015 demonstrates that prior bleaching history does not determine response to subsequent bleaching. What non-significant trends exist indicate a stronger likelihood that prior bleaching history negatively impacted response to subsequent stressors than for a favorable acclimatization response. The severe partial mortality suffered by acclimatized corals suggests that even the exceptions to the negative trend are not a credible source of hope.

I incorrectly hypothesized that prior bleaching or resistance to bleaching would mediate a dynamic response in subsequent bleaching events. Given numerous 
experiments documenting an ability of corals to increase bleaching resistance without changing symbiont community over the short term (Middlebrook et al. 2008; Bellantuono et al. 2012), the lack of "coral-only" acclimatization documented here and in other field studies is surprising (Grottoli et al. 2014; Hughes et al. 2017). Similarly, corals residing within highly variable thermal environments may demonstrate increased thermal resistance while controlling for the effects of host genetics and effects of Symbiodiniaceae community composition (Palumbi et al. 2014; Bay and Palumbi 2015). Several other field studies also documented acclimatization (sensu lato) to inter-annual bleaching. However, previous studies either did not characterize the Symbiodiniaceae community and/or rule out the possibility of selective enrichment for thermally tolerant genotypes by selective mortality so the mechanism of adaptation remains unknown (Brown et al. 2002; Pratchett et al. 2013; Maynard et al. 2015; McClanahan 2017; Gintert et al. 2018).

Nevertheless, instances of increased thermal tolerance are encouraging, although bleaching resistance appears to have weakened in other cases of repeated inter-annual bleaching (Berkelmans et al. 2004; Hughes et al. 2017). Perhaps acclimatization is a transient mechanism, requiring frequent 'reminders' (e.g., constitutively stressful or frequently varying environments) to sustain memory and suggesting that demonstrated instances of innate acclimatization may not be relevant to annually repetitive bleaching scenarios (Fenner and Heron 2008; reviewed in Hoegh-Guldberg 2014). Transient innate acclimatization is consistent with inter-annual manipulative bleaching of three Caribbean species which only revealed increased bleaching resistance when accompanied by changes in the Symbiodiniaceae community (Grottoli et al. 2014). 


\subsubsection{Minute Thermal Stress-driven Symbiodiniaceae Community Dynamism is not Relevant to Bleaching Response}

The Symbiodiniaceae community responded to the hyperthermal events through a fine-scale increase in heterologous symbiont abundance and prevalence. The current study is the first report of Breviolum psygmophilium associating with Atlantic Acropora. Breviolum psygmophilium is commonly found in a facultative relationship with the temperate scleractinian coral, Astrangia poculata, and temperate populations of Exaiptasia pallida anemones (Lajeunesse 2001; Thornhill et al. 2008).

The other heterologous colonizer, Durusdinium trenchii, is a non-native species associated with thermal tolerance and increased bleaching resistance (Pettay et al. 2015). Corals hosting D. trenchii or switching to host the resistant species have been shown to outperform conspecifics in both field and manipulative thermal stress scenarios (Grottoli et al. 2014; Silverstein et al. 2014; Cunning et al. 2015). Despite the acquisition of $D$. trenchii, the relative abundance of $D$. trenchii within ramets did not drastically increase during and following hyper-thermal events, although prevalence of heterologous symbionts dramatically increased amongst ramets mirroring recent work by Lewis et al. in Dendrogyra cylindrus during the same two bleaching years (Lewis et al. 2019).

The nature of the relationship between coral hosts and extremely low abundance Symbiodiniaceae species remains relatively unknown. It has been suggested that such low abundances of heterologous species could be the result of extracellular association with coral mucus or even contamination from the water column. However, the composition of the rare Symbiodiniaceae biosphere I describe appears non-random and 
relatively stable through time. In the event that rare Symbiodiniaceae taxa were temporarily lodged in coral mucus or merely contaminating the sample from the surrounding seawater, the rare biosphere should share the identity, diversity, and temporal stability of the free-living Symbiodiniaceae community. Although I did not sample the water column, the cryptic community I recovered is not consistent with purely happenstance distribution of free-living Symbiodiniaceae in coral mucus (GranadosCifuentes et al. 2015). The inconsistency between free-living and A. cervicornis associated cryptic symbionts suggests a role of environment in structuring their presence. Association with cryptic symbionts could be as part of a canonical mutualism (i.e., intracellular) or the result of selection for fitness in various host-associated niches (e.g., mucosal) which may facilitate commensal, mutualistic, or parasitic lifestyles.

Neither the present study nor any published work to our knowledge has demonstrated a physiological consequence of hosting extremely rare $<1 \%$ members of the Symbiodiniaceae community except when they grow to become more dominant community members and thereby cease to be members of the "rare biosphere." The ability for coral-associated Symbiodiniaceae assemblages to shuffle in dominance, however, means that while rare members may not presently modulate holobiont fitness, they represent a potential adaptive resource in the face of continued disturbance (reviewed in Baker 2003).

My work reaffirms the strong dominance Symbiodinium" fitti" (A3) has in A. cervicornis whether facilitated by host specificity or competitive dynamics amongst symbiont species within A. cervicornis. Similarly, despite decades of warming, S. "fitti" remains the strongly dominant symbiont of Caribbean Acropora. The lack of symbiont 
diversity in Caribbean Acropora (Thornhill et al. 2006; Baums et al. 2010; Baums et al. 2014) may partially explain the failure of such rapidly growing coral species to reestablish their once dominant populations on shallow Caribbean reefs following the ongoing declines starting in the 1980s (Aronson and Precht 2006).

Surprisingly, the failure of heterologous symbionts to correlate with any repetitive bleaching category not only demonstrates that Symbiodiniaceae community dynamics did not influence bleaching response, but that bleached and healthy corals were equally likely to associate with heterologous Symbiodiniaceae. Our results are in stark contrast with numerous examples whereby coral bleaching acts as the primary mechanism enabling switching or shuffling of Symbiodiniaceae community structure (Baker 2001; Thornhill et al. 2006; Diaz-Pulido et al. 2009; LaJeunesse et al. 2009; Silverstein et al. 2014).

In the case of symbiont generalist host taxa such as Montastraea, Orbicella and Siderastrea, Symbiodiniaceae communities are diverse and dynamic (Correa et al. 2009; Bongaerts et al. 2015; Gates et al. 2015; Kemp et al. 2015; Bonthond et al. 2018; Cunning et al. 2018). When corals change symbionts from thermally susceptible to thermally tolerant species it may be followed by a post-recovery reversion to a thermally susceptible species (Thornhill et al. 2006; LaJeunesse et al. 2009; Lewis et al. 2019). Constant or frequent selective pressure for non-canonical symbionts may even be responsible for symbiont specificist corals such as A. cervicornis to endure constitutively warmer inshore environments with compliments of stress-tolerant symbionts (Baums et al. 2010). In instances where restorationists wish to transplant symbiont generalist corals with stress susceptible symbionts into environments with constitutively harsh conditions, 
preparatory manipulation of Symbiodiniaceae community may reduce initial mortality and bleaching.

Further exploration of the trade-off between temporary metabolic loss due to bleaching and long-term fitness advantages of hosting a putatively adaptive symbiont is required for symbiont generalists.

\subsubsection{Coral Genetic Identity Structures Bleaching Response and Represents an Important}

\section{Conservation Resource}

Host genet was the only factor examined in the present study to have a detectable effect on bleaching response. The sizable effect of host genetic identity appears to have the most potential to modulate bleaching resistance, particularly in the case of symbiontspecialist corals. Our findings are well supported by other studies linking coral host genotype with numerous measures of robustness to Anthropocene stressors including disease, bleaching, and growth under acidification (Vollmer and Kline 2008; Cole et al. 2018; Merselis et al. 2018; Muller et al. 2018; Manzello et al. 2019).

The highly variable host driven bleaching resistance in Acropora cervicornis adds hope to the notion that coral species may be able to adapt to anthropocene conditions (Granados-Cifuentes et al. 2013; Matz et al. 2018). However, evolution requires successful reproduction and recruitment of offspring which has essentially collapsed for A. cervicornis in the Florida Keys (Williams et al. 2008; Miller et al. 2016) and is sharply declining in other species and locations (Vermeij et al. 2011; Price et al. 2019). 
It may be possible to leverage host genotype to facilitate Symbiodiniaceae community manipulation as specificity may be hereditary (Quigley et al. 2018). To ascertain whether S." fitti" dominance of Acropora cervicornis is mediated by host genetic specificity or competitive dominance of $S$. "fitti" over D. trenchii within the coral host, reciprocal transplants should be conducted between rare inshore Durusdinium hosting Acropora cervicornis and their offshore counterparts.

\subsubsection{Conclusions and Recommendations}

I conclude that manipulative colonization by stress-tolerant symbionts may not be practical for A. cervicornis, but if realized would be useful in preparation for outplanting to sites with sustained stress conditions. Host genetics appears to be the most powerful adaptive resource available for increasing bleaching resistance of Acropora cervicornis, but the rate of ocean warming out-paces any evolution expected in the field. Selective breeding has been suggested (van Oppen et al. 2017), while assisted gene flow (Hagedorn et al. 2018) and genetic modification have been demonstrated for Acropora (Cleaves et al. 2018).

Currently, genetic modification or importation of individuals from distant populations for conservation purposes is legally challenging although both approaches must be seriously considered given unavoidable continued warming amongst numerous other stressors. The theory of selective breeding is well-understood, tractable, and proven given its pervasive role in agriculture. Unfortunately, sexual recombination of corals has historically been technically challenging with limited opportunities for investigators to 
learn and improve. Incorporation of sexual reproduction will benefit from recent advances in achieving more frequent coral spawning (Craggs et al. 2017; Craggs et al. 2018), more successful recruitment (Chamberland et al. 2015; Hagedorn et al. 2018), and faster growth through improved culture practices (Forsman et al. 2015; Page et al. 2018), though continued progress is needed to enable rapid adaptation.

The focus of the discussion surrounding selective breeding has been to develop "super-corals" resistant to disease, bleaching, acidification, and numerous other stressors that scleractinian corals will continue to encounter (van Oppen et al. 2015). However, identification of "winner" and "loser" genets should also be used to identify and save valuable genetic diversity that will predictably be lost in the near term.

Caribbean Acropora populations have declined so dramatically that every remnant colony falls within a small percentile of "anthropogenically-selected" genotypes (Gardner et al. 2003). An entire genome cannot be considered maladaptive because of performance in a single assay or panel of assays. Loser genets are likely winners in other contexts due to strong genet by site interactions (Drury et al. 2017). Given the copious offspring that can be produced by few healthy colonies, relatively few crosses between "loser" and "winner" genets could result in thousands of recruits with expert husbandry (Hagedorn et al. 2018). Subsequent artificial or natural selection should provide numerous genets carrying otherwise lost genetic material within a phenotype robust against the stressor of interest. 


\subsection{Figures:}

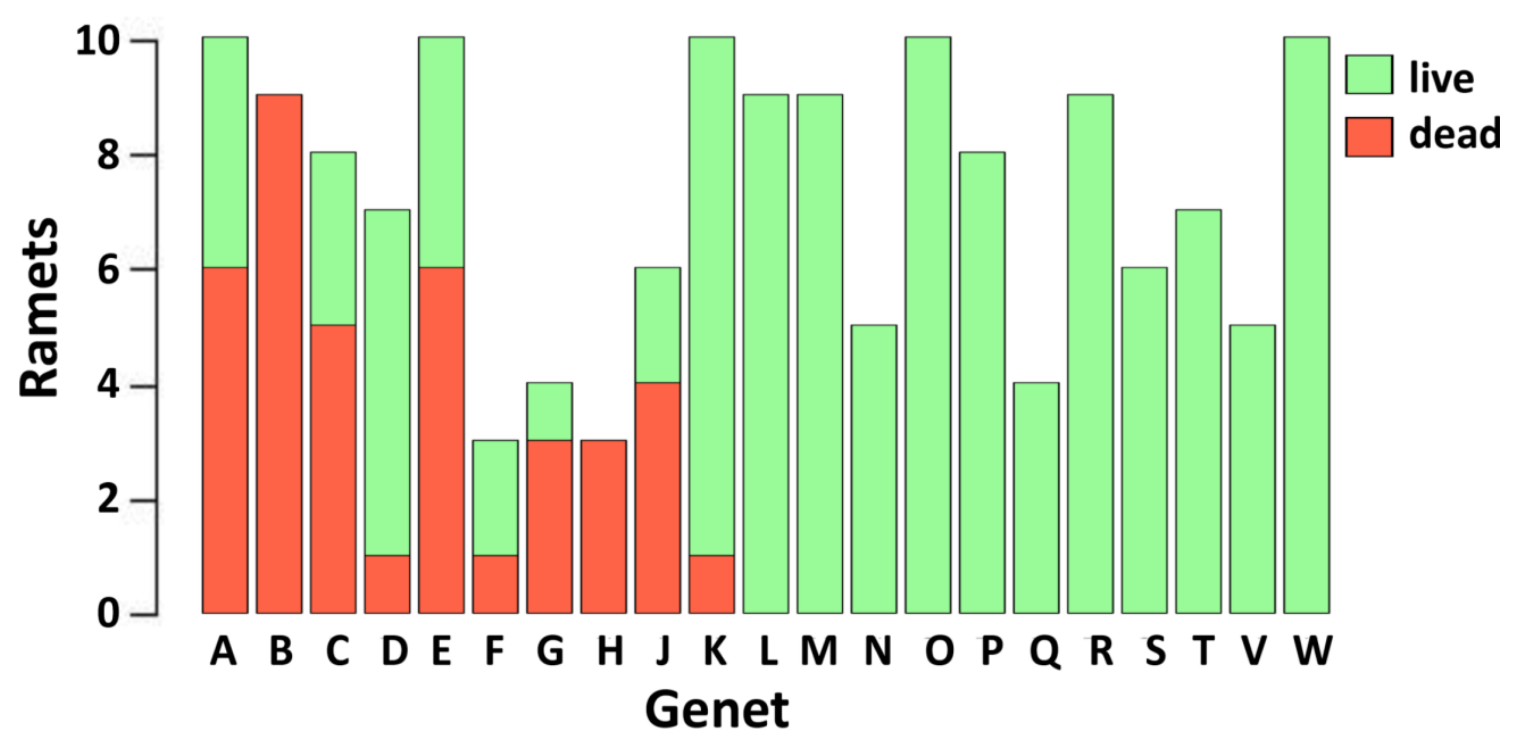

Fig. 2.1 Acropora cervicornis Mortality Prior to 2015 Bleaching: $x$-axis letters denote genet identifications. red: individuals (ramets) suffering complete mortality; green: healthy ramets and ramets suffering from partial mortality. In total, 39 ramets suffered complete mortality by March 2015 

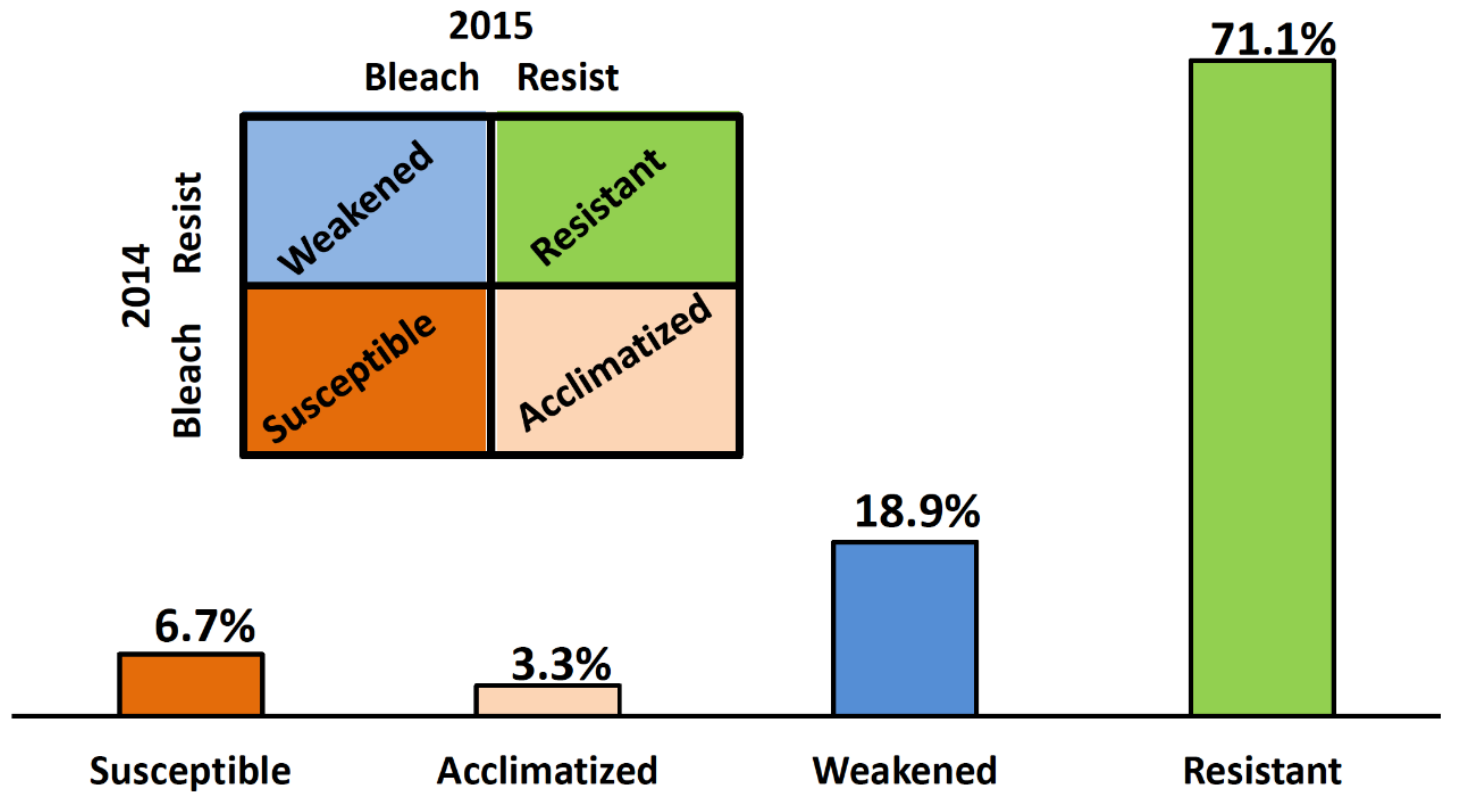

Fig. 2.2 Repetitive Bleaching Outcomes for Acropora cervicornis following the 2014 / 2015 Mass Bleaching Events: Percentage of ramets in each of four possible repetitive bleaching outcomes: Susceptible (bleached both years), Acclimatized (bleached in 2014, but resisted bleaching in 2015), Weakened (resisted bleaching in 2014, but bleached in 2015), or Resistant (resisted bleaching both years). Inset: graphical representation of repetitive bleaching category definitions. 


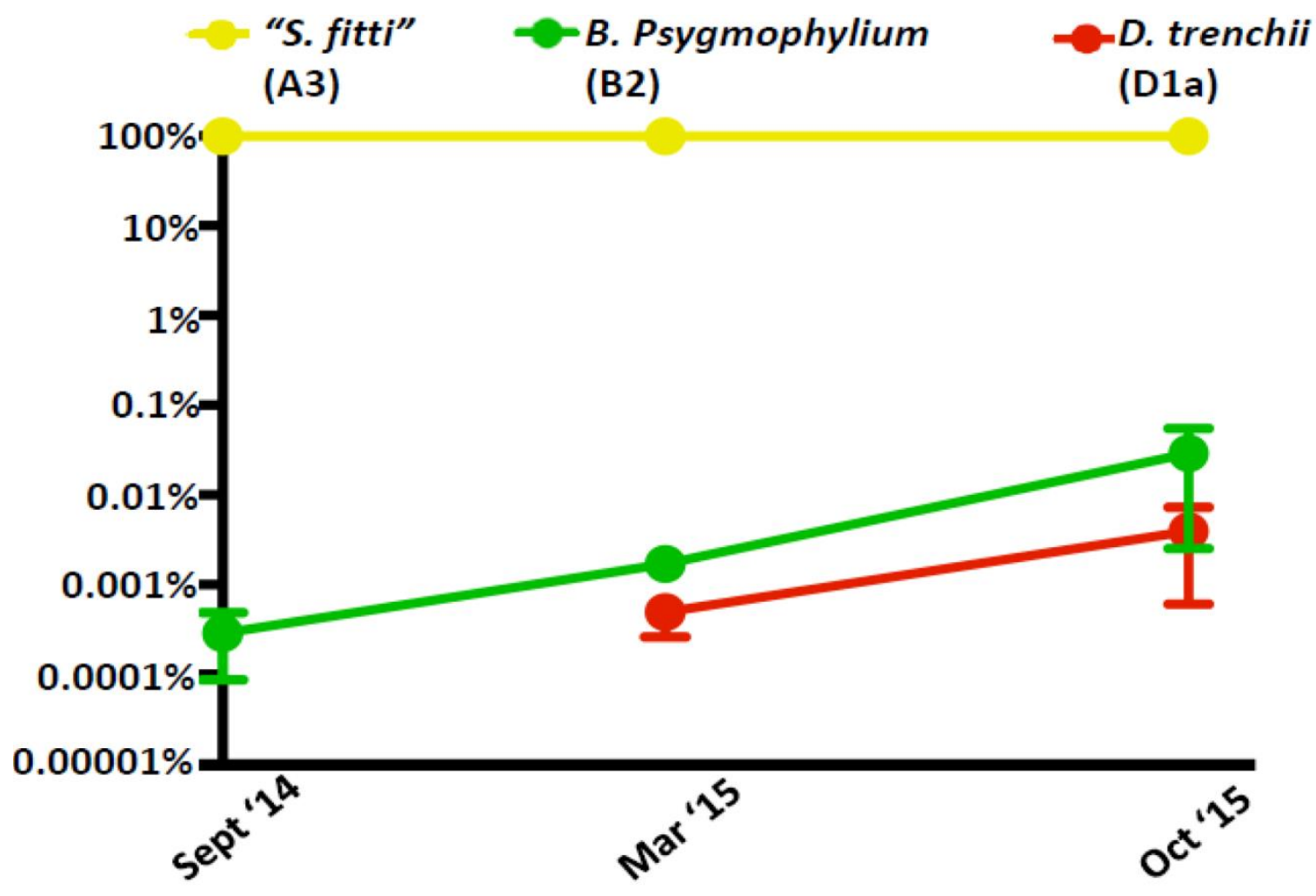

Fig. 2.3 Symbiodiniaceae Community through 2014 / 2015 Mass Bleaching Events: Note the log-scale y-axis of relative symbiont abundance. "Symbiodinium fitti "(nomen novum, yellow), Breviolum psygmophilium (green), and Durusdinium trenchii (red). 


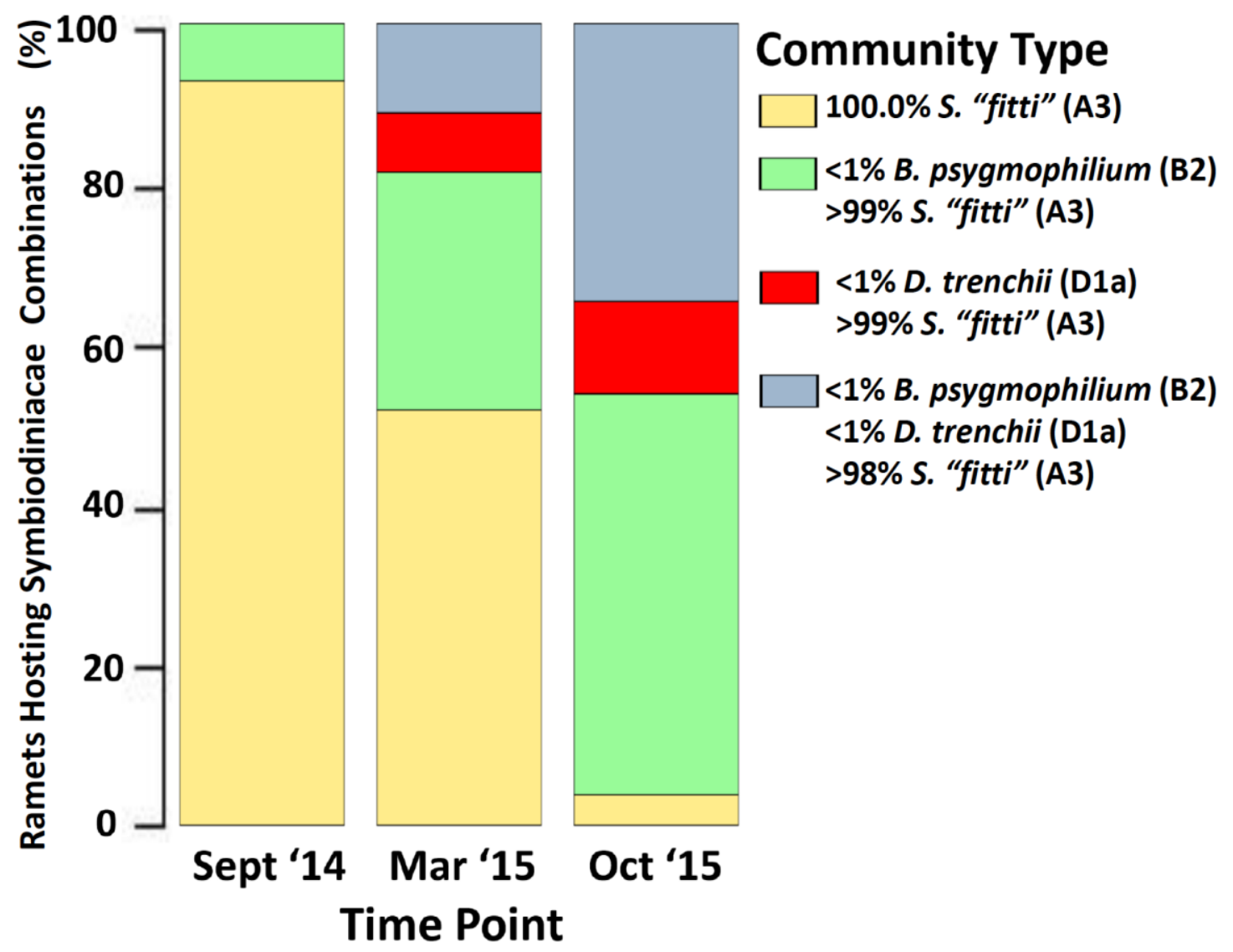

Fig. 2.4 Ramets Categorized by Symbiodiniaceae Community Identity through Time: Symbiodinium fitti (nomen novum) only (tan), S. fitti with $<1 \%$ Breviolum psygmophilium (green), S. fitti with $<1 \%$ Durusdinium trenchii (red), or S. fitti with $<1 \%$ each of S. fitti and D. trenchii. 


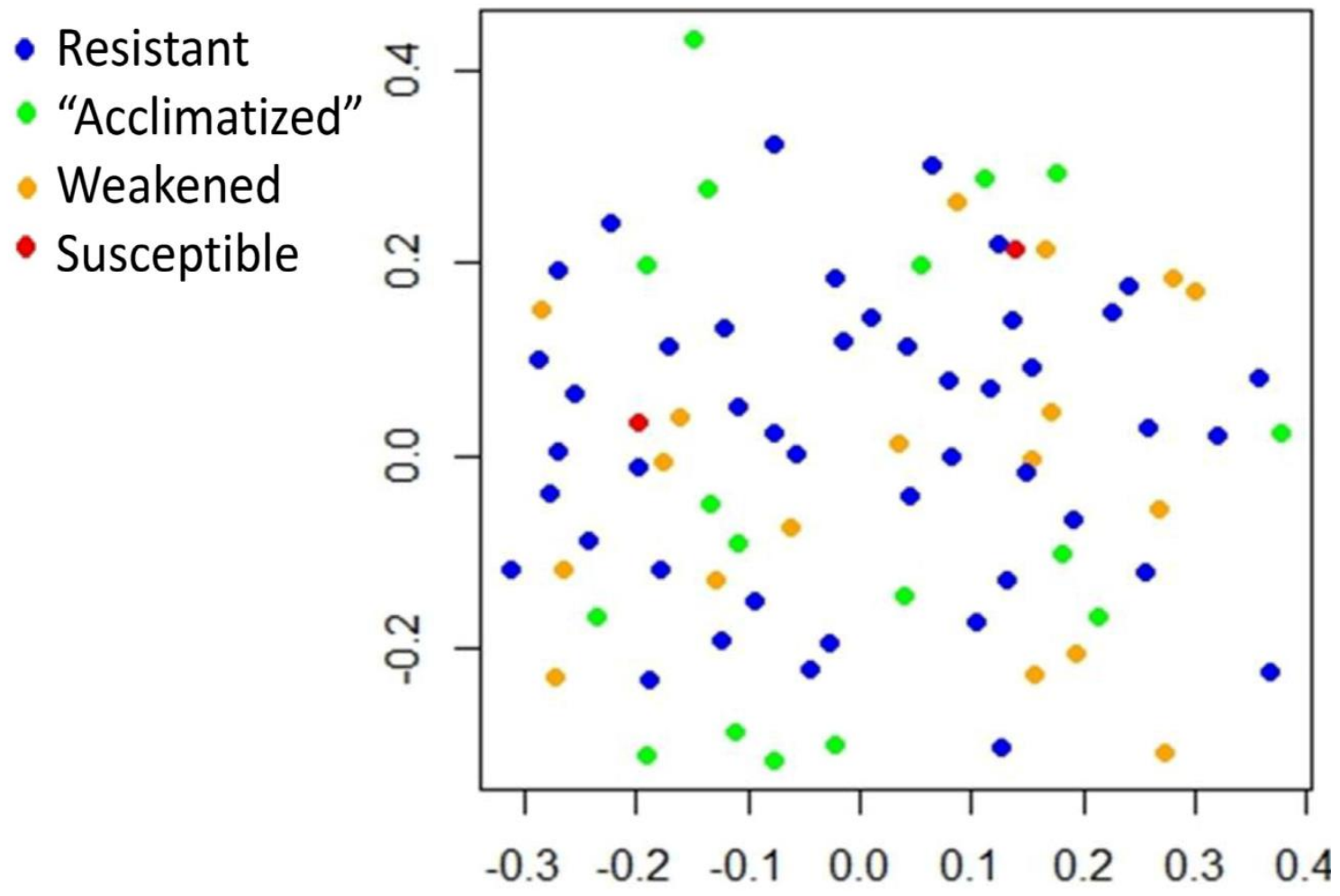

Fig. 2.5 Ramets' Symbiodiniaceae Communities Ordinated through Non-metric Multi-Dimensional Scaling (nMDS): according to similarity of Symbiodiniaceae community composition and colored according to ramet response to repetitive bleaching. Blue- Resistant (resisted bleaching both years), Green- Acclimatized (bleached in 2014, but resisted bleaching in 2015), Orange- Weakened (resisted bleaching in 2014, but bleached in 2015), Red- Susceptible (Bleached both years) 


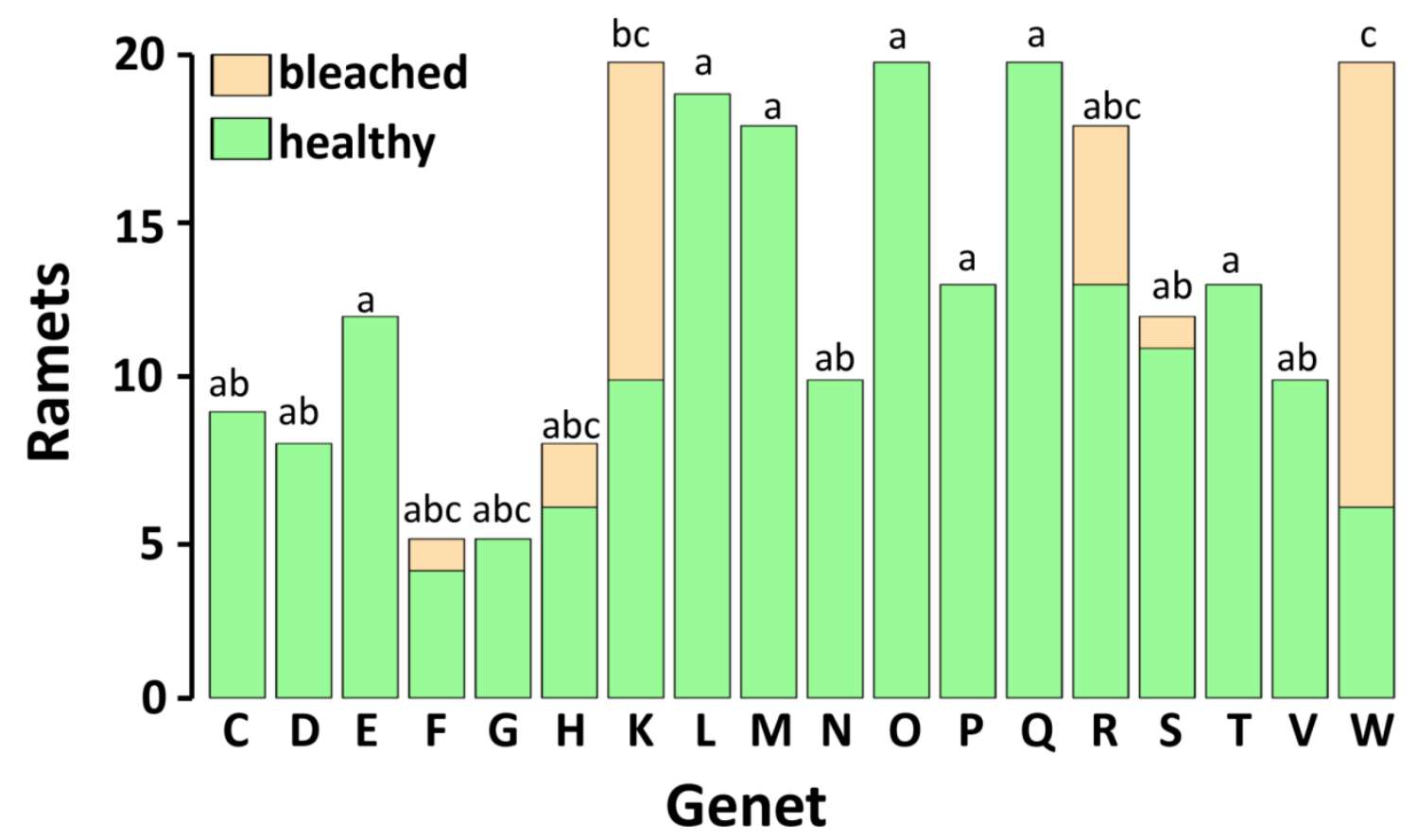

Fig. 2.6 Bleaching Resistance by Host Genet in 2014 and 2015:

Ramets either bleached (beige) or remaining healthy (green). Graph includes summary data of both 2014 and 2015 mass bleaching events. Fisher's exact test: $p=1.033 \mathrm{e}-13$. Shared letters indicate no significant difference between genets. 


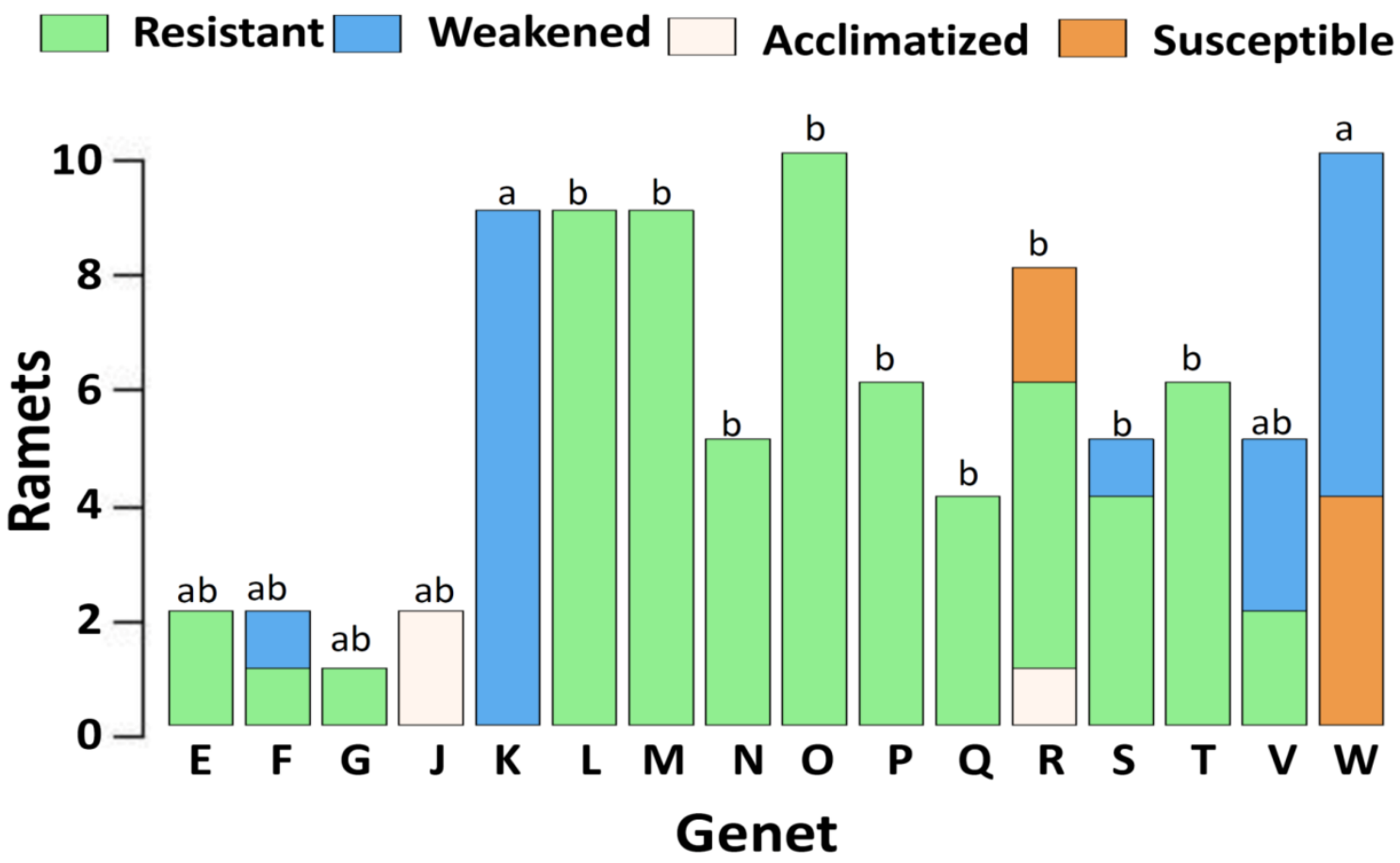

Fig. 2.7 Ramet Membership in Repetitive Bleaching Response Categories by Genet:

Green- Resistant (resisted bleaching both years), Beige- Acclimatized (bleached in 2014, but resisted bleaching in 2015), Blue- Weakened (resisted bleaching in 2014, but bleached in 2015), Brown- Susceptible (Bleached both years) Fisher's exact test: $\mathrm{p}=1.79 \mathrm{e}-19$. Shared letters indicate no significant difference between genets. 


\subsection{References}

Anthony KRN, Hoogenboom MO, Maynard JA, et al. (2009) Energetics approach to predicting mortality risk from environmental stress: a case study of coral bleaching. Funct Ecol 23:539-550. doi: 10.1111/j.1365-2435.2008.01531.x

Aronson RB, Precht WF (2006) Conservation, precaution, and Caribbean reefs. Coral Reefs 25:441-450. doi: 10.1007/s00338-006-0122-9

Baird A, Marshall P (2002) Mortality, growth and reproduction in scleractinian corals following bleaching on the Great Barrier Reef. Mar Ecol Prog Ser 237:133-141. doi: 10.3354/meps 237133

Baker A (2003) Flexibility and Specificity in Coral-Algal Symbiosis: Diversity, Ecology, and Biogeography of Symbiodinium. Annu Rev Ecol Evol Syst 34:661-689. doi: $10.1146 / 132417$

Baker AC (2001) Reef corals bleach to survive change. Nature 411:765-766.

Baums I, Devlin-Durante K, Brown L, Pinzon JH (2009) Nine novel, polymorphic microsatellite markers for the study of threatened Caribbean acroporid corals. Mol Ecol Resour 9:1155-1158. doi: 10.1111/j.1755-0998.2009.02588.x

Baums IB, Devlin-Durante MK, LaJeunesse TC (2014) New insights into the dynamics between reef corals and their associated dinoflagellate endosymbionts from population genetic studies. Mol Ecol 23:4203-4215. doi: 10.1111/mec.12788

Baums IB, Johnson ME, Devlin-Durante MK, Miller MW (2010) Host population genetic structure and zooxanthellae diversity of two reef-building coral species along the Florida Reef Tract and wider Caribbean. Coral Reefs 29:835-842. doi: 10.1007/s00338-010-0645-y

Baums IB, Miller MW, Hellberg ME (2005) Regionally isolated populations of an imperiled Caribbean coral, Acropora palmata. Mol Ecol 14:1377-1390. doi: 10.1111/j.1365-294X.2005.02489.x

Bay RA, Palumbi SR (2015) Rapid acclimation ability mediated by transcriptome changes in reef-building corals. Genome Biol Evol 7:1602-1612. doi: $10.1093 /$ gbe/evv085

Bellantuono AJ, Hoegh-Guldberg O, Rodriguez-Lanetty M (2012) Resistance to thermal stress in corals without changes in symbiont composition. Proc Biol Sci 279:1100-7. doi: $10.1098 /$ rspb.2011.1780

Berkelmans R, De'ath G, Kininmonth S, Skirving WJ (2004) A comparison of the 1998 and 2002 coral bleaching events on the Great Barrier Reef: spatial correlation, patterns, and predictions. Coral Reefs 23:74-83. doi: 10.1007/s00338-003-0353-y 
Berkelmans R, van Oppen MJH (2006) The role of zooxanthellae in the thermal tolerance of corals: a "nugget of hope" for coral reefs in an era of climate change. Proc Biol Sci 273:2305-12. doi: 10.1098/rspb.2006.3567

Bongaerts P, Carmichael M, Hay KB, et al. (2015) Prevalent endosymbiont zonation shapes the depth distributions of scleractinian coral species. R Soc Open Sci. doi: 10.1098/rsos.140297

Bonthond G, Merselis DG, Dougan KE, et al. (2018) Inter-domain microbial diversity within the coral holobiont Siderastrea siderea from two depth habitats. PeerJ 6:e4323. doi: 10.7717/peerj.4323

Brown BE, Dunn RP, Goodson MS, Douglas AE (2002) Experience shapes the susceptibility of a reef coral to bleaching. 119-126. doi: 10.1007/s00338-002-0215-z

Chamberland V, Vermeij M, Brittsan M, et al. (2015) Restoration of critically endangered elkhorn coral (Acropora palmata) populations using larvae reared from wild-caught gametes. Glob Ecol Conserv 4:526-537. doi: 10.1016/j.gecco.2015.10.005

Cleaves P, Strader M, Bay LK, et al. (2018) CRISPR/Cas9-mediated genome editing in a reef-building coral. PNAS. doi: 10.1073/pnas.1722151115

Cole C, Finch A, Hintz K, Allison N (2018) Effects of seawater p CO 2 and temperature on calcification and productivity in the coral genus Porites spp.: An exploration of potential interaction mechanisms. Coral Reefs 37:471-481. doi: 10.1007/s00338018-1672-3

Correa AMS, Brandt ME, Smith T, et al. (2009) Symbiodinium associations with diseased and healthy scleractinian corals. Coral Reefs 28:437-448. doi: 10.1007/s00338-0080464-6

Costanza R, de Groot R, Sutton P, et al. (2014) Changes in the global value of ecosystem services. Glob Environ Chang 26:152-158. doi: 10.1016/j.gloenvcha.2014.04.002

Craggs J, Guest JR, Davis M, et al. (2017) Inducing broadcast coral spawning ex situ: Closed system mesocosm design and husbandry protocol. Ecol Evol 7:1106611078. doi: 10.1002/ece3.3538

Craggs JRK, Guest JR, Brett A, et al. (2018) Maintaining natural spawning timing in Acropora corals following long distance inter-continental transportation. J Zoo Aquarium Res 6:30-36. doi: 10.19227/jzar.v6i2.317

Cunning R, Silverstein RN, Baker AC (2015) Investigating the causes and consequences of symbiont shuffling in a multi-partner reef coral symbiosis under environmental change. Proc R Soc B Biol Sci 282:20141725-20141725. doi: 10.1098/rspb.2014.1725

Cunning R, Silverstein RN, Baker AC (2018) Symbiont shuffling linked to differential photochemical dynamics of Symbiodinium in three Caribbean reef corals. Coral Reefs 37:145-152. doi: 10.1007/s00338-017-1640-3 
De'ath G, Fabricius KE, Sweatman H, Puotinen M (2012) The 27-year decline of coral cover on the Great Barrier Reef and its causes. Proc Natl Acad Sci 109:1799517999. doi: 10.1073/pnas.1208909109

Diaz-Pulido G, McCook LJ, Dove S, et al. (2009) Doom and Boom on a Resilient Reef: Climate Change, Algal Overgrowth and Coral Recovery. PLoS One. doi: 10.1371/journal.pone.0005239

Drury C, Manzello D, Lirman D (2017) Genotype and local environment dynamically influence growth, disturbance response and survivorship in the threatened coral, Acropora cervicornis. PLoS One 12:1-21. doi: 10.1371/journal.pone.0174000

Fenner D, Heron SF (2008) Annual summer bleaching of a multi-species coral community in backreef pools of American Samoa : a window on the future? Proc 11th Int Coral Reef Symp 7-11.

Forsman ZH, Page CA, Toonen RJ, Vaughan D (2015) Growing coral larger and faster: micro-colony-fusion as a strategy for accelerating coral cover. PeerJ 3:e1313. doi: $10.7717 /$ peerj. 1313

Gardner TA, Côté IM, Gill JA, et al. (2003) Long-term region-wide declines in Caribbean corals. Science (80- ) 301:958-960. doi: 10.1126/science.1086050

Gates RD, Cunning R, Yost DM, et al. (2015) Variability of Symbiodinium communities in waters, sediments, and corals of thermally distinct reef pools in American Samoa. 1-17. doi: 10.1371/journal.pone.0145099

Gintert BE, Manzello DP, Enochs IC, et al. (2018) Marked annual coral bleaching resilience of an inshore patch reef in the Florida Keys: A nugget of hope, aberrance, or last man standing? Coral Reefs 37:533-547. doi: 10.1007/s00338-018-1678-x

Glynn P (1983) Extensive" bleaching" and death of reef corals on the Pacific coast of Panama. Environ Conserv 10:149-154.

Granados-Cifuentes C, Bellantuono AJ, Ridgway T, et al. (2013) High natural gene expression variation in the reef-building coral Acropora millepora: potential for acclimative and adaptive plasticity. BMC Genomics 14:228. doi: 10.1186/14712164-14-228

Granados-Cifuentes C, Neigel J, Leberg P, Rodriguez-Lanetty M (2015) Genetic diversity of free-living Symbiodinium in the Caribbean: the importance of habitats and seasons. Coral Reefs 34:927-939. doi: 10.1007/s00338-015-1291-1

Groot R De, Brander L, Ploeg S Van Der, et al. (2012) Global estimates of the value of ecosystems and their services in monetary units. Ecosyst Serv 1:50-61. doi: 10.1016/j.ecoser.2012.07.005

Grottoli AG, Warner ME, Levas SJ, et al. (2014) The cumulative impact of annual coral bleaching can turn some coral species winners into losers. Glob Chang Biol 1-11. doi: $10.1111 / \mathrm{gcb} .12658$ 
Hagedorn M, Page CA, ONeill K, et al. (2018) Successful demonstration of assisted gene flow in the threatened coral Acropora Palmata across genetically-isolated Caribbean populations using cryopreserved sperm. bioRxiv 1:492447. doi: 10.1101/492447

Hoegh-Guldberg O (2011) Coral reef ecosystems and anthropogenic climate change. Reg Environ Chang 11:215-227. doi: 10.1007/s10113-010-0189-2

Hoegh-Guldberg O (2014) Coral reef sustainability through adaptation: glimmer of hope or persistent mirage? Curr Opin Environ Sustain 7:127-133. doi: 10.1016/j.cosust.2014.01.005

Howells EJ, Berkelmans R, van Oppen MJH, et al. (2013) Historical thermal regimes define limits to coral acclimatization. Ecology 94:1078-1088. doi: 10.1890/121257.1

Hughes TP, Kerry JT, Álvarez-Noriega M, et al. (2017) Global warming and recurrent mass bleaching of corals. Nature 543:373-377. doi: 10.1038/nature21707

Hughes TP, Kerry JT, Baird AH, et al. (2018) Global warming transforms coral reef assemblages. Nature 556:492-496. doi: 10.1038/s41586-018-0041-2

Kemp DW, Thornhill DJ, Rotjan RD, et al. (2015) Spatially distinct and regionally endemic Symbiodinium assemblages in the threatened Caribbean reef-building coral Orbicella faveolata. Coral Reefs 34:535-547. doi: 10.1007/s00338-015-1277-z

Kuffner IB, Bartels E, Stathakapoulus A, et al. (2017) Plasticity in skeletal characteristics of nursery-raised staghorn coral, Acropora cervicornis. Coral Reefs 36:679-684. doi: 10.1007/s00338-017-1560-2

Lajeunesse TC (2001) Investigating the biodiversity, ecology, and phylogeny of endosymbiotic dinoflagellates in the genus Symbiodinium using the ITS Region: In search of a "species" level marker. J Phycol 880:866-880. doi: 10.1046/j.15298817.2001.01031.x

LaJeunesse TC, Smith RT, Finney J, Oxenford H (2009) Outbreak and persistence of opportunistic symbiotic dinoflagellates during the 2005 Caribbean mass coral “bleaching” event. Proc Biol Sci 276:4139-48. doi: 10.1098/rspb.2009.1405

Lesser MP (2011) Coral Bleaching: Causes and Mechanisms. Coral Reefs: An Ecosystem in Transition. Springer Netherlands, Dordrecht, pp 405-419

Levitan D, Boudreau W, Jara J, Knowlton N (2014) Long-term reduced spawning in Orbicella coral species due to temperature stress. Mar Ecol Prog Ser 515:1-10. doi: 10.3354/meps 11063

Lewis CL, Neely K, Rodriguez-lanetty M (2019) Recurring episodes of thermal stress shift the balance from a dominant host-specialist to a background host-generalist zooxanthella in the threatened pillar coral. Front Mar Sci 6:1-15. doi: 10.3389/fmars.2019.00005 
Lirman D, Schopmeyer S, Galvan V, et al. (2014) Growth dynamics of the threatened Caribbean staghorn coral Acropora cervicornis: influence of host genotype, symbiont identity, colony size, and environmental setting. PLoS One 9:e107253. doi: 10.1371/journal.pone.0107253

Mangiafico S (2019) rcompanion: Functions to support extension education program evaluation.

Manzello DP (2015) Rapid recent warming of coral reefs in the Florida Keys. Sci Rep 5:16762. doi: 10.1038/srep16762

Manzello DP, Jankulak M, Matz M V, et al. (2019) Role of host genetics and heat tolerant algal symbionts in sustaining populations of the endangered coral Orbicella faveolata in the Florida Keys with ocean warming. Glob Chang Biol 1016-1031. doi: $10.1111 / \mathrm{gcb} .14545$

Matz M V, Treml EA, Aglyamova G V, Bay LK (2018) Potential and limits for rapid genetic adaptation to warming in a Great Barrier Reef coral. PLOS Genet 1-19.

Maynard J, Van Hooidonk R, Eakin CM, et al. (2015) Projections of climate conditions that increase coral disease susceptibility and pathogen abundance and virulence. Nat Clim Chang 5:688-694. doi: 10.1038/nclimate2625

McClanahan TR (2017) Changes in coral sensitivity to thermal anomalies. Mar Ecol Prog Ser 570:71-85. doi: 10.3354/meps 12150

Merselis DG, Lirman D, Rodriguez-Lanetty M (2018) Symbiotic immuno-suppression: Is disease susceptibility the price of bleaching resistance? PeerJ 6:e4494. doi: 10.7717/peerj.4494

Middlebrook R, Hoegh-Guldberg O, Leggat W (2008) The effect of thermal history on the susceptibility of reef-building corals to thermal stress. J Exp Biol 211:1050-6. doi: $10.1242 /$ jeb.013284

Miller MW, Williams DE, Fisch J (2016) Genet-specific spawning patterns in Acropora palmata. Coral Reefs 35:1393-1398. doi: 10.1007/s00338-016-1472-6

Morikawa MK, Palumbi SR (2019) Using naturally occurring climate resilient corals to construct bleaching-resistant nurseries. Proc Natl Acad Sci U S A. doi: 10.1073/pnas. 1721415116

Muller EM, Bartels E, Baums IB (2018) Bleaching causes loss of disease resistance within the threatened coral species Acropora cervicornis. Elife 3:1-20.

Muscatine L, Porter J (1977) Reef corals: mutualistic symbioses adapted to nutrient-poor environments. Bioscience 27:454-460.

Page CA, Muller EM, Vaughan DE (2018) Microfragmenting for the successful restoration of slow growing massive corals. Ecol Eng 123:86-94. doi:

10.1016/j.ecoleng.2018.08.017 
Palumbi SR, Barshis DJ, Traylor-Knowles N, Bay RA (2014) Mechanisms of reef coral resistance to future climate change. Science (80- ) 344:895-898. doi:

10.1071/MF99078

Pandolfi JM, Jackson JBC, Baron N, et al. (2005) Are U.S. coral reefs on the slippery slope to slime? Science (80- ) 307:1725 LP-1726.

Pettay DT, Wham DC, Smith RT, et al. (2015) Microbial invasion of the Caribbean by an Indo-Pacific coral zooxanthella. Proc Natl Acad Sci 112:7513-7518. doi: 10.1073/pnas. 1502283112

Pratchett MS, McCowan D, Maynard JA, Heron SF (2013) Changes in bleaching susceptibility among corals subject to ocean warming and recurrent bleaching in Moorea, French Polynesia. PLoS One 8:1-10. doi: 10.1371/journal.pone.0070443

Price N, Muko S, Legendre L, et al. (2019) Global biogeography of coral recruitment: tropical decline and subtropical increase. Mar Ecol Prog Ser 621:1-17. doi: $10.3354 /$ meps 12980

Quigley KM, Bay LK, Willis BL (2018) Leveraging new knowledge of Symbiodinium community regulation in corals for conservation and reef restoration. Mar Ecol Prog Ser 600:245-253.

R Core Team (2017) R: A language and environment for statistical computing.

Rodrigues LJ, Grottoli AG (2007) Energy reserves and metabolism as indicators of coral recovery from bleaching. Limnol Oceanogr 52:1874-1882. doi:

10.4319/lo.2007.52.5.1874

Siebeck UE, Marshall NJ, Klüter a., Hoegh-Guldberg O (2006) Monitoring coral bleaching using a colour reference card. Coral Reefs 25:453-460. doi: 10.1007/s00338-006-0123-8

Silverstein RN, Cunning R, Baker AC (2014) Change in algal symbiont communities after bleaching, not prior heat exposure, increases heat tolerance of reef corals. Glob Chang Biol 1-14. doi: 10.1111/gcb.12706

Szmant A, Gassman N (1990) The effects of prolonged "bleaching" on the tissue biomass and reproduction of the reef coral Montastrea annularis. Coral reefs 8:217-224.

Thornhill DJ, Kemp DW, Bruns BU, et al. (2008) Correspondence between cold tolerance and temperate biogeography in a western Atlantic Symbiodinium (Dinophyta) lineage. J Phycol 44:1126-1135. doi: 10.1111/j.15298817.2008.00567.x

Thornhill DJ, LaJeunesse TC, Kemp DW, et al. (2006) Multi-year, seasonal genotypic surveys of coral-algal symbioses reveal prevalent stability or post-bleaching reversion. Mar Biol 148:711-722. doi: 10.1007/s00227-005-0114-2 
Torda G, Donelson JM, Aranda M, et al. (2017) Rapid adaptive responses to climate change in corals. Nat Clim Chang 7:627-636. doi: 10.1038/nclimate3374

Van Hooidonk R, Maynard JA, Planes S (2013) Temporary refugia for coral reefs in a warming world. Nat Clim Chang 3:508-511. doi: 10.1038/nclimate1829

van Oppen MJH, Gates RD, Blackall LL, et al. (2017) Shifting paradigms in restoration of the world's coral reefs. Glob Chang Biol 23:3437-3448. doi: 10.1111/gcb.13647

van Oppen MJH, Oliver JK, Putnam HM, Gates RD (2015) Building coral reef resilience through assisted evolution. Proc Natl Acad Sci 112:2307-2313. doi:

10.1073/pnas. 1422301112

Vermeij MJA, Bakker J, van der Hal N, Bak RPM (2011) Juvenile coral abundance has decreased by more than $50 \%$ in only three decades on a small Caribbean island. Diversity 3:296-307. doi: 10.3390/d3030296

Vollmer S V., Kline DI (2008) Natural disease resistance in threatened staghorn corals. PLoS One 3:1-5. doi: 10.1371/journal.pone.0003718

Weis VM (2008) Cellular mechanisms of Cnidarian bleaching: Stress causes the collapse of symbiosis. J Exp Biol 211:3059-66. doi: 10.1242/jeb.009597

Williams D, Miller MW, Kramer K (2008) Recruitment failure in Florida Keys Acropora palmata, a threatened Caribbean coral. Coral Reefs 697-705. doi: 10.1007/s00338008-0386-3 


\section{Chapter 3: Coral Genetic Identity Structures Competitive Ability, Growth, and Survivorship Across a Depth Cline in Symbiont and Depth Generalists Orbicella annularis and Orbicella faveolata}

\subsection{Abstract:}

Coral reef ecosystems face collapse under the threat of numerous anthropogenic stressors. Adaptive mechanisms such as coral evolution, Symbiodiniaceae community rearrangement, and acclimatization have been touted as tools for conservation efforts while use and protection of stressor refugia have been proposed as management policies. To determine the potential of each adaptive mechanism we established common gardens along a depth-cline with symbiont and depth generalist species. Orbicella annularis and Orbicella faveolata. Our approach simultaneously created a reserve of shallow water coral genotypes on the border of the mesophotic reef and evaluated the potential of each adaptive mechanism to facilitate coral survival against environmental change and benthic competition.

Greater depth had non-significant trends for slower growth and increased mortality, but its only significant effect was to impair the spatial competitive ability of Orbicella fragments at 30m. The Symbiodiniaceae community, despite considerable diversity and coral host flexibility, did not respond to transplantation across depths, although symbiont community structure did predict growth. Coral host identity, both at the species and genotype level significantly structured all measured variables including growth, competitive ability, survivorship, and Symbiodiniaceae community structure. 
My study reaffirms the substantial potential of host identity to dictate persistence and prosperity through environmental changes. Results commend conservation strategies which leverage or facilitate the power of host coral genetics through sexual recombination such as selective breeding, assisted sexual reproduction, and assisted migration. Several coral genotypes were identified as depth specialists, reinforcing the need for banking of shallow water specialist corals and the challenge of doing so even at the shallowest extent of the mesophotic reef.

\subsection{Introduction:}

The health of coral reefs around the world are rapidly deteriorating in response to an array of human derived stressors. Local stressors such as overfishing or nutrient enrichment promote coral smothering algal growth (Jackson et al. 2001; Vermeij et al. 2010) while global stressors such as climate change threaten even the most remote reefs with mass coral bleaching and coral disease outbreaks (Pandolfi et al. 2005; HoeghGuldberg 2011). Such numerous stressors have intensified in the face of a growing human population and largely inadequate regulatory measures. The continued existence of the entire coral reef ecosystem in an ecologically and societally valuable form is in jeopardy (Donner 2009; Van Hooidonk et al. 2013). Although our efforts will fall short without decisive action on climate change and other threats, restorationists and conservationists must leverage mechanisms for adaptation and acclimatization in reef building corals (van Oppen et al. 2015; van Oppen et al. 2017).

There are three well understood mechanisms which govern a coral holobiont's ability to adapt to changing environmental conditions. The coral animal's genetic 
composition equips it for optimal performance in one or several possible sets of environmental conditions and remain unchanged for the lifetime of the coral. Genetic recombination occurs during sexual, but not asexual reproduction. To our knowledge, genetic constitution of the coral host has been implicated as a structuring factor in every trait for which it has been tested including disease resistance (Vollmer and Kline 2008; Merselis et al. 2018), bleaching resistance (Drury et al. 2017; Merselis et al. 2018), growth rates (Lirman et al. 2014; Ladd et al. 2017), growth form (Willis and Ayre 1985), symbiont hosting specificity/flexibility (Quigley et al. 2017), reproductive behavior (Miller et al. 2016), and reproductive output (Baums et al. 2013). Chimerism or colony fusion between multiple coral genotypes occurs and may allow a single coral colony to capitalize on the strengths of multiple coral genomes although primarily in early life (Amar et al. 2008; Puill-Stephan et al. 2009).

Despite the rigidity of genetic composition, corals display a wide breadth of plasticity in growth form, light and thermal tolerance, and numerous other traits when genetic factors are controlled for or clones are compared (Middlebrook et al. 2008; Bellantuono et al. 2012; Palumbi et al. 2014; Morikawa and Palumbi 2019). The ability for acclimatization, facilitated by epigenetic modification of chromatin, occurs in response to diverse environmental cues and is widespread amongst diverse taxa (reviewed in: Eirin-Lopez and Putnam 2018).

Possibly the most well-studied mechanism of holobiont acclimatization is the acquisition of new Symbiodiniaceae or dynamism of Symbiodiniaceae community assemblage (switching or shuffling, sensu Baker 2003) which allows symbionts to alter holobiont fitness through their proliferation and expression of their own phenotypes 
(Silverstein et al. 2014; Cunning et al. 2015b; Lewis et al. 2019b; Morikawa and Palumbi 2019). Symbiodiniaceae community change may be understood as a selective process when considered from the perspective of Symbiodiniaceae community or the holobiont whose genomic content is altered, but as an example of acclimatization or plasticity on the part of the coral animal whose genetic makeup does not change. Rearrangement of Symbiodiniaceae community identity is common in certain reef building corals, but exceedingly rare or even un-reported in other coral species (Goulet 2006; Thornhill et al. 2006a; LaJeunesse et al. 2009; Silverstein et al. 2012). Depending on conditions such as environment and coral species, Symbiodiniaceae community re-arrangement may persist in the short-term only to revert to the initial assemblage and therefore fail to prepare the coral holobiont to recurrent stress (Thornhill et al. 2006b; LaJeunesse et al. 2009).

Coral associated microbial and viral community dynamism can both cause and prevent coral bleaching and disease and are supported as adaptive mechanisms (Reshef et al. 2006; Rosenberg et al. 2007; Danovaro et al. 2008; Efrony et al. 2009; Cohen et al. 2013; Mills et al. 2013). Coral microbiome structure correlates with environmental factors, holobiont physiology, and demonstrate coral-species and coral genotype specificity (Rodriguez-Lanetty et al. 2013; Ziegler et al. 2017; Bonthond et al. 2018; Glasl et al. 2019). However, disentangling the physiological impact of microbiome identity dynamism is not readily possible owing to our limited understanding of the physiological and ecological roles individual coral associated microbes in coral health. Our understanding of the interconnection between Symbiodiniaceae identity and holobiont physiology is relatively advanced, however, such that Symbiodiniaceae community may be readily related to variation in host performance. While the importance 
of microbial communities is clear, the present work aimed to investigate those wellunderstood mechanisms whose effects could be reliably measured.

Beyond leveraging adaptive mechanisms, management efforts must focus on preserving climate change refugia against other stressors for which they are not refugia. In particular, per the deep reef refugia hypothesis (reviewed in Bongaerts et al. 2010), the deep area of the reef may shield corals from intense sunlight and warm waters implicated in both coral bleaching and disease. Deep populations may then re-populate degraded reefs in the event that environmental conditions improve (Smith et al. 2014; Holstein et al. 2015). Depth specialization may render merely protecting deep refugia inadequate, as deeper reefs may be impaired from effectively re-seed shallow reefs if they are not carriers of shallow water specialist innovations. It may be important to "bank" shallow water origin genotypes in deeper waters or land-based facilities.

The aim of my study is to use a depth gradient to investigate the role of acclimatization, coral genetic identity, and symbiont identity in determining competitive ability, growth, and survivorship of Orbicella annularis and Orbicella faveolata fragments. Studying along a depth-cline also had the advantage of establishing a deepwater reserve of shallow-water origin genotypes of depth generalist species on the border of the mesophotic zone $(30 \mathrm{~m})$.

I hypothesized that, as symbiont generalists, Orbicella spp. inhabiting different depths will have their broad symbiont specificity winnowed to become dominated by Symbiodiniaceae adapted to environmental conditions at each depth. Host identity (both species and genotypes) will interact with depth in the selection process based upon biases 
in symbiont flexibility and specificity at the host genetic level. I reasoned that Symbiodiniaceae community and environmental experience (acclimation to depth) would therefore act concordantly in shaping growth and survival. I also hypothesized that both coral genotype and species would strongly influence growth, competitive ability, and survivorship outcomes for Orbicella with interactions by depth to which certain genotypes would be better adapted.

\subsection{Methods:}

\subsubsection{Coral Collection}

Between September 2013 and July 2016, 10 mother colonies each of Orbicella faveolata and Orbicella annularis were collected at an approximate depth of three to ten meters in the upper keys by the Coral Restoration Foundation (CRF) under permits FKNMS2011-159-A3 and FKNMS2011-159-A4. Colonies were brought back to the CRF warehouse where they were briefly kept in a recirculating coral culture system until they could be fragmented. Using a drill press with a diamond hole saw bit, the 20 mother colonies were each cored into a minimum of 45 clonal fragments. The mother colony and all its descendent fragments compose a genet, or genetically identical population of individual colonies, each known as a ramet. Resultant cores were shortened as much as possible with a circular saw and then mounted to plastic cards printed with a visible size standard (Fig. 3.1a, b), photographed, and returned to the recirculating aquaculture system. Keeping cores short minimized the amount of vertical growth necessary for ramets to begin growing across coral cards. Corals were then brought to the CRF 
Tavernier nursery where they were hung from coral nursery trees (Fig. 3.1c) at $\sim 8 \mathrm{~m}$ depth until the start of the experiment in July 2016.

\subsubsection{Depth Transplantation Experiment}

In July 2016, during the $21^{\text {st }}$ mission of the NASA Extreme Environment Mission Operations (NEEMO) program at FIU-Aquarius Reef Base, coral nurseries were constructed by Aquarius and NEEMO personnel at 20 and 30m. To our knowledge, the $30 \mathrm{~m}$ nursery was the deepest coral nursery in the world, but both nurseries are still well above the maximum depth range of Orbicella spp. (Fricke and Meischner 1985). Fifteen ramets from each host genet were haphazardly chosen for redistribution to each of the $8 \mathrm{~m}$ (CRF Tavernier) nursery, $20 \mathrm{~m}$ nursery, and 30m nursery. Total replication consisted of 300 ramets per nursery, 900 for the entire study. Within nurseries, ramets were distributed in a stratified randomized pattern, such that each of the 5 coral tree structures at each nursery contained one branch with three ramets of each genet. The depth of the branch of each genet was randomized for each tree such that effects attributed to genet identity would not be confounded by small differences between branch depth (Fig. 3.2). Nurseries were left in place over approximately one year until NEEMO 22 in June 2017. During the second mission, nursery corals were brought to land in seawater collected on site, photographed, and rinsed with sterile seawater. A small piece $\left(\sim 5 \mathrm{~mm}^{2}\right)$ of each surviving ramet was removed with diamond bit Dremel circular blades and immediately placed in sterile filtered salt saturated 20\% DMSO for DNA preservation. Coral ramets were then returned to their nurseries of origin. 


\subsubsection{Symbiodiniaceae Community Characterization via Amplicon Sequencing of the}

\section{Chloroplast $23 S$}

After field collection, samples were processed at the IMaGeS laboratory at FIU. Symbiodiniaceae DNA was extracted with the MP Fast Spin DNA kit for Soil following the manufacturer's instructions except with the addition of a secondary ethanol-SEWS-M wash. Eluted DNA was ethanol precipitated and re-suspended in 0.1x Tris-EDTA as an additional step to remove PCR inhibitors. An approximately 480bp region of the Symbiodiniaceae chloroplast 23S (cp23S) gene was amplified with the primers F: AATAACGACCTGCATGAAAC, R: GCCTGTTATCCGTAGAGTAGC using GoTaq polymerase. Despite the relatively high error rate of GoTaq polymerase compared to high fidelity polymerases, it was chosen because troubleshooting with temperature, $\mathrm{MgCl}_{2}$, and template concentration gradients failed to produce consistent positive and specific amplification with other polymerases. Polymerase errors were collapsed through bioinformatic approaches below.

The PCR reactions consisted of $10 \mu \mathrm{L}$ of $2 \mathrm{x}$ GoTaq polymerase master mix, $1 \mu \mathrm{L}$ of DNA template, $0.5 \mu \mathrm{L}$ of each the Forward and Reverse primers, $1.2 \mu \mathrm{L}$ of $25 \mathrm{mM}$ $\mathrm{MgCl}_{2}$, and $6.8 \mu \mathrm{L}$ of molecular water. Initial PCR reaction had a denaturation step at $95^{\circ} \mathrm{C}$ for 3 minutes and then 35 cycles of $95^{\circ} \mathrm{C}$ for 30 s, annealing at $55^{\circ} \mathrm{C}$ for $30 \mathrm{~s}$, and $72^{\circ} \mathrm{C}$ extension for $30 \mathrm{~s}$. PCRs concluded with a final extension at $72^{\circ} \mathrm{C}$ for five minutes. After the initial PCR, DNA was purified per Illumina's 16S amplicon sequencing protocol with the use of magnetic beads and several ethanol washes (Illumina). 
Amplicons were then barcode-indexed following the Illumina $16 \mathrm{~S}$ amplicon sequencing protocol with 3 minutes at $95^{\circ} \mathrm{C}$ followed by ten cycles of $95^{\circ} \mathrm{C}$ for $30 \mathrm{~s}, 30 \mathrm{~s}$ of annealing at $55^{\circ} \mathrm{C}$, and extension at $72^{\circ} \mathrm{C}$ for 30 seconds. A final extension step of $72^{\circ} \mathrm{C}$ for five minutes concluded the indexing step. DNA was purified and concentrations were normalized amongst samples using SequalPrep plates following manufacturer's instructions. Indexed DNA samples were then pair end 300 cycle sequenced on a Mi-seq.

Paired-end reads were joined in QIIME2 and denoised using the DADA2 plug-in. Primer sequences and chimeric sequences were removed (Caporaso et al. 2010; Callahan et al. 2016). Reads were truncated to $250 \mathrm{bp}$ and then forward and reverse reads were joined. Representative sequences were clustered using $99 \%$ similarity to collapse polymerase errors. Estimates derived from GoTaq manufacturer error rates determined that an average length amplicon had a $17.5 \%$ chance of containing a single error and a $3 \%$ chance of containing two single nucleotide polymerase errors. At an average length of $480 \mathrm{bps}$, two errors would be responsible for a $0.4 \%$ deviance from true sequence which was corrected by clustering amongst samples into Operational Taxonomic Units (OTUs) at a 99\% similarity threshold.

All OTUs which represented less than $1 \%$ or 100 reads of one sample were removed as they could be the consequence of environmental contamination and would likely not be one of the substantial contributors to host coral growth and survival that my study aims to identify. No immediate physiological relevance of the rare biosphere has ever been demonstrated for Symbiodiniaceae on its host. 
Because the classifier was able to identify several OTUs within several species in certain Symbiodiniaceae genera but failed to classify below the genus level for other genera, OTUs were compressed to represent meaningful taxonomic groups (i.e., identified or putative species). Compression was conducted to prevent drawing comparisons between genotypes within a Symbiodiniaceae species against larger taxonomic units such as Symbiodiniaceae genera. Comparisons amongst genotypes within a Symbiodiniaceae species were considered outside of the scope of the present work. A study seeking to identify genotype effects would ideally use symbiont specialist coral species to maximize power and compare amongst genotypes within one or few symbiont species. Our approach is further justified as a means of standardization across the differential resolution of the cp23S locus across different Symbiodiniaceae genera. Compression of OTUs into putative species also prevented the loss of statistical power associated with the increased number of tests that would accompany the separate consideration of taxonomically synonymous OTUs.

Specifically, the cp23s locus has little ability to distinguish between different Cladocopium species and Orbicella is known to host multiple Cladocopium species, so Cladocopium OTUs were kept separate as they could represent numerous species (Thornhill et al. 2006b; Sampayo et al. 2009; Thornhill et al. 2014; Kemp et al. 2015; Kennedy et al. 2016). Performance of the cp23S and our classifier failed to assign any sub-genus names to Durusdinium OTUs. All Durusdinium OTUs were compressed into a single taxon renamed Durusdinium trenchii, as it is the only known Durusdinium species in the Caribbean (Pettay et al. 2015). Similarly, six B2 OTUs were detected and merged into a single taxon as the only B2 species is Breviolum psygmophilium. Eleven B1 OTUs 
were also identified and preserved as they could represent distinct species within the B1 lineage- several of which are known to associate with Orbicella spp. (Lajeunesse et al. 2012; Parkinson et al. 2015; Lewis et al. 2019a). Both Gerakladium OTUs matched to the species Gerakladium spongiolum and were therefore combined. Within the Symbiodinium genus, both A4 OTUs were combined. No other species synonymous OTUs were present.

\subsubsection{Measuring Orbicella Ramet Survivorship and Growth Over One Year}

Photographs taken during sampling in June 2017 were assessed to determine survivorship. Fragment size was determined by measuring surface area using ImageJ normalized to size standards on the coral cards, repeated in triplicate, and binned to the nearest square cm (Schneider et al. 2012). The measurement of surface area neglects to detect vertical growth of ramets, but successfully approximates overall growth for ramets, because the vast majority of growth in small fragments of Orbicella occurs in an encrusting fashion over flat cards (current study, Chris Page, Mote Marine Laboratorypersonal communication). Surface area was used as a proxy for growth in subsequent

analyses, because all fragments were cored with the same hole saw and thus had the same initial size.

\subsubsection{Characterization of Spatial Competitive Interactions}

Photographs revealed the settlement and spread of numerous competing organisms including bivalves, sponges, encrusting Millepora $\mathrm{sp}(\mathrm{p})$, vermetid snails, hair 
algae, mixed micro-algaes, crustose coralline algae (CCA), macro-algae and cyanobacterial biofilm for space. For each instance that competing organisms contacted the coral ramet on the card, they were identified to the taxonomic bins listed above. In the case of bivalves, sponges, fire coral, vermetid snails, hair algae, and CCA competition it was frequently possible to determine whether the coral was overgrowing the competing organism or being overgrown by it. Where possible, the competitive interaction was categorized as a favorable or unfavorable outcome from the corals' perspective. In cases where corals competed against cyanobacterial mats or microalgae it was particularly difficult to tell if algae had actively overgrown live coral tissue or if coral tissue had died for an unrelated reason and the skeleton was then colonized. Where the dynamics of the interaction could not be determined from the photograph, the interaction was excluded from further analyses.

\subsubsection{Suitability of Data Collected from the 8m Nursery}

The $8 \mathrm{~m}$ nursery is an active CRF restoration nursery where fragments were frequently cleaned and fragmented and were therefore not comparable for growth or competitive ability assessment. Therefore, data from the $8 \mathrm{~m}$ nursery were excluded from all downstream analyses concerning survivorship, competition, and growth, but were included for analyses conducted to elucidate the factors structuring the composition of the Symbiodiniaceae community. 


\subsubsection{Determining the Role of Host Identity in Growth, Competition, and Survivorship}

Mortality rates between species, genets, and depths were compared with Fisher's exact tests. Where comparisons were significant and to explore interactions of depth by host identity, Benjamini-Hochberg corrected pair-wise Fisher's exact tests were conducted via the R companion package in R (R Core Team 2017; Mangiafico 2019). Similarly, competitive ability was compared through a Fisher's exact test using binomial favorable or unfavorable outcomes of competitive interactions by depth and species. The interaction of depth and species was explored using a Benjamini-Hochberg corrected pair-wise Fisher's exact test. Genets' competitive ability was compared with a Fisher's exact test and significant differences were explored with a post-hoc pairwise Fisher test with Benjamini-Hochberg correction.

Fragment size data were neither homoscedastic nor normally distributed and could not be normalized through transformations. Consequently, the non-parametric Mood's Median test was implemented through the RVmemoire package for R to compare amongst species, genets, depths, and interactions amongst depth and host factors (Hervé 2019). Where significant differences were detected, Benjamini-Hochberg corrected posthoc pair-wise Mood's median tests were employed. Tests excluded data from the $8 \mathrm{~m}$ nursery as explained above. 


\subsubsection{Parity amongst Survivorship, Competitive Ability, and Growth}

To evaluate the extent to which competitive index, growth, and survivorship might influence each other, pairwise linear regression was performed between each of the three genet-wide measures of performance.

\subsubsection{Influence of Symbiodiniaceae Assemblage on Survivorship and Growth}

To determine if the Symbiodiniaceae assemblage significantly contributed to growth, redundancy analysis (RDA) was performed and visualized using the vegan package and constrained to consider fragment size binned by square $\mathrm{cm}$, depth, species, and host genet as explanatory variables with the community as a response (Oksanen et al. 2019). A Permanova with 10,000 permutations was then used to test for the significance of the Symbiodiniaceae assemblage in determining fragment size using the permute package for R (Simpson 2016). Tests excluded data from the $8 \mathrm{~m}$ nursery as explained above.

\subsubsection{Influence of Depth and Host Identity on Symbiodiniaceae Assemblage}

Including data from the $8 \mathrm{~m}$ nursery, an RDA was performed as above. A Permanova with 10,000 permutations was then used to determine the significance of host species, genet, and depth in structuring the Symbiodiniaceae assemblage. A post-hoc Adonis was used to detect significant differences amongst genets (Martinez-Arbizu 2017). 


\subsection{Results:}

3.4.1 Symbiodiniaceae Assemblage of Orbicella Ramets After One Year at Eight, 20, or $30 m$

The QIIME pipeline and classifier identified 38 OTUs which were compressed into 19 putative species (see methods) for the 231 ramets that passed quality control measures.

The Symbiodiniaceae community was diverse and varied significantly by species genet. The total Symbiodiniaceae community was dominated (66.8\%) by unidentified Cladocopium across depths and species with substantial minorities of B1 Breviolum (23.0\%) and smaller abundances of the thermally tolerant Durusdinium trenchii (3.4\%), A3 (2.0\%) and A4 (1.8\%) Symbiodinium, Breviolum psygmophilium (1.7\%), and a small minority of Gerakladium spongiolum (0.6\%), unidentified Breviolum (0.3\%), and unidentified Symbiodinium (0.2\%; Fig. 3.3a and b). Cladocopium dominance was most pronounced for $O$. annularis, while $O$. faveolata had much more substantial representation of Symbiodinium, Breviolum, and Durusdinium (Fig. 3.3b). As depth increased, there was a pattern for the abundance of Symbiodinium and Durusdinium to also non-significantly increase at the expense of Breviolum while Cladocopium remained dominant (Fig. 3.3a and d). Though the pattern held true across species and depths (Fig. 3.3c and d) genets hosted dramatically different Symbiodiniaceae communities (Fig. 3.3e). Exceptions from Cladocopium dominance included several genets either dominated by Breviolum types or co-dominated by Breviolum B1 with either Durusdinium or Cladocopium (Fig. 3.3e). 
Interesting patterns emerged for Breviolum B1 types across genets (Fig. 3.3e). B1.3 appeared exclusively in three O. faveolata genets (Fig. 3.3e). While B1.4 was the largest Breviolum constituent of the assemblage across all depths, species, and genets, except for genet F10 (O. faveolata 10$)$ which exclusively hosted Cladocopium (Fig. $3.3 e)$.

Between ramets, symbiont assemblages were extremely variable and ramets tended to host very few symbionts relative to the genet they originated from (Fig. 3.3f). Despite the apparent diversity when examining the community by depth, species, or genet, ramets hosted a median of only two Symbiodiniaceae taxa. For example, B1.3 either dominated ramets or was entirely absent (Fig. 3.3, O. faveolata genets F07, F11, and F13). Further, two ramets taken from the same mother colony and mounted to the same card at $8 \mathrm{~m}$ for the duration of the experiment were found to host entirely different assemblages at the end of the experiment. One ramet hosted only Cladocopium while the other was co-dominated by a B1 Breviolum and Durusdinium trenchii without any Cladocopium. Though ramets mounted on the same card do not represent independent replicates and were therefore not considered in the statistical analyses of the current study, they were treated the same as the ramets in the current study and the difference between them is illustrative of ramet-wise variability even when controlling for coral card. 


\subsubsection{Depth and Host Identity as Structuring Factors of Symbiodiniaceae Assemblage}

Depth did not significantly structure the Symbiodiniaceae assemblage (Fig. 3.4a), but species and genets were significant predictors for Symbiodiniaceae community structure (PermANOVA p $<0.05$ and 0.00001 respectively, Fig. 3.4 b and c). Most Symbiodiniaceae taxa played little role in explaining overall community variation, with unclassified Cladocopium, Durusdinium trenchii, and a B1 Breviolum OTU (B1.3) explaining a tremendous amount of community disparity (Fig. 3.4b). Variation in Cladocopium was particularly important to overall community composition and its abundance did not vary with depth. Breviolum B1.3 abundance was responsible for less variation than Cladocopium and was non-significantly slightly positively correlated with increasing depth. Variation in Durusdinium trenchii abundance was non-significantly negatively correlated with increasing depth (Fig. 3.4c) and explained less community variation than Cladocopium or B1.3. Symbiont taxa were further correlated with host species and genet identities (Fig. 3.4d). Genets A20, F11, and F26 were correlated with Durusdinium trenchii abundance, while A22 was most associated with B1.3. Genets A4, A10, F17, A18, F21, A23, and A24 were most tightly correlated with unidentified Cladocopium. O. faveolata was negatively associated with Cladocopium compared to $O$. annularis, although the strength of the correlation was non-significant.

Congruently, the RDA's ability to explain variability in the Symbiodiniaceae community structure depended substantially on host species identity (33.3\% variance explained) and genet identity nested within species (78\% of variance explained or $45 \%$ improvement over species identity alone). The addition of depth only improved the 
model by $0.1 \%$, while an additional $21.6 \%$ of variation could not be explained by the factors explored here (Fig. 3.5).

3.4.3 Survivorship, Growth, and Spatial Competition of Orbicella Ramets at 20 and 30m

Survivorship was significantly structured by host identity, but not by depth.

Substantial mortality was observed in both species with $O$. annularis suffering significantly less mortality than O. faveolata (Fig. 3.6a; Fisher's Test $\mathrm{p}<0.05$ ). Mortality was not significantly different between the 20 and 30m depths, nor did the pattern of higher survivorship for $O$. annularis vary with depth (Fig. 3.6a-c). Mortality was significantly different amongst genets (Fisher's Test $\mathrm{p}<1 \times 10^{-15}$; Fig. 3.6d) and varied more widely amongst $O$. faveolata genets than $O$. annularis genets. For $O$. faveolata, mortality ranged from $100 \%$ for genet F23 to $21 \%$ of genet F26 while O. annularis genets only ranged between 70 and $21 \%$ between genets A23 and A22, respectively. Genet-wise survivorship did not vary with depth except for A24 and F13 which both had better survivorship at $20 \mathrm{~m}$ than $30 \mathrm{~m}(\mathrm{p}<0.05$, Fig. 3.6e). There was not a significant correlation between genet wide mortality rates to genet wide Symbiodiniaceae community assemblage for the experiment as a whole or for either depth considered individually $(\mathrm{p}>0.1)$.

As with variation in survivorship, variation in growth was governed significantly by host identity- not depth. $O$. annularis grew significantly more than $O$. faveolata (mood's median test $\mathrm{p}<0.05$ ), but growth did not vary significantly by nursery depth, although there was slightly more growth at $20 \mathrm{~m}$ than $30 \mathrm{~m}$ (mood's median test $\mathrm{p}>0.10$; 
Fig. 3.8a-b). Growth varied markedly different between genets (mood's median test $\mathrm{p}<$ 0.0001 ) both in terms of median growth and variance in growth. Orbicella annularis genets had greater variability in growth both within and between genets relative to $O$. faveolata genets, the opposite of variability for mortality (Fig. 3.6D). Neither species nor genet growth interacted significantly with depth.

Growth was significantly structured by the Symbiodiniaceae community assemblage (Fig. 3.9a; PermANOVA p < 0.01) as determined by the RDA excluding the $8 \mathrm{~m}$ depth. The lack of correlation between depth and growth in structuring Symbiodiniaceae community recapitulated the lack of a depth effect on growth given that Symbiodiniaceae community assemblage was deterministic of growth (Fig. 3.9a). Most Symbiodiniaceae taxa reported here played very little role in explaining overall community variation when the $8 \mathrm{~m}$ depth was excluded to allow for analysis of growth (see methods). However, unclassified Cladocopium, Durusdinium trenchii, and B1.3 explained a tremendous amount of community variation (Fig. 3.9b). As in the previous RDA which included data from the $8 \mathrm{~m}$ common garden, variation in Cladocopium was most explanatory of overall community composition variation, followed by Breviolum B1.3, and finally Durusdinium trenchii. Interestingly, unidentified Cladocopium was positively correlated with growth, while Durusdinium trenchii and, to a lesser extent, Breviolum B1.3 were negatively correlated with growth (Fig. 3.9b).

Competition for space was universal to coral cards and competing benthic organisms were diverse. After one year cards were colonized by benthic competitors including sponges, fire coral (Millepora), bivalves, macro-algae, cyanobacterial mats, hair algae, and mixed algae which presented obstacles to the growth of Orbicella 
fragments (Fig. 3.7). Competition between Orbicella and mixed micro-algae was identified for every surviving coral analyzed from 20 and 30m. In most of cases of coral micro-algal competition, a 'winner' could not be determined. Of the 242 non-mixedmicro-algal competitive interactions Orbicella ramets encountered at 20 and 30m, $28.1 \%$ were with cyano-bacterial mats, $22.7 \%$ were with Millepora (fire coral), $12.0 \%$ were with bivalves, $12.0 \%$ were with hair-algae, $7.4 \%$ were with sponges, $7.4 \%$ were with vermetid snails, $7.4 \%$ were with CCA, and $0.41 \%$ were with macro-algae. In 164 or $67.8 \%$ of interactions, a "winner" could be identified.

Success in spatial competition was structured by both host identity and depth, though most competitive interactions were unsuccessful for Orbicella ramets. Both Orbicella species were losing a majority of competitive interactions at one year, but $O$. annularis was a significantly better competitor than $O$. faveolata (Fisher's exact test $\mathrm{p}<$ 0.01, Fig. 3.10a). Almost all genets were more likely to lose than win a competitive interaction (Fig. 3.10b) with six genets losing every single detected competitive interaction, although the proportion of favorable vs. unfavorable outcomes differed greatly amongst genets (Fisher's exact test $\mathrm{p}<0.01$, Fig. 3.10b). Depth was a significant determinant of competitive potential, with more successful interactions detected at 20 than 30m (Fisher's exact test $\mathrm{p}<0.05$, Fig. 3.10c). There were not any species by depth interactions for competitive ability.

There was significant parity between competitive ability and growth within genets, but little parity between performance metrics and survivorship. The linear correlation of competitive ability with growth explained nearly $60 \%$ of variance and was highly significant (linear regression, $\mathrm{R}^{2}=0.59 ; \mathrm{f}=25.14, \mathrm{p}<0.001$, Fig. 3.11), while 
competitive ability was not a good predictor of survivorship $\left(R^{2}=0.05 ; f=0.97, p>0.3\right.$, Fig. 3.12). For example, the genets with $50 \%$ or greater successful competitive outcomes were genets A17, F21, A09, A20, and A18 (Fig 3.13). The same genets were ranked second, fifth, sixth, third, and first in terms of growth, but only fourth, 12th, fourth, 10th, and 13th in survivorship, respectively (genets A17 and A09 tied in fourth with $63.3 \%$ survivorship). The worst competitors were genets A22, A23, F07, F10, F12, and F26 and were documented as losers in every single competitive interaction. The same six genets were all ranked in the bottom 50th percentile performers in terms of growth (14th, 18th, 16th, 10th, 12th, and 11th respectively; table 3.1), but varied widely in survivorship (first, 17th, 13th, 19th, 17th, and first respectively with ties between Genets A22 and F26 tied for first at $73.3 \%$ survivorship and also between A23 and F12 for 17th with $30.0 \%$ survival).

Similarly, genet-wide growth was a poor and non-significant predictor of survivorship $\left(\mathrm{R}^{2}<0.001 ; \mathrm{f}=0.003, \mathrm{p}>0.9\right.$, Fig. 3.14). Genets A09, A17, and A20 experienced the most growth, but ranked 13th, fourth, and 10th in survivorship. Besides F23 which experienced complete mortality, the worst growing genets were F13, A23, and A04, but were ranked third, 17th, and ninth in terms of survivorship (Fig. 3.12).

\subsection{Discussion:}

\subsubsection{Symbiodiniaceae Community Structure Affects Growth, but not Mortality}

My study successfully correlated three Symbiodiniaceae taxa with holobiont growth. Faster growth for ramets more heavily dominated by Cladocopium with sparser 
compliments of Durusdinium matches literature revealing Durusdinium as more stresstolerant, but less metabolically generous partners (Little et al. 2004; Cantin et al. 2009; Jones and Berkelmans 2010). Despite decreased growth, the trade-offs between stresstolerant and metabolically optimal symbionts are complex and modulated by environmental conditions (Mieog et al. 2009; Cunning et al. 2015a). The B1 Breviolum spp. are not considered stress tolerant, though it may be that B1.3's negative correlation with growth is a consequence of poorer performance at 20 and $30 \mathrm{~m}$ depths than for the unclassified Cladocopium. Indeed, Bongaerts et al. (2015) were unable to detect B1 in Orbicella faveolata at 25m despite highly prevalent B1 Breviolum dominance at $10 \mathrm{~m}$. In shallow Orbicella colonies, B1 is associated with more brightly illuminated areas of colonies (Kemp et al. 2015).

Genet-wide Symbiodiniaceae assemblage did not have a bearing on genet-wide survivorship. Despite the widely acknowledged physiological importance of photosynthetic endosymbiont identity, we are confident in the null result for the present study. Genet was a highly significant predictor for Symbiodiniaceae assemblage and mortality, demonstrating their substantial variability, while the Symbiodiniaceae community included many taxa. Therefore, our analyses should be quite sensitive to any such effect. Perhaps if the study were continued in the long term and ramets were in direct competition for space, growth associated Symbiodiniaceae would enable their hosts to overgrow slow growing ramets. 


\subsubsection{Symbiodiniaceae Community is Structured by Coral Host Identity, but not Depth}

In contrast with our findings, Symbiodiniaceae assemblage is very heterogeneous along depth clines in wild Orbicella and numerous other coral host genera (Baker 2001; Toller et al. 2001a; Finney et al. 2010; Bongaerts et al. 2011; Bongaerts et al. 2013; Bongaerts et al. 2015; Bonthond et al. 2018). Flexibility to host numerous Symbiodiniaceae species has been associated with the capacity of coral species (including Orbicella spp.) to live across wide depth ranges (Bongaerts et al. 2015). The lack of such an effect here could be attributed to the short time frame of our study. While the literature is largely informed by surveyed corals which grew in-situ along a depth gradient (Toller et al. 2001a; Finney et al. 2010; Bongaerts et al. 2013; Bongaerts et al. 2015; Bonthond et al. 2018), here I imposed a depth gradient on corals already hosting a full complement of Symbiodiniaceae. The difference reflects not only a smaller time scale for community assemblage zonation to emerge, but also an absence of coral developmental stages potentially vital to acquisition and winnowing of the symbiotic community (Coffroth et al. 2001).

Perhaps the absence of any disturbance event in the current study prevented Symbiodiniaceae community assemblage change. Shuffling or switching of symbiont dominance is frequently mediated by bleaching which may leave corals susceptible to recolonization by exogenous or non-dominant alternative species (Toller et al. 2001b; Lewis and Coffroth 2004; Thornhill et al. 2006b; LaJeunesse et al. 2009; Silverstein et al. 2014; Cunning et al. 2015b; Lewis et al. 2019b). Of particular relevance, Baker (2001) performed a reciprocal transplant of diverse Caribbean scleractinians between 2-4m and 20-24m for one year. Considerable re-arrangement of symbiont community was detected 
in corals transplanted to a shallower location where many corals bleached. However, corals that were transplanted deeper did not experience bleaching or considerable Symbiodiniaceae community dynamism, reinforcing the necessity of bleaching to facilitate rapid switching or shuffling of symbiotic dinoflagellates. Transplantations across geographic scales have also failed to yield locally selected Symbiodiniaceae communities except when accompanied by bleaching (Berkelmans and van Oppen 2006; Howells et al. 2013).

Host organisms are adapted to minimize diversity amongst their symbionts. Evolutionary theory dictates that competitive interactions between symbionts of the same host tend to enrich for 'selfish' opportunist symbionts that more thoroughly exploit host resources while investing their own in reproduction rather than holobiont fitness (Douglas 2008). To prevent an evolutionary 'race to the bottom' of symbiont generosity, even symbiont generalist coral species must constrain symbiont diversity, even if only at sub-colony scales (Baums et al. 2014). Host specificity may slow or inhibit symbiont shuffling in the absence of bleaching.

Our Orbicella ramets likely did not undergo substantive symbiont shuffling and their Symbiodiniaceae community identities were not optimized for their new environments. The present study reports the most independent samples ever analyzed for Orbicella along a depth-cline, so it is unlikely that the absence of a depth effect is a type II error. Our ramets' Symbiodiniaceae communities weren't disturbed by bleaching and their distribution amongst depths doesn't match the patterns of zonation repeatedly characterized for Orbicella spp. Despite the absence of temporal tracking, the coring 
process and low Symbiodiniaceae richness of ramets relative to genets hints at community stasis.

Under the static community interpretation, it seems that the most likely explanation for the sizable structuring role of host species and genet would be found in the symbiont uptake by the mother colony. Orbicella spp. have spatially patchy Symbiodiniaceae community compositions within a single colony (Toller et al. 2001b; Kemp et al. 2015), so the process of coring mother colonies into ramets explains our low median Symbiodiniaceae taxa per ramet (2) and much larger median number of taxa per genet (6, neglecting rare taxa composing $<1 \%$ of the community) and further explains the high variability amongst ramets within the same genet. Ultimately, the static community hypothesis cannot be supported because we do not have a time-course, but it would be un-parsimonious to suggest the opposite, that Symbiodiniaceae communities were dynamic and yet still produced high variability amongst ramets of the same genets at the same depth without any zonation by depth.

The timescale of the current experiment was limited by the destruction of the 20 and 30m nurseries by hurricane Irma in 2017 preventing repeated sampling efforts to determine if the Symbiodiniaceae community structure would eventually follow the zonation by depth detected in natural populations. Future work is required to ascertain time frames for Symbiodiniaceae assemblage adaptation to in-situ conditions for the success of future restoration efforts operating across depths.

The mechanism accounting for significant differences in community composition by species remains unknown. The overlap between $O$. faveolata and $O$. annularis depth 
and geographic species range, overlap in canonical symbionts, and the narrow depth and geographic range which mother colonies were collected across leaves limited possibilities as to the source of differences between coral two species. Stochastic differences in microenvironment during the initial settlement for genet mother-colonies would not result in a significant species effect, although it may account for the differences amongst genets. Colony morphology is markedly different between species. The steep bumps of $O$. faveolata may create a more patchy distribution of shady micro-environments than the comparatively smoother coral heads produced by $O$. annularis. The shade casting morphology of $O$. faveolata might favor Cladocopium which typifies the shaded sides of Orbicella colonies (Kemp et al. 2015). However, O. annularis ramets had a greater average proportion of Cladocopium.

Future attempts to achieve rapid adaptation of Symbiodiniaceae community could explore whether transplanted corals could more rapidly select for adaptive symbiont community identity if Symbiodiniaceae were first purged via menthol-bleaching (Matthews et al. 2016). The tradeoff between short term photosynthetate deprivation prior to recovery of symbionts and the long-term advantages of an environmentally adapted Symbiodiniaceae community would need to be assessed.

As a further recommendation to restoration efforts, the intra-genet mosaicism of Symbiodiniaceae communities should be characterized. If disparate Symbiodiniaceae community compositions are stable, restoration groups may be able to culture clonal ramets with various known symbiont identities. Using abundant knowledge of niche partitioning by symbiont species, restorationists can represent all genets at all sites to 
maximize the potential of sexual recombination of coral genomes while also preventing transplantation of mal-adapted symbiont communities.

\subsubsection{Depth Significantly Determines Competitive Ability, but not Survivorship or Growth}

Depth, through its influence on numerous other factors such as light and temperature has been recognized as an important structuring factor on reefs throughout the world, determining growth rates and morphologies of scleractinians and octocorals (Fricke and Meischner 1985; Rodríguez-Lanetty et al. 2003; Einbinder et al. 2009; Groves et al. 2018). The current study recapitulates the trend of better performance in shallower depths (Huston 1985; Groves et al. 2018) for zooxanthellate corals with significantly better competitive outcomes at $20 \mathrm{~m}$ than $30 \mathrm{~m}$ and a non-significant trend for slower growth in deeper environments.

The current study differs from previous work by measuring less energetically intensive encrusting growth rather than the vertical growth typically recorded. Vertical growth relies more heavily on energetically expensive calcification so it is possible that decreasing photosynthetic production at greater depths would not impede encrusting growth to the same extent as vertical growth. The possibility for rapid encrusting growth overcoming decreased growth with greater depth may present an exciting opportunity for further investigation by restoration groups employing the micro-fragmentation and fusion technique (Forsman et al. 2015). Despite decreasing survivorship with increasing depth and slightly less growth at $30 \mathrm{~m}$, no significant difference in growth was detected across depths. 
Both species had one genet with significantly greater mortality at $30 \mathrm{~m}$ than $20 \mathrm{~m}$, suggesting they may be shallow-water depth specialists. Depth specialization reinforces the importance of actively preserving shallow-water adapted alleles in a deeper refugia, rather than allowing warming oceans to select for corals that happen to reside at deeper depths as it risks losing shallow-reef-specialized alleles.

\subsubsection{Coral Species and Genet Strongly Shape Competitive Ability, Growth, and Survival}

Of the mechanisms for environmental adaptation considered presently, host identity captured the most variability in terms of survival, growth, and competitive ability. Both species and genet were significant determinants of mortality with $O$. annularis suffering less mortality and experiencing more growth than $O$. faveolata. Species effect patterns may be a consequence of more successful competition by $O$. annularis than O. faveolata. Interestingly, the opposite trend has previously been established in terms of Orbicella species' relative competitive ability (Weil and Knowlton 1994; Manfred et al. 1996).

Host genet was responsible for large divergence in performance and had the greatest effect on structuring growth, competitive ability, and survivorship from amongst the factors examined here. Restoration programs have identified genets that substantially outperform their con-specifics in a nursery setting (Lirman et al. 2014). In nursery studies, top-performing nursery genets are typified by their ability to rapidly grow in the artificial absence of competing organisms in a typical coral nursery. In the current study, the close correspondence between genet-growth and genet-competitive ability evidences 
that our best growing genets were also robust to competition. The use of a common garden approach should have controlled for variance within the nursery, but our nurseries were in close proximity preventing us from broad generalizations about specific genets. Besides the limited geographic distribution of the study, a strong genet by site interaction exists even amongst environmentally similar sites (Drury et al. 2017).

\subsubsection{Study Limitations and Future Directions}

Poor correspondence between competitive ability and survivorship indicates that the major cause of mortality in the current study wasn't due to overgrowth by competitors. As the main driver of the substantial mortality reported here remains unknown, similar studies with more frequent monitoring are required to advise restoration and management interested in leveraging deep reef refugia. A similar study is underway at FIU's Aquarius Reef Base including more frequent and longer-term monitoring.

Characteristics attributed here as genet-dependent may also be structured by epigenetic, microbiome, or nutritional factors of mother colonies confounding genet effects. Specifically, mother colonies/ genets were not all co-cultured in a common garden prior to transplantation. More broadly, the potential for confounding mother colony derived effects other than host genetics has not received much attention in the restoration or coral heredity literature. Future studies should implement experimental designs that more fully disentangle genetic identity and mother colony effects. 


\subsubsection{Conclusions}

By detecting a correlation between growth and the abundance of an unidentified Cladocopium and a negative correlation with Durusdinium abundance, my study succeeded in identifying a physiological consequence of symbiont identity within a highly diverse Symbiodiniaceae assemblage of symbiont generalist coral species. Results re-affirm the integral role of Symbiodiniaceae identity in the growth and persistence of reef corals and supports a growth trade-off associated with hosting thermally tolerant Durusdinium spp.

Coral host identity was an important structuring agent of the Symbiodiniaceae assemblage across depths and within coral species. Our findings are not inconsistent with established heritability for Symbiodiniaceae community preference (Quigley et al. 2017).

The variation in mortality, competitive success, and growth across coral species and genets confirms the physiological importance of coral host identity. The substantial impact of host genetic identity reveals genotypic diversity as a promising resource with which restorationists can seek to improve the coral holobiont's fitness under deteriorating environmental conditions. Not only does host identity deserve special attention because it has a sizable effect, but also because it is the only mechanism for environmental adaptation that we cannot expect to work without human intervention. Other mechanisms of holobiont adaptation/ acclimatization, such as Symbiodiniaceae and microbiome community rearrangement or holobiont acclimatization to heat are increasingly common on reefs (i.e., more frequent exposure to warmer temperatures provide more opportunities for acclimatization, increasing abundance of thermally tolerant Symbiodiniaceae, 
selection amongst Symbiodiniaceae both within and amongst species; Silverstein et al. 2012; Van Hooidonk et al. 2013; Cunning et al. 2015b; Manzello 2015). By contrast, recombination of coral host genetics in the field is declining as reproductive output (Baird and Marshall 2002; Vermeij et al. 2011; Levitan et al. 2014; Price et al. 2019), recruitment (Vermeij et al. 2011; Price et al. 2019), and therefore reef connectivity decline. Approaches that leverage host identity such as selective breeding or facilitation of sexual reproduction offer the largest potential to increase environmental adaptation with the least risk of redundancy to evolution and acclimatization occurring in the field. 


\subsection{Figures:}

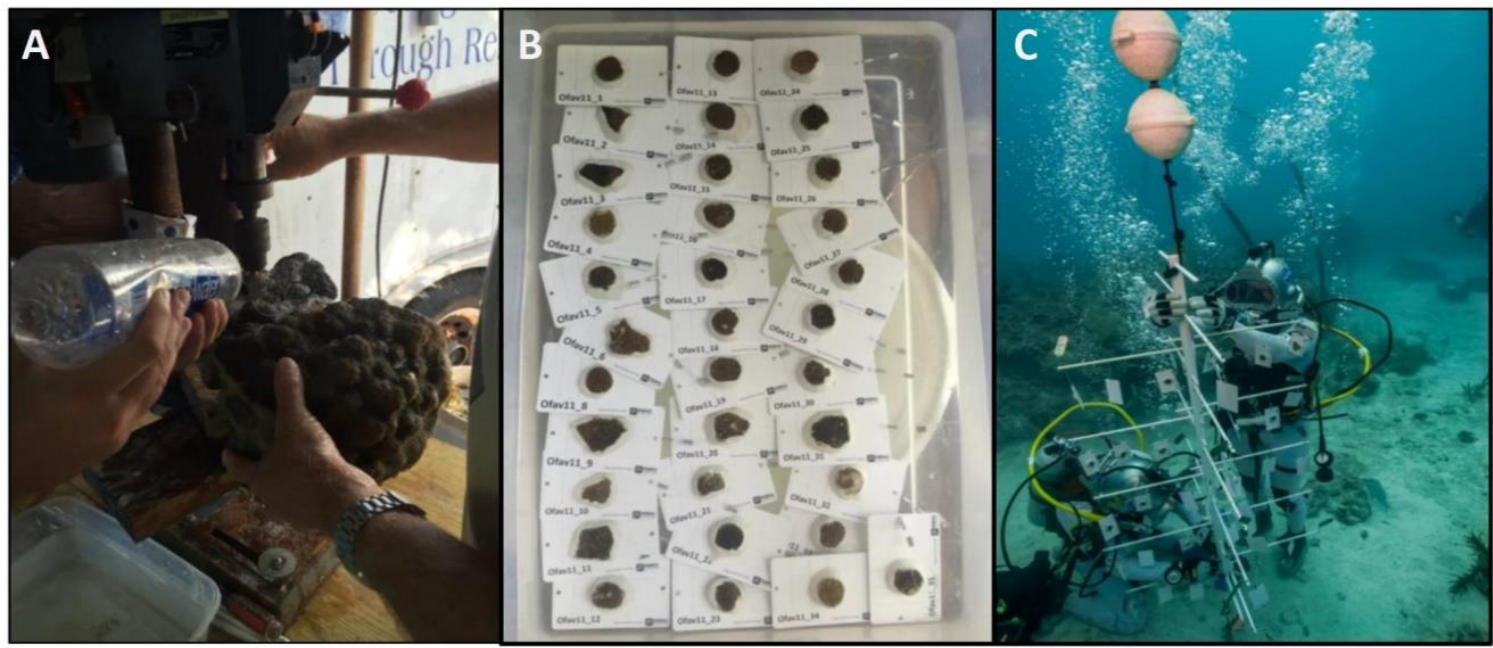

Fig. 3.1 Coral Deployment Workflow: A) "Corals of opportunity" were taken from the reef and drilled into ramets / cores with a hole saw. B) Cores were subsequently epoxied onto cards containing labels and size standards for photography. C) Finally, cards were affixed to coral nursery structures at designated depths.

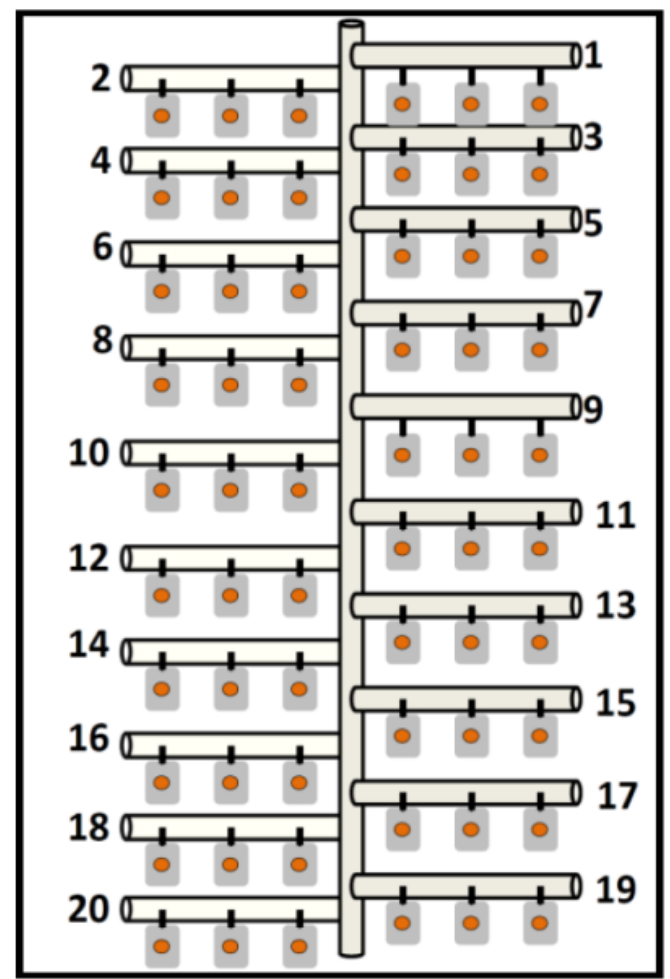

Fig. 3.2: Coral Tree Layout: Schematic of a PVC "coral tree" with 20 branches each supporting 3 ramets from the same genet. Each Nursery consisted of five trees and the branch number of each genet was randomly distributed on each tree such that each genet had the same average depth in each nursery. 
A

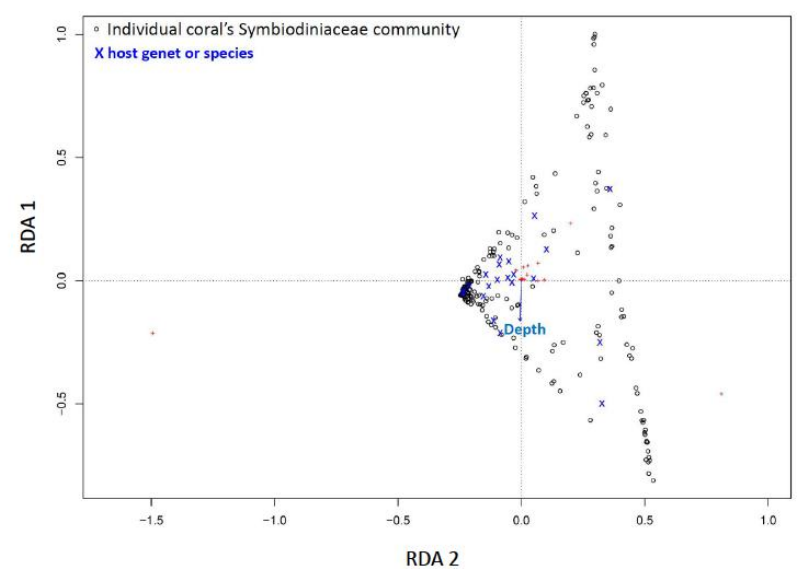

B

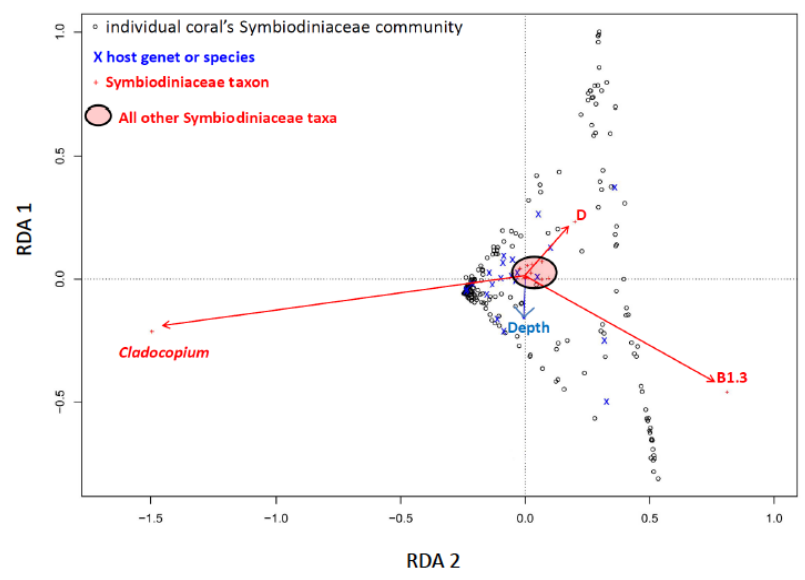

Fig. 3.3 Principle Component Analysis of Symbiodiniaceae Community Redundancy Analysis including all Depths: Figure 3.3 includes community assemblages from all depths, so it is suitable to identify the factors (including depth) structuring Symbiodiniaceae community composition. Circles represent individual ramets' Symbiodiniaceae assemblages. The blue vectors represent the effect of Depth on the community. Red vectors show the Symbiodiniaceae taxa whose variance is responsible for differences amongst community assemblages. Green vectors show the influence of host identity (species or genets) on structuring the Symbiodiniaceae community. The similarity between vector headings reflect degree of positive or negative correlation while the

length of arrows corresponds to relative effect size. A) the short length of the depth vector corresponds with the small, non-significant effect of depth on structure. B) The influence of Symbiodiniaceae taxa whose variance explains differences in the assemblage. C- following page) Correspondence between host identities (both genets and species) and Symbiodiniaceae assemblage. D- following page) Overlay of all previously mentioned structuring factors, allowing for the correlation of host identities and Symbiodiniaceae identity. 
C

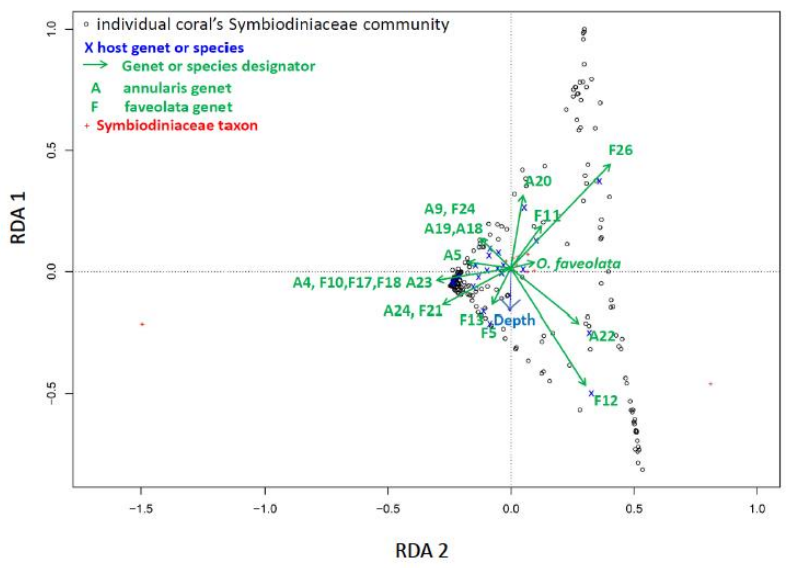

D

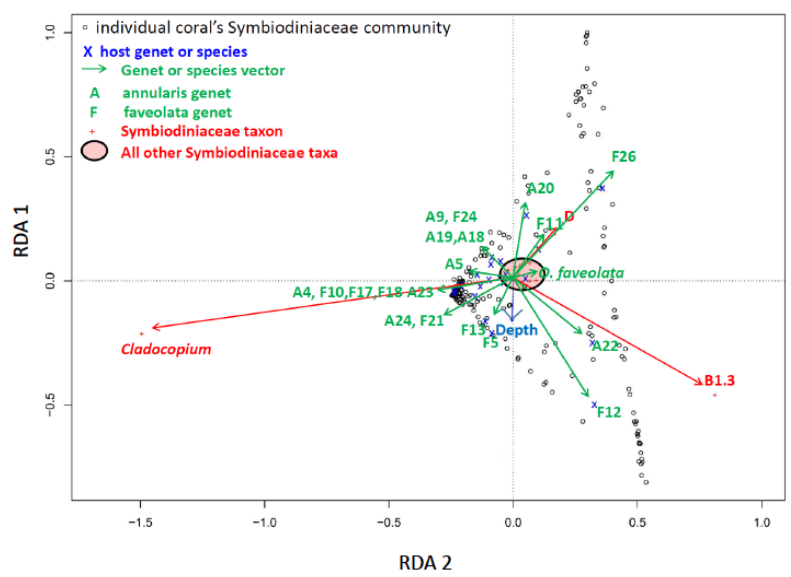




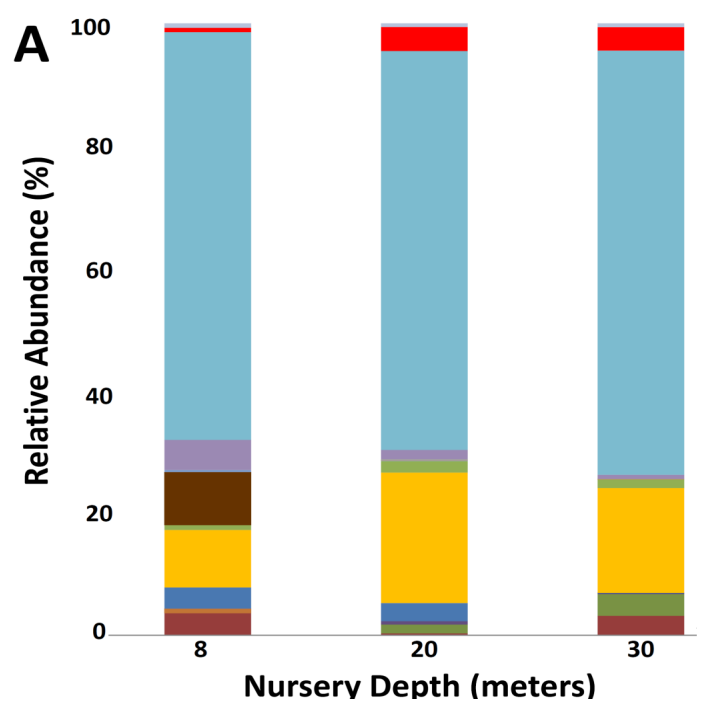

G. Spongiolum

D. Trenchii

Unclassified Cladocopium

B. Psygmophilum

B1.11

B1.10

B1.9

B1.8

B1.7

B1.6

B $^{100}$

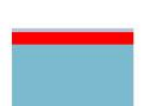

B1.5

B1.4

B1.3

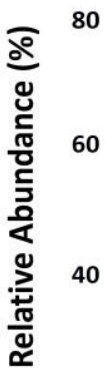

B1.2

B1.1

Unclassified Breviolum

- A3

- A4

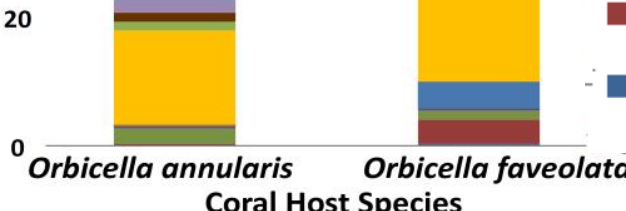

\section{Unclassified Symbiodinium}

Coral Host Species

Fig 3.4 Relative Abundance of Symbiodiniaceae Taxa by Orbicella spp, Depth, and

Genet: A) by depth: The Symbiodiniaceae community did not vary significantly by depth ( $>>0.05)$ B) by species: Orbicella annularis and Orbicella faveolata had significantly different symbiont community structures $(\mathrm{p}<0.05) \mathrm{C}$ ) by depth and species: no significant interaction was detected between depth and species ( $p>0.05) \mathrm{D}$ ) by species and depth $\mathrm{E}$ ) by genet: genet had a significant structuring effect on the Symbiodiniaceae community structure $(\mathrm{p}<0.00001) \mathrm{F}$ ) by ramet for O. annularis $\mathrm{G})$ by ramet for O. faveolata (C through $\mathrm{G}$ on following pages) 


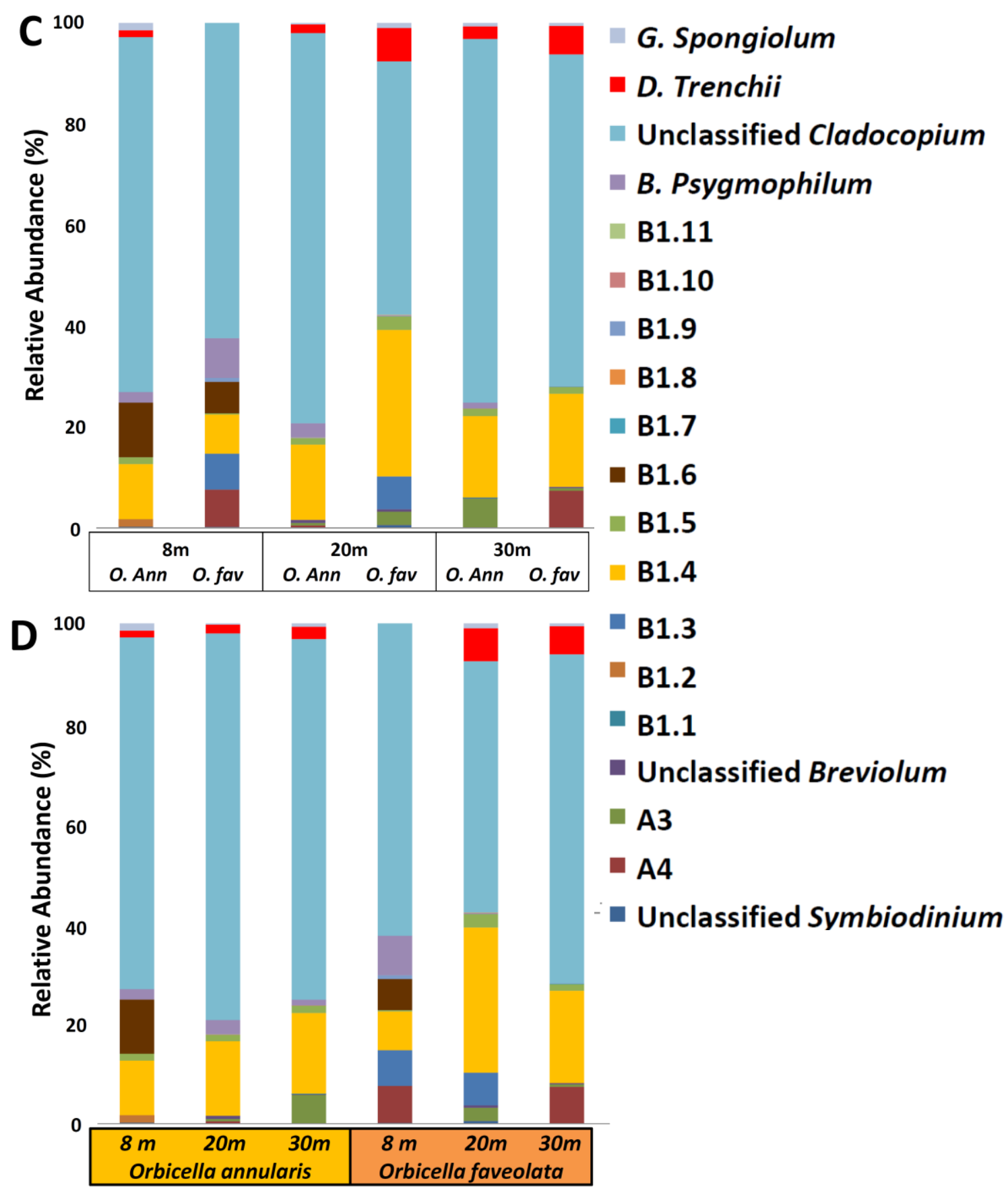




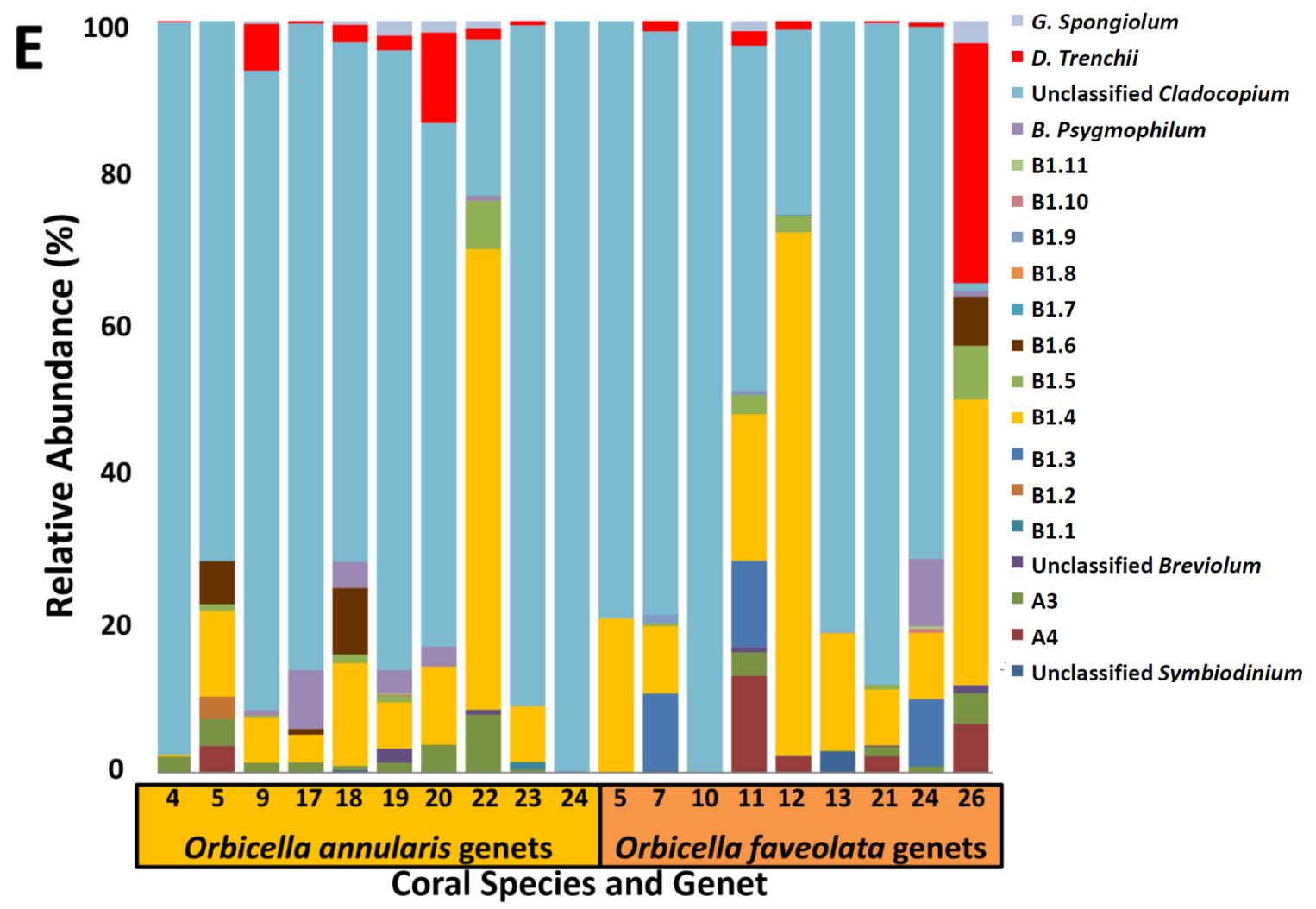



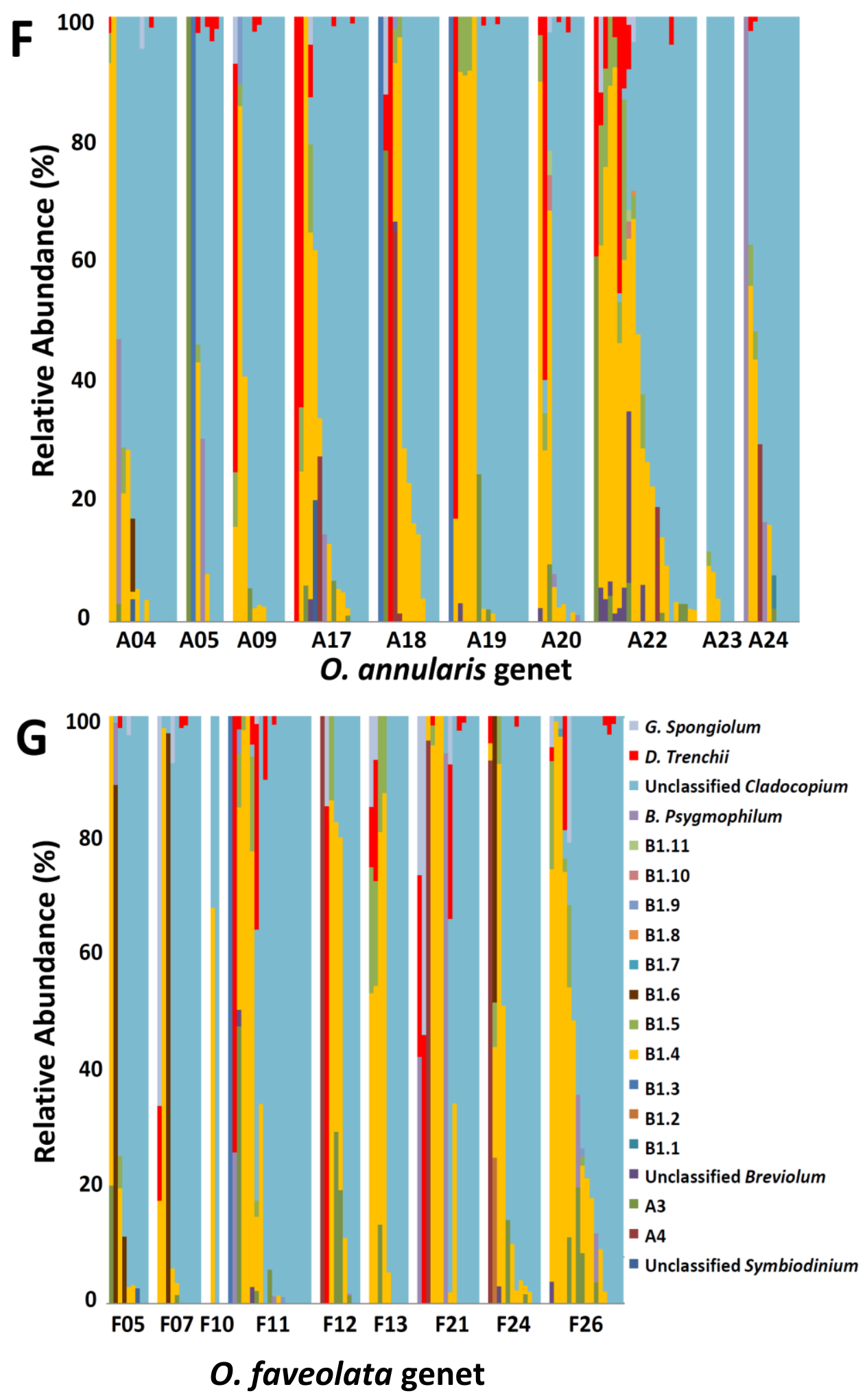


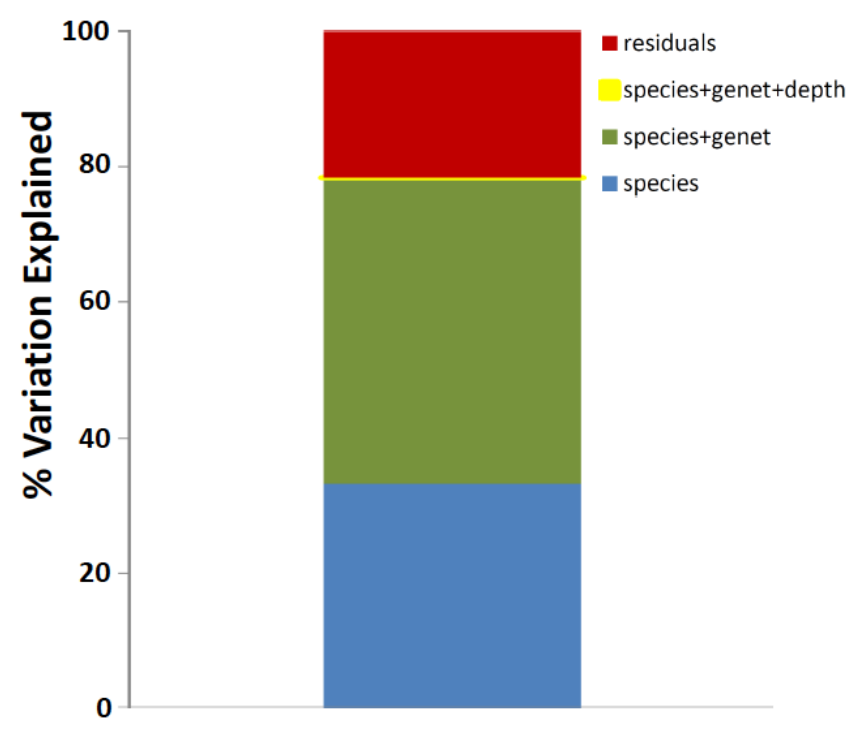

Fig. 3.5 Percent Symbiodiniaceae Community Variation explained by each of Species, Genet, and Depth 
A

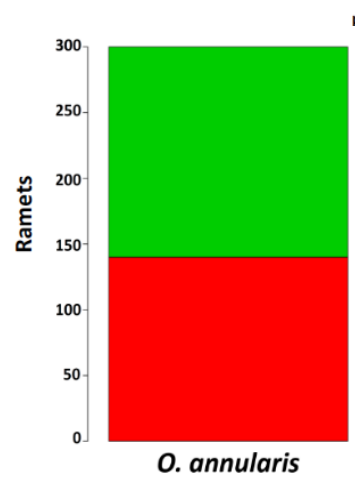

C
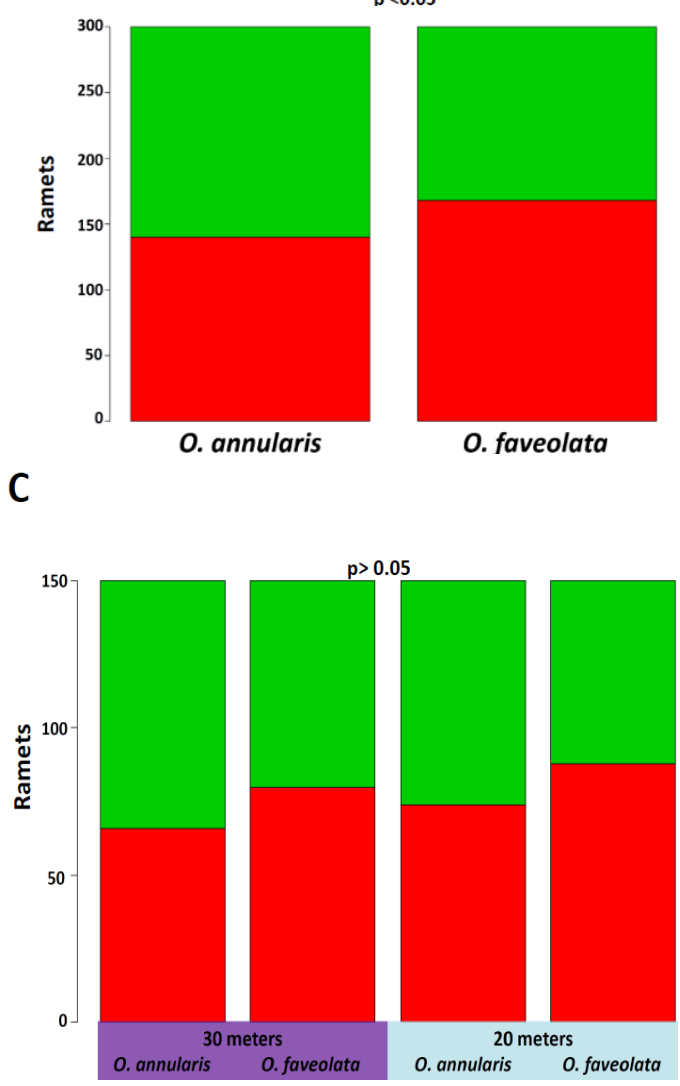

O. faveolata
B

20 meters

D

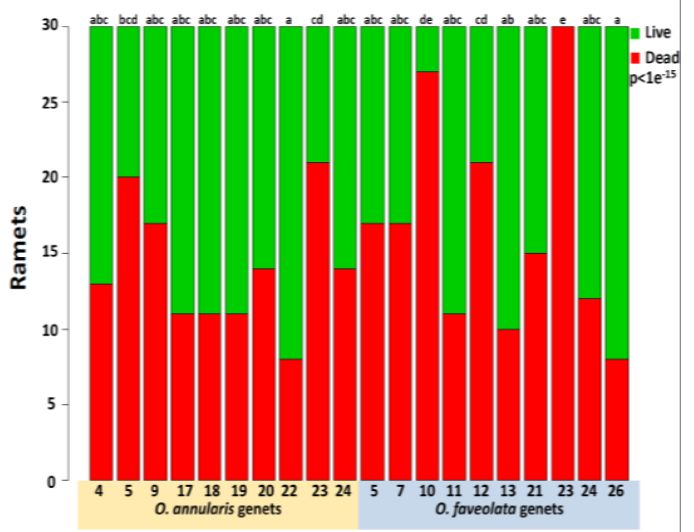

$E$

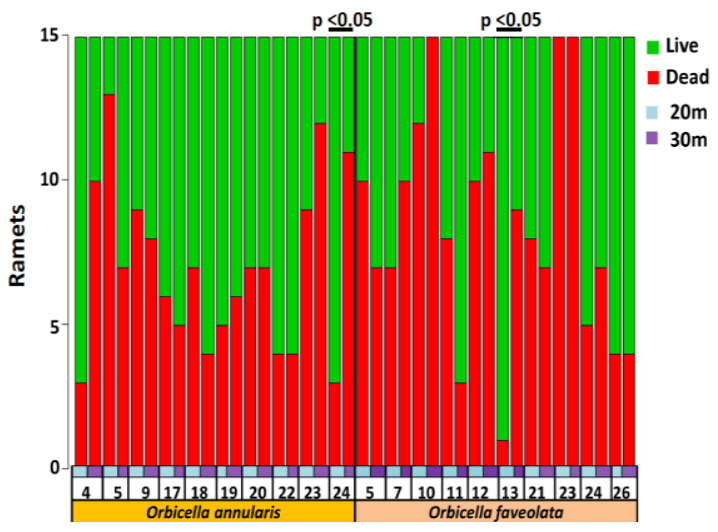

Fig. 3.6: Survivorship of Orbicella Ramets after One Year at 20 or 30m: Red- dead ramets at the conclusion of the study; Green- live ramets at the conclusion of the study. A) Mortality by coral species B) Mortality between the 20 and 30m nurseries C) Mortality of Orbicella ramets by species and depth. D) Survivorship by genet E) Mortality by depth and genet. Benjamini-Hochberg pairwise Fisher's tests 


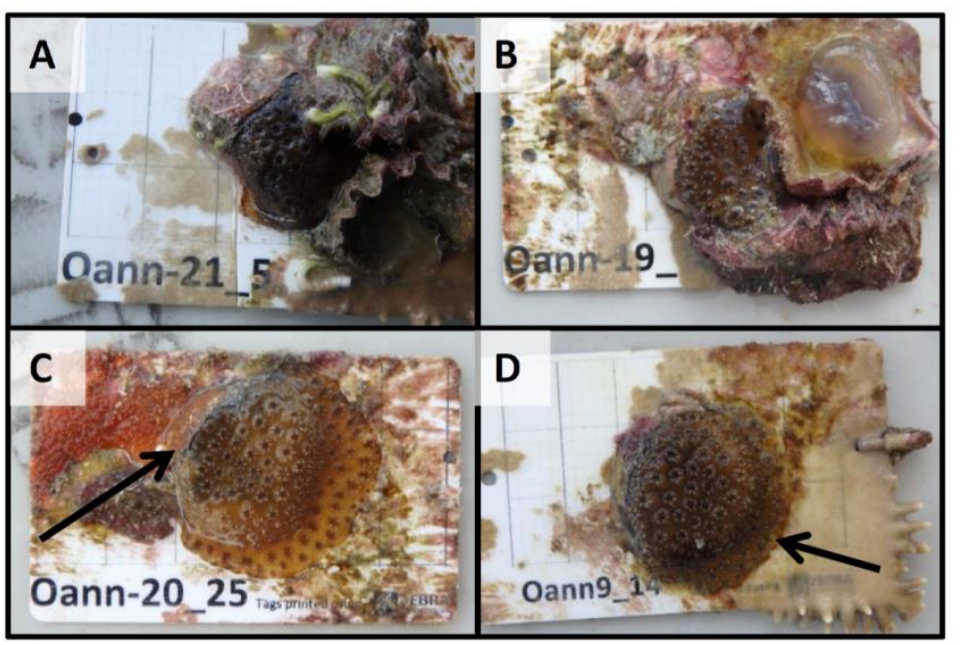

Fig. 3.7: Examples of Orbicella Growth and Competition After One Year at 20 or $30 \mathrm{~m}$ :

Orbicella ramets engaged in spatial competition with a diverse array of benthic organisms with mixed results. A) Oysters and Vermetid snails overgrowing an Orbicella ramet. B) An Orbicella ramet competing against bivalves. C) Outward growth from Orbicella ramet is apparent by the thin flat projections outside of the taller, original fragment. Arrow: Some recent Orbicella growth is being overgrown by an encrusting sponge. D) Arrow: Orbicella ramet overgrowing an encrusting fire coral (Millepora).

A

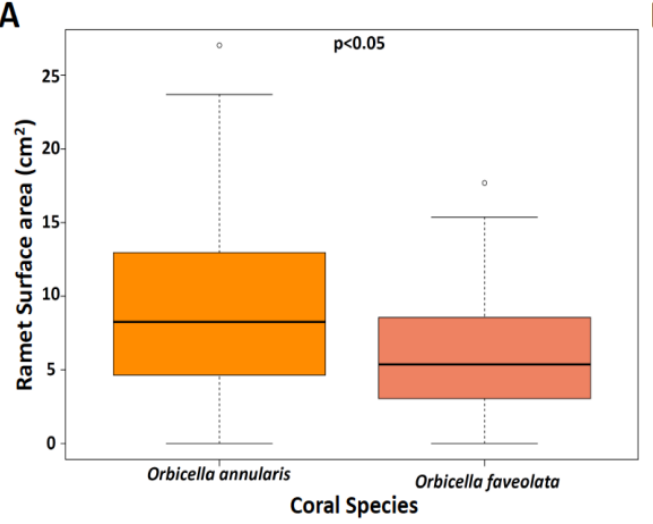

C

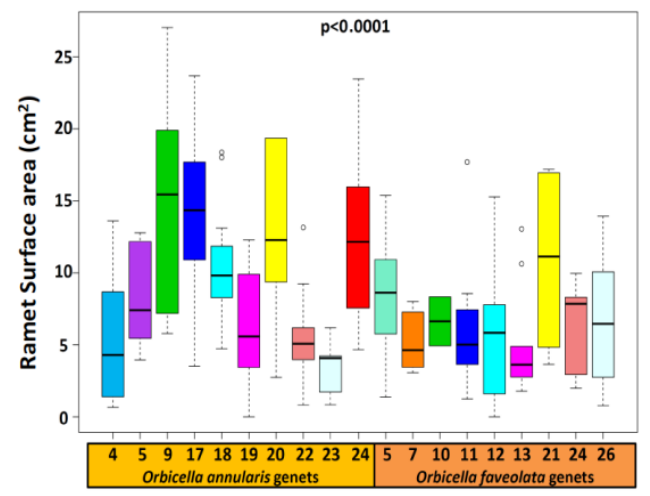

B

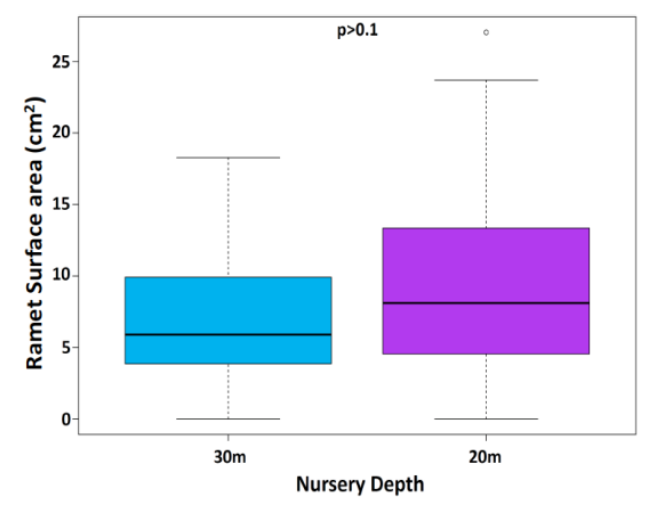

Fig. 3.8 Growth of Orbicella Ramets after one Year at 20 or 30m: As all ramets started the study with the same size, Fragment size at the conclusion of the study may be used as a proxy for growth. A) Growth by Coral Species B) Growth by Nursery Depth C) Growth by Coral Genet (No data is shown for F23 which had no surviving ramets at the conclusion of the study) Mood's Median Test 
A

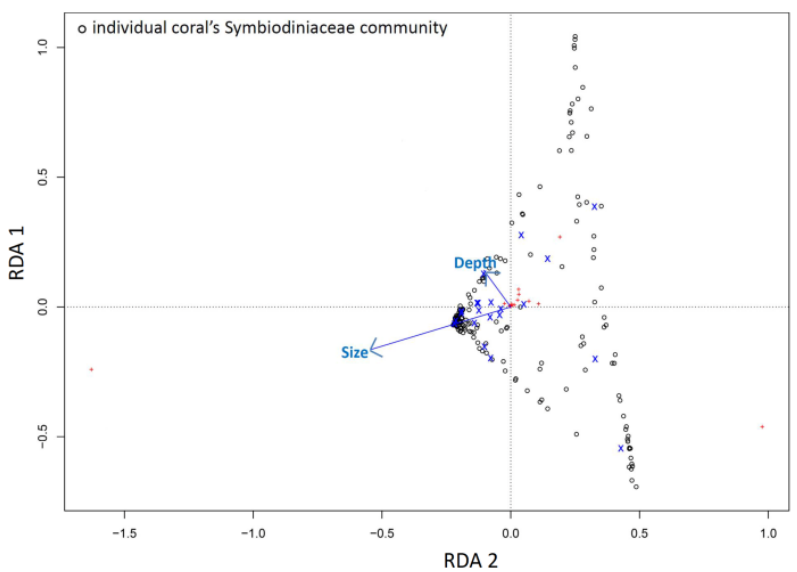

B

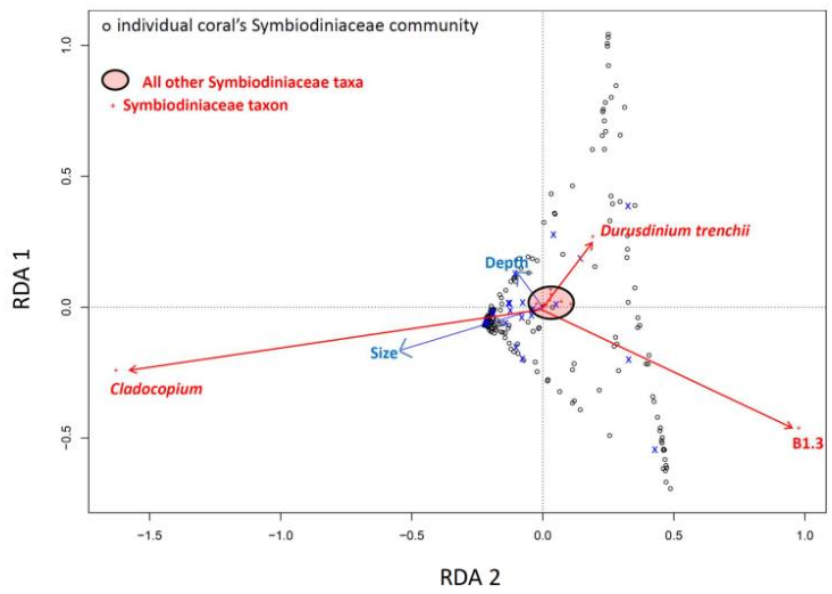

Fig. 3.9 PCA of the Symbiodiniaceae RDA to Determine Factors Governing

Growth: Figure 3.9 does not include data from the $8 \mathrm{~m}$ nursery which were not comparable for growth measurements (see methods), but which can be used to determine correspondence between community members and ramet growth. Circles represent individual ramets' Symbiodiniaceae assemblages. Blue vectors represent effect of Depth and Fragment Size. Red vectors show Symbiodiniaceae taxa whose variance is responsible for differences amongst community assemblages. Green vectors show the influence of host identity (species or genet) on structuring the Symbiodiniaceae community. The similarity between vector headings reflect degree of positive or negative correlation while the length of arrows corresponds to relative effect size. A) Correspondence between Symbiodiniaceae community structure and fragment size B) Relative Contribution of individual Symbiodiniaceae taxa in explaining variation in structure. 
A

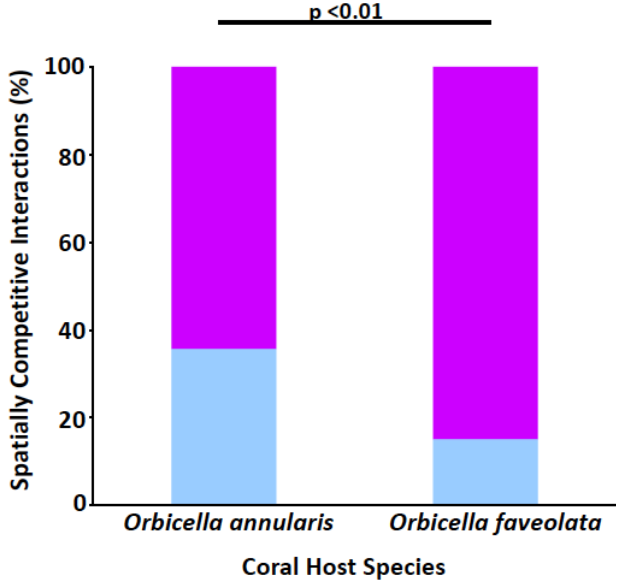

C

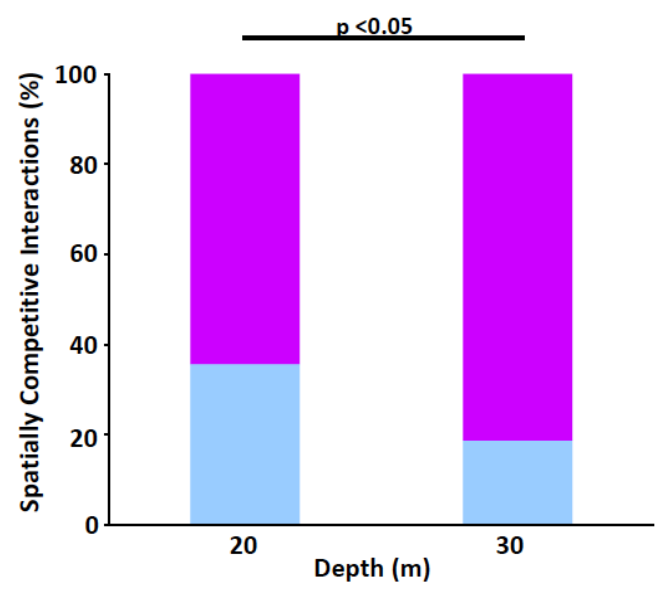

B

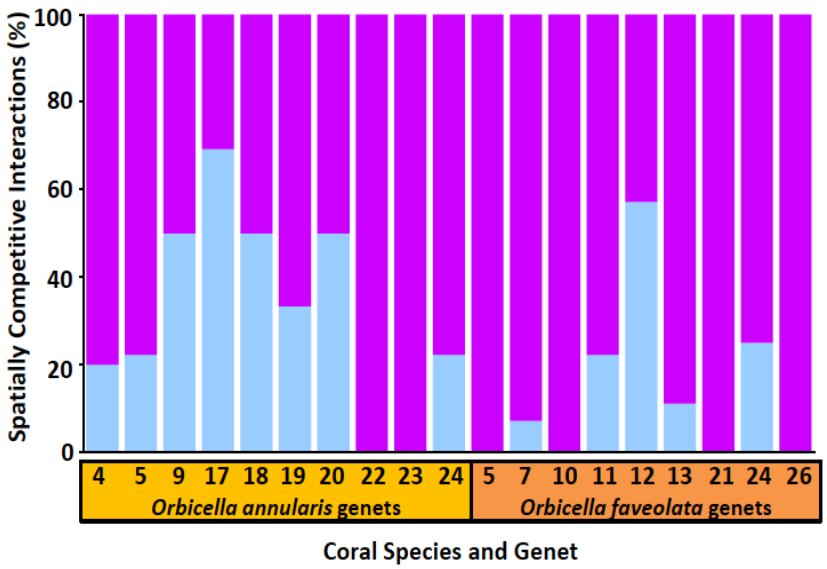

Fig. 3.10 Outcomes of Interactions between Orbicella Ramets and Competing Benthic Organisms: Purple- competitive interactions favoring the Orbicella opponent. Bluecompetitive interactions favoring Orbicella ramets. A) Competitive performance of Orbicella annularis and Orbicella faveolata B) Competitive performance by genet $\mathrm{C}$ ) Competitive performance by nursery depth. Fisher's tests 


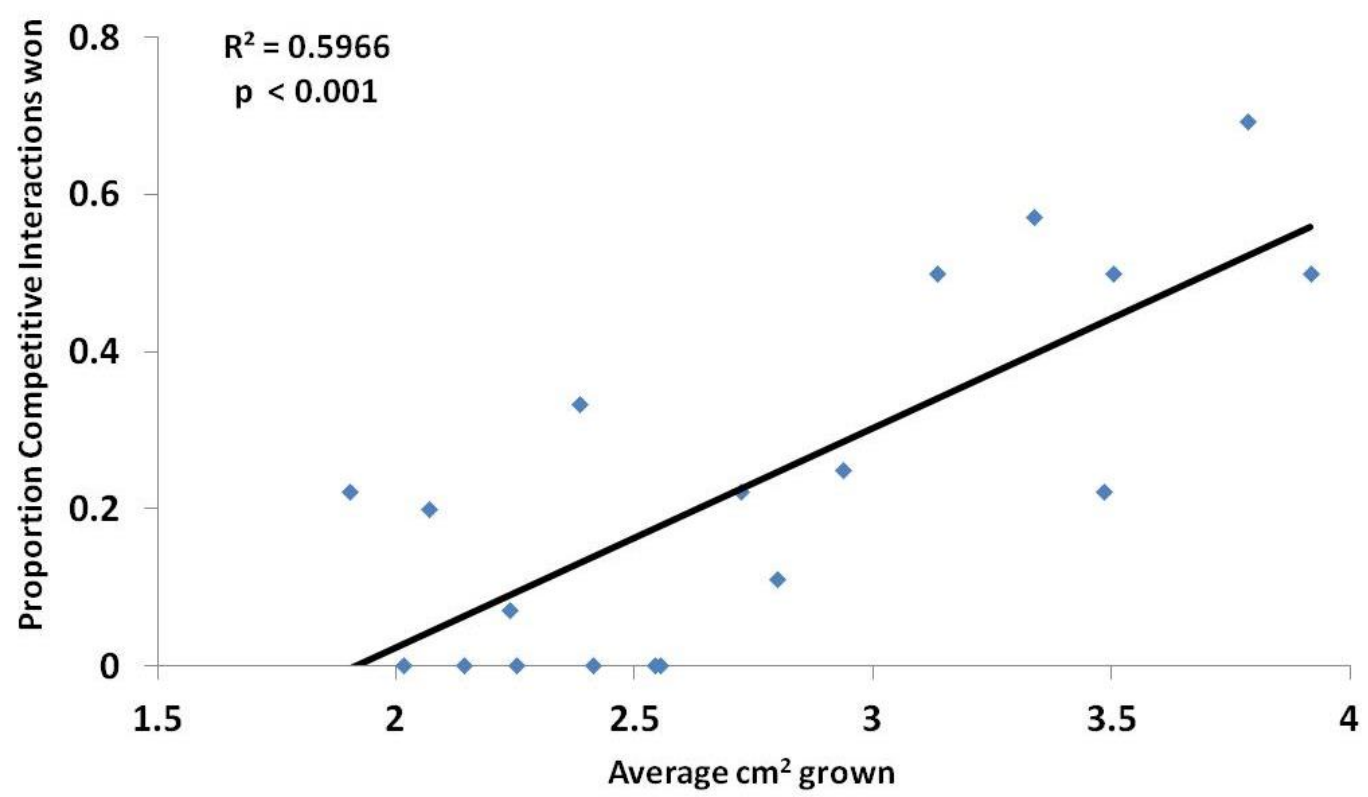

Fig. 3.11 Linear Regression between Growth and Competitive Ability

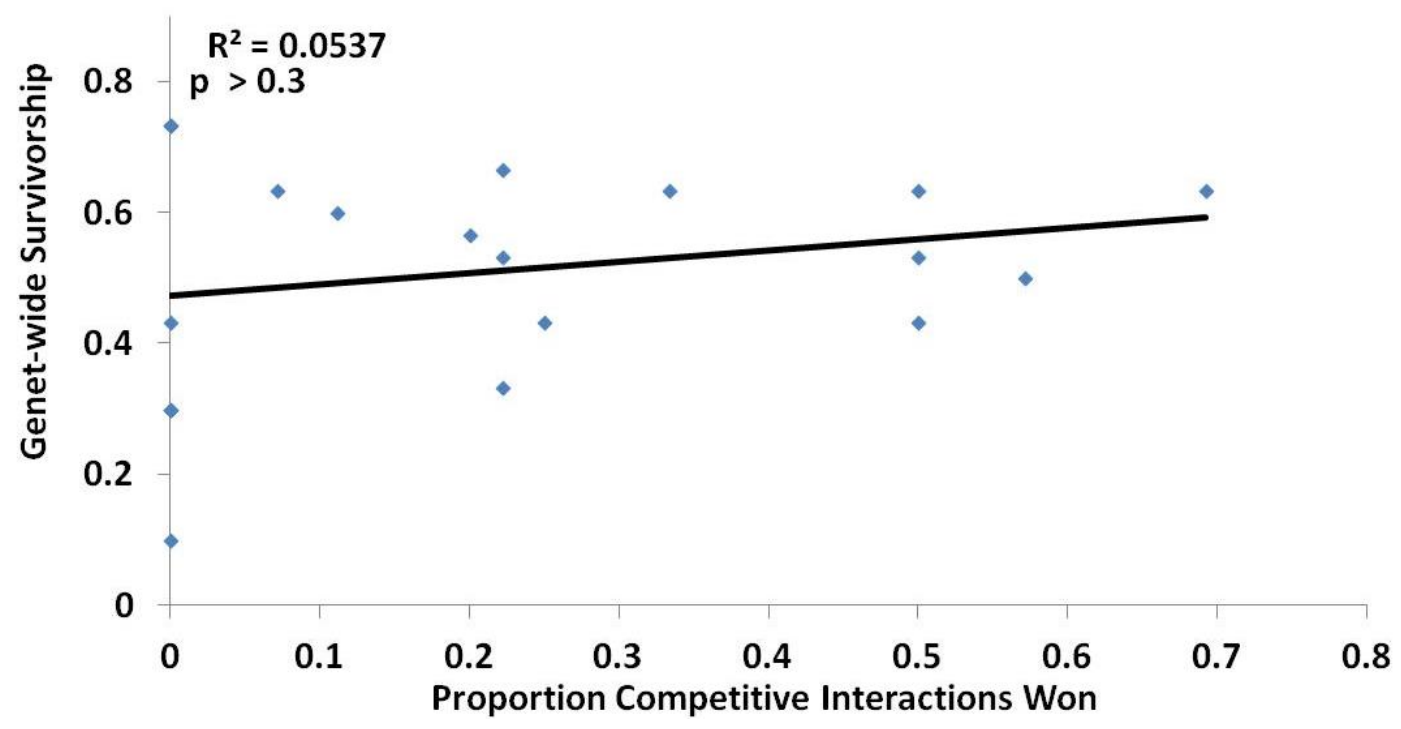

Fig. 3.12 Linear Regression between Genet-wide Survivorship and Competitive Ability 


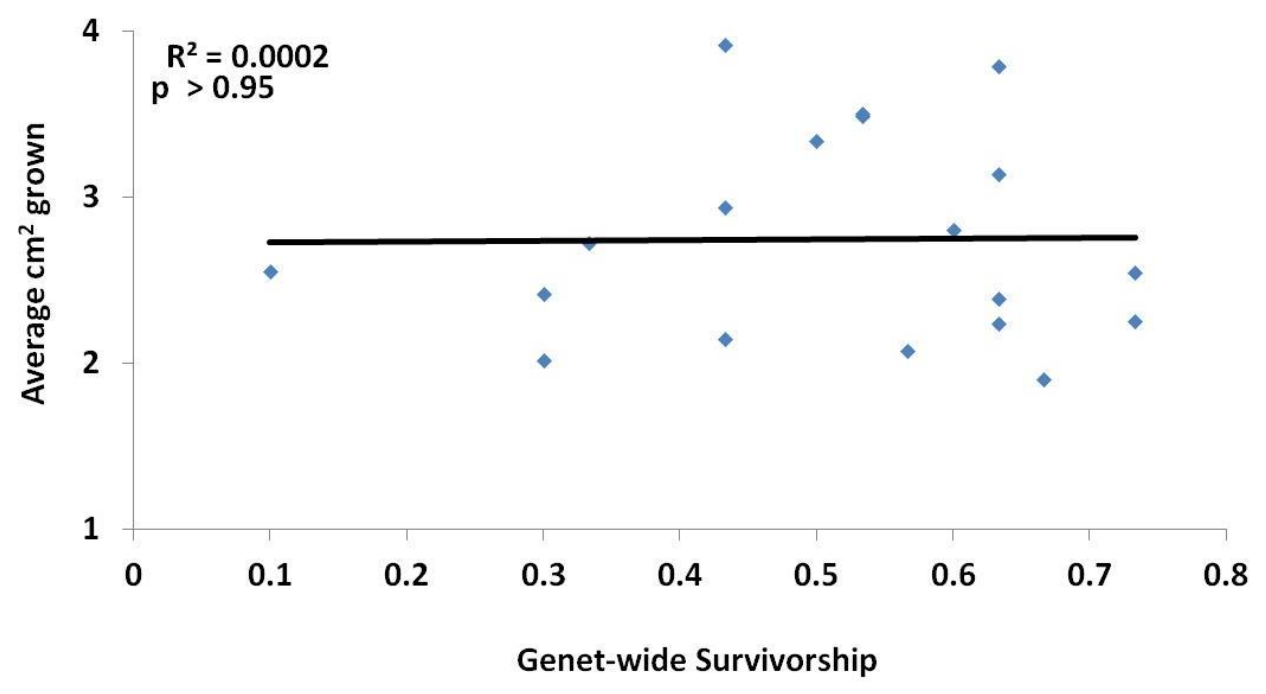

Fig. 3.13 Linear Regression between Genet-wide Growth and Survivorship

Ranking by

Genet Survivorship Growth Competition

\begin{tabular}{ccccc}
\hline A17 & 4 & 2 & 1 \\
\hline F21 & 12 & 5 & 2 \\
\hline A09 & 13 & 1 & 3 \\
\hline A18 & 4 & 6 & 3 \\
\hline A20 & 10 & 3 & 3 \\
\hline A19 & 4 & 13 & 6 \\
\hline F05 & 13 & 7 & 7 \\
\hline A05 & 16 & 9 & 8 \\
\hline A24 & 10 & 4 & 8 \\
\hline F13 & 3 & 19 & 8 \\
\hline A04 & 9 & 17 & 11 \\
\hline F24 & 8 & 8 & 12 \\
\hline F11 & 4 & 15 & 13 \\
\hline A22 & 1 & 14 & 14 \\
\hline A23 & 17 & 18 & 14 \\
\hline F07 & 13 & 16 & 14 \\
\hline F10 & 19 & 10 & 14 \\
\hline F12 & 17 & 12 & 14 \\
\hline F26 & 1 & 11 & 14 \\
\hline F23 & 20 & N/A & N/A \\
\hline & & & \\
\hline & & & \\
\hline & 17 & 14 \\
\hline
\end{tabular}

Fig. 3.14 Genet-wide Ranking by

Performance: Repeated rank values are the results of ties amongst genets. N/A records of F23 for growth and competition are a result of F23's complete mortality prior to the one year sampling point. 


\subsection{References}

Amar KO, Chadwick NE, Rinkevich B (2008) Coral kin aggregations exhibit mixed allogeneic reactions and enhanced fitness during early ontogeny. BMC Evol Biol 8:1-10. doi: 10.1186/1471-2148-8-126

Baird A, Marshall P (2002) Mortality, growth and reproduction in scleractinian corals following bleaching on the Great Barrier Reef. Mar Ecol Prog Ser 237:133-141. doi: $10.3354 /$ meps 237133

Baker A (2003) Flexibility and Specificity in Coral-Algal Symbiosis: Diversity, Ecology, and Biogeography of Symbiodinium. Annu Rev Ecol Evol Syst 34:661-689. doi: $10.1146 / 132417$

Baker AC (2001) Reef corals bleach to survive change. Nature 411:765-766.

Baums IB, Devlin-Durante MK, LaJeunesse TC (2014) New insights into the dynamics between reef corals and their associated dinoflagellate endosymbionts from population genetic studies. Mol Ecol 23:4203-4215. doi: 10.1111/mec.12788

Baums IB, Devlin-Durante MK, Polato NR, et al. (2013) Genotypic variation influences reproductive success and thermal stress tolerance in the reef building coral, Acropora palmata. Coral Reefs 32:703-717. doi: 10.1007/s00338-013-1012-6

Bellantuono AJ, Hoegh-Guldberg O, Rodriguez-Lanetty M (2012) Resistance to thermal stress in corals without changes in symbiont composition. Proc Biol Sci 279:1100-7. doi: $10.1098 /$ rspb.2011.1780

Berkelmans R, van Oppen MJH (2006) The role of zooxanthellae in the thermal tolerance of corals: a "nugget of hope" for coral reefs in an era of climate change. Proc Biol Sci 273:2305-12. doi: 10.1098/rspb.2006.3567

Bongaerts P, Carmichael M, Hay KB, et al. (2015) Prevalent endosymbiont zonation shapes the depth distributions of scleractinian coral species. R Soc Open Sci. doi: 10.1098/rsos.140297

Bongaerts P, Frade PR, Ogier JJ, et al. (2013) Sharing the slope: Depth partitioning of agariciid corals and associated Symbiodinium across shallow and mesophotic habitats (2-60 m) on a Caribbean reef. BMC Evol Biol 13:205. doi: 10.1186/14712148-13-205

Bongaerts P, Ridgway T, Sampayo EM, Hoegh-Guldberg O (2010) Assessing the "deep reef refugia" hypothesis: Focus on Caribbean reefs. Coral Reefs 29:1-19. doi: $10.1007 / \mathrm{s} 00338-009-0581-\mathrm{x}$

Bongaerts P, Riginos C, Hay KB, et al. (2011) Adaptive divergence in a scleractinian coral: Physiological adaptation of Seriatopora hystrix to shallow and deep reef habitats. BMC Evol Biol. doi: 10.1186/1471-2148-11-303 
Bonthond G, Merselis DG, Dougan KE, et al. (2018) Inter-domain microbial diversity within the coral holobiont Siderastrea siderea from two depth habitats. PeerJ 6:e4323. doi: 10.7717/peerj.4323

Callahan BJ, McMurdie PJ, Rosen MJ, et al. (2016) DADA2: High-resolution sample inference from Illumina amplicon data. Nat Methods 13:581-583. doi: 10.1038/nmeth.3869

Cantin NE, Van Oppen MJH, Willis BL, et al. (2009) Juvenile corals can acquire more carbon from high-performance algal symbionts.

Caporaso JG, Kuczynski J, Stombaugh J, et al. (2010) QIIME allows analysis of highthroughput community sequencing data. Nat Methods 7:335.

Coffroth MA, Santos SR, Goulet TL (2001) Early ontogenetic expression of specificity in a cnidarian-algal symbiosis. Mar Ecol Prog Ser 222:85-96.

Cohen Y, Joseph Pollock F, Rosenberg E, Bourne DG (2013) Phage therapy treatment of the coral pathogen Vibrio coralliilyticus. Microbiologyopen 2:64-74. doi: $10.1002 / \mathrm{mbo} 3.52$

Cunning R, Gillette P, Capo T, et al. (2015a) Growth tradeoffs associated with thermotolerant symbionts in the coral Pocillopora damicornis are lost in warmer oceans. Coral Reefs 34:155-160. doi: 10.1007/s00338-014-1216-4

Cunning R, Silverstein RN, Baker AC (2015b) Investigating the causes and consequences of symbiont shuffling in a multi-partner reef coral symbiosis under environmental change. Proc R Soc B Biol Sci 282:20141725-20141725. doi: 10.1098/rspb.2014.1725

Danovaro R, Bongiorni L, Corinaldesi C, et al. (2008) Sunscreens cause coral bleaching by promoting viral infections. Environ Health Perspect 116:441-447. doi: 10.1289/ehp.10966

Donner SD (2009) Coping with commitment: projected thermal stress on coral reefs under different future scenarios. PLoS One 4:e5712. doi: 10.1371/journal.pone.0005712

Douglas AE (2008) Conflict, cheats and the persistence of symbiosis. New Phytol 849858. doi: 10.1111/j.1469-8137.2007.02326.x

Drury C, Manzello D, Lirman D (2017) Genotype and local environment dynamically influence growth, disturbance response and survivorship in the threatened coral, Acropora cervicornis. PLoS One 12:1-21. doi: 10.1371/journal.pone.0174000

Efrony R, Atad I, Rosenberg E (2009) Phage therapy of coral white plague disease: Properties of phage BA3. Curr Microbiol 58:139-145. doi: 10.1007/s00284-0089290-x 
Einbinder S, Mass T, Brokovich E, et al. (2009) Changes in morphology and diet of the coral Stylophora pistillata along a depth gradient. Mar Ecol Prog Ser 381:167-174. doi: 10.3354/meps07908

Eirin-Lopez JM, Putnam HM (2018) Marine Environmental Epigenetics. Ann Rev Mar Sci 11:335-368. doi: 10.1146/annurev-marine-010318-095114

Finney JC, Pettay DT, Sampayo EM, et al. (2010) The relative significance of hosthabitat, depth, and geography on the ecology, endemism, and speciation of coral endosymbionts in the genus Symbiodinium. Microb Ecol 60:250-263. doi: $10.1007 / \mathrm{s} 00248-010-9681-\mathrm{y}$

Forsman ZH, Page CA, Toonen RJ, Vaughan D (2015) Growing coral larger and faster: micro-colony-fusion as a strategy for accelerating coral cover. PeerJ 3:e1313. doi: 10.7717/peerj.1313

Fricke H, Meischner D (1985) Depth limits of Bermudan scleractinian corals: a submersible survey. Mar Biol 187:175-187.

Glasl B, Smith CE, Bourne DG, Webster NS (2019) Disentangling the effect of hostgenotype and environment on the microbiome of the coral Acropora tenuis. PeerJ 7:e6377. doi: 10.7717/peerj.6377

Goulet T (2006) Most corals may not change their symbionts. Mar Ecol Prog Ser 321:17.

Groves SH, Holstein DM, Enochs IC, et al. (2018) Growth rates of Porites astreoides and Orbicella franksi in mesophotic habitats surrounding St . Thomas, US Virgin Islands. Coral Reefs 37:345-354. doi: 10.1007/s00338-018-1660-7

Hervé M (2019) RVAideMemoire: Testing and Plotting Procedures for Biostatistics.

Hoegh-Guldberg O (2011) Coral reef ecosystems and anthropogenic climate change. Reg Environ Chang 11:215-227. doi: 10.1007/s10113-010-0189-2

Holstein DM, Smith TB, Gyory J, Paris CB (2015) Fertile fathoms: Deep reproductive refugia for threatened shallow corals. Sci Rep 5:1-12. doi: 10.1038/srep12407

Howells EJ, Berkelmans R, van Oppen MJH, et al. (2013) Historical thermal regimes define limits to coral acclimatization. Ecology 94:1078-1088. doi: 10.1890/121257.1

Huston M (1985) Variation in coral growth rates with depth. Coral Reefs 19-25.

Jackson JBC, Kirby MX, Berger WH, et al. (2001) Historical overfishing and the recent colllapse of coastal ecosystems. Science (80) 293:629-638. doi:

10.1126/science.1059199

Jones A, Berkelmans R (2010) Potential costs of acclimatization to a warmer climate: Growth of a reef coral with heat tolerant vs. sensitive symbiont types. PLoS One. doi: 10.1371/journal.pone.0010437 
Kemp DW, Thornhill DJ, Rotjan RD, et al. (2015) Spatially distinct and regionally endemic Symbiodinium assemblages in the threatened Caribbean reef-building coral Orbicella faveolata. Coral Reefs 34:535-547. doi: 10.1007/s00338-015-1277-z

Kennedy E V., Tonk L, Foster NL, et al. (2016) Symbiodinium biogeography tracks environmental patterns rather than host genetics in a key caribbean reef-builder, Orbicella annularis. Proc R Soc B Biol Sci. doi: 10.1098/rspb.2016.1938

Ladd M, Shantz A, Bartels E, Burkepile D (2017) Thermal stress reveals a genotypespecific tradeoff between growth and tissue loss in restored Acropora cervicornis.

Lajeunesse TC, Parkinson JE, Reimer JD (2012) A genetics-based description of Symbiodinium minutum sp. nov. and S. psygmophilum sp. nov. (dinophyceae), two dinoflagellates symbiotic with cnidaria. J Phycol 48:1380-1391. doi: $10.1111 / j .1529-8817.2012 .01217 . x$

LaJeunesse TC, Smith RT, Finney J, Oxenford H (2009) Outbreak and persistence of opportunistic symbiotic dinoflagellates during the 2005 Caribbean mass coral "bleaching" event. Proc Biol Sci 276:4139-48. doi: 10.1098/rspb.2009.1405

Levitan D, Boudreau W, Jara J, Knowlton N (2014) Long-term reduced spawning in Orbicella coral species due to temperature stress. Mar Ecol Prog Ser 515:1-10. doi: 10.3354/meps11063

Lewis AM, Chan AN, LaJeunesse TC (2019a) New species of closely related endosymbiotic Dinoflagellates in the Greater Caribbean have niches corresponding to host coral phylogeny. J Eukaryot Microbiol 66:469-482. doi: 10.1111/jeu.12692

Lewis CL, Coffroth MA (2004) The acquisition of exogenous algal symbionts by an octocoral after bleaching. Science 304:1490-2. doi: 10.1126/science.1097323

Lewis CL, Neely K, Rodriguez-lanetty M (2019b) Recurring episodes of thermal stress shift the balance from a dominant host-specialist to a background host-generalist zooxanthella in the threatened pillar coral. Front Mar Sci 6:1-15. doi: 10.3389/fmars.2019.00005

Lirman D, Schopmeyer S, Galvan V, et al. (2014) Growth dynamics of the threatened Caribbean staghorn coral Acropora cervicornis: influence of host genotype, symbiont identity, colony size, and environmental setting. PLoS One 9:e107253. doi: 10.1371/journal.pone.0107253

Little AF, Oppen MJH van, Willis BL (2004) Flexibility in algal endosymbioses shapes growth in reef corals. Science (80- ) 304:1492-1495. doi: 10.1126/science.1095733

Manfred L, Van Veghel D, Clear F.R., Bak Rolf PM (1996) Interspecific interactions and competitive ability of the polymorphic reef-building coral Montastrea annularis. Bull Mar Sci 58:792-803.

Mangiafico S (2019) rcompanion: Functions to Support Extension Education Program Evaluation. 
Manzello DP (2015) Rapid recent warming of coral reefs in the Florida Keys. Sci Rep 5:16762. doi: $10.1038 /$ srep 16762

Martinez-Arbizu P (2017) pairwiseAdonis: Pairwise Multilevel Comparison using Adonis.

Matthews JL, Sproles AE, Oakley CA, et al. (2016) Menthol-induced bleaching rapidly and effectively provides experimental aposymbiotic sea anemones (Exaiptasia sp.) for symbiosis investigations. J Exp Biol 306-310. doi: 10.1242/jeb.128934

Merselis DG, Lirman D, Rodriguez-Lanetty M (2018) Symbiotic immuno-suppression: Is disease susceptibility the price of bleaching resistance? PeerJ 6:e4494. doi: 10.7717/peerj.4494

Middlebrook R, Hoegh-Guldberg O, Leggat W (2008) The effect of thermal history on the susceptibility of reef-building corals to thermal stress. J Exp Biol 211:1050-6. doi: $10.1242 /$ jeb.013284

Mieog JC, Olsen JL, Berkelmans R, et al. (2009) The roles and interactions of symbiont, host and environment in defining coral fitness. PLoS One. doi: 10.1371/journal.pone.0006364

Miller MW, Williams DE, Fisch J (2016) Genet-specific spawning patterns in Acropora palmata. Coral Reefs 35:1393-1398. doi: 10.1007/s00338-016-1472-6

Mills E, Shechtman K, Loya Y, Rosenberg E (2013) Bacteria appear to play important roles in both causing and preventing the bleaching of the coral Oculina patagonica. Mar Ecol Prog Ser 489:155-162. doi: 10.3354/meps10391

Morikawa MK, Palumbi SR (2019) Using naturally occurring climate resilient corals to construct bleaching-resistant nurseries. Proc Natl Acad Sci U S A. doi: 10.1073/pnas. 1721415116

Oksanen J, Blanchet FG, Friendly M, et al. (2019) vegan: Community Ecology Package.

Palumbi SR, Barshis DJ, Traylor-Knowles N, Bay RA (2014) Mechanisms of reef coral resistance to future climate change. Science (80- ) 344:895-898. doi: 10.1071/MF99078

Pandolfi JM, Jackson JBC, Baron N, et al. (2005) Are U.S. coral reefs on the slippery slope to slime? Science (80- ) 307:1725 LP-1726.

Parkinson JE, Coffroth MA, LaJeunesse TC (2015) New species of Clade B Symbiodinium (Dinophyceae) from the greater Caribbean belong to different functional guilds: S. aenigmaticum sp. nov., S. antillogorgium sp. nov., S. endomadracis sp. nov., and S. pseudominutum sp. nov. J Phycol 51:850-858. doi: 10.1111/jpy. 12340

Pettay DT, Wham DC, Smith RT, et al. (2015) Microbial invasion of the Caribbean by an Indo-Pacific coral zooxanthella. Proc Natl Acad Sci 112:7513-7518. doi: $10.1073 /$ pnas. 1502283112 
Price N, Muko S, Legendre L, et al. (2019) Global biogeography of coral recruitment: tropical decline and subtropical increase. Mar Ecol Prog Ser 621:1-17. doi: 10.3354/meps12980

Puill-Stephan E, Willis BL, van Herwerden L, van Oppen MJH (2009) Chimerism in wild adult populations of the broadcast spawning coral Acropora millepora on the Great Barrier Reef. PLoS One. doi: 10.1371/journal.pone.0007751

Quigley KM, Willis BL, Bay LK (2017) Heritability of the Symbiodinium community in vertically- and broadcast spawning corals. Sci Rep 1-14. doi: 10.1038/s41598-017$08179-4$

R Core Team (2017) R: A language and environment for statistical computing.

Reshef L, Koren O, Loya Y, et al. (2006) The coral probiotic hypothesis. Environ Microbiol 8:2068-73. doi: 10.1111/j.1462-2920.2006.01148.x

Rodriguez-Lanetty M, Granados-Cifuentes C, Barberan A, et al. (2013) Ecological Inferences from a deep screening of the Complex Bacterial Consortia associated with the coral, Porites astreoides. Mol Ecol 22:4349-62. doi: 10.1111/mec.12392

Rodríguez-Lanetty M, Marquez LM, Losada F (2003) Changes in gorgonian morphology along a depth gradient at Isla Alcatraz, San Esteban National Park, Venezuela. Bull Mar Sci 72:1019-1023.

Rosenberg E, Koren O, Reshef L, et al. (2007) The role of microorganisms in coral health, disease and evolution. Nat Rev Microbiol 5:355-62. doi: $10.1038 /$ nrmicro 1635

Sampayo EM, Dove S, Lajeunesse TC (2009) Cohesive molecular genetic data delineate species diversity in the dinoflagellate genus Symbiodinium. Mol Ecol 18:500-519. doi: 10.1111/j.1365-294X.2008.04037.x

Schneider CA, Rasband WS, Eliceiri KW (2012) NIH Image to ImageJ: 25 years of image analysis. Nat Methods 9:671-675. doi: 10.1038/nmeth.2089

Silverstein RN, Correa AMS, Baker AC (2012) Specificity is rarely absolute in coralalgal symbiosis: implications for coral response to climate change. Proc Biol Sci 279:2609-18. doi: 10.1098/rspb.2012.0055

Silverstein RN, Cunning R, Baker AC (2014) Change in algal symbiont communities after bleaching, not prior heat exposure, increases heat tolerance of reef corals. Glob Chang Biol 1-14. doi: 10.1111/gcb.12706

Simpson GL (2016) permute: Functions for Generating Restricted Permutations of Data.

Smith TB, Glynn PW, Maté JL, et al. (2014) A depth refugium from catastrophic coral bleaching prevents regional extinction. Ecology 95:1663-1673. doi: 10.1890/130468.1 
Thornhill DJ, Fitt WK, Schmidt GW (2006a) Highly stable symbioses among western Atlantic brooding corals. Coral Reefs 25:515-519. doi: 10.1007/s00338-006-0157-y

Thornhill DJ, LaJeunesse TC, Kemp DW, et al. (2006b) Multi-year, seasonal genotypic surveys of coral-algal symbioses reveal prevalent stability or post-bleaching reversion. Mar Biol 148:711-722. doi: 10.1007/s00227-005-0114-2

Thornhill DJ, Lewis AM, Wham DC, Lajeunesse TC (2014) Host-specialist lineages dominate the adaptive radiation of reef coral endosymbionts. Evolution (N Y) 68:352-367. doi: 10.1111/evo.12270

Toller WW, Rowan R, Knowlton N (2001a) Zooxanthellae of the Montastraea annularis Species Complex : Patterns of Distribution of Four Taxa of Symbiodinium on Different Reefs and Across Depths. Biol Bull 3:348-359.

Toller WW, Rowan R, Knowlton N (2001b) Repopulation of Zooxanthallae in the Carribean Corals Montastraea annularis and Montastraea faveolata Experimental and Disease-Associated Bleaching. Biol Bull 1-14.

Van Hooidonk R, Maynard JA, Planes S (2013) Temporary refugia for coral reefs in a warming world. Nat Clim Chang 3:508-511. doi: 10.1038/nclimate1829

van Oppen MJH, Gates RD, Blackall LL, et al. (2017) Shifting paradigms in restoration of the world's coral reefs. Glob Chang Biol 23:3437-3448. doi: 10.1111/gcb.13647

van Oppen MJH, Oliver JK, Putnam HM, Gates RD (2015) Building coral reef resilience through assisted evolution. Proc Natl Acad Sci 112:2307-2313. doi:

$10.1073 /$ pnas. 1422301112

Vermeij MJA, Bakker J, van der Hal N, Bak RPM (2011) Juvenile coral abundance has decreased by more than $50 \%$ in only three decades on a small Caribbean Island. Diversity 3:296-307. doi: 10.3390/d3030296

Vermeij MJA, van Moorselaar I, Engelhard S, et al. (2010) The effects of nutrient enrichment and herbivore abundance on the ability of turf algae to overgrow coral in the Caribbean. PLoS One 5:1-8. doi: 10.1371/journal.pone.0014312

Vollmer S V., Kline DI (2008) Natural disease resistance in threatened staghorn corals. PLoS One 3:1-5. doi: 10.1371/journal.pone.0003718

Weil E, Knowlton N (1994) A Multi-Character Analysis of the Caribbean Coral Montastaea annularis (Ellis and Solander, 1786 ) and its two sibling species, $M$. Faveolata (Ellis and Solander, 1786 ). Bull Mar Sci 55:151-175.

Willis BL, Ayre DJ (1985) Asexual reproduction and genetic determination of growth form in the coral Pavona cactus: Biochemical genetic and immunogenic evidence. Oecologia 65:516-525. 
Ziegler M, Seneca FO, Yum LK, et al. (2017) Bacterial community dynamics are linked to patterns of coral heat tolerance. Nat Commun 8:1-8. doi: 10.1038/ncomms14213 


\section{CHAPTER 4: Symbiotic Immuno-suppresion: is Disease Susceptibility the Price of}

\section{Bleaching Resistance?}

The following chapter was published in PEERJ on 17 April 2018. Its text and figures are reproduced here with the permission of me, the copyright owner, Daniel Merselis. It was submitted on 19 September 2017 and accepted on 22 February 2018. Symbiotic Immuno-suppresion: is Disease Susceptibility the Price of Bleaching Resistance?

Daniel G Merselis ${ }^{1}$, Diego Lirman ${ }^{2}$, and Mauricio Rodriguez-Lanetty ${ }^{1}$

1. Department of Biological Sciences, Florida International University, Miami, USA

2. Department of Marine Biology and Ecology, University of Miami, Miami, USA

Running Title: Symbiotic Immuno-Suppresion

\subsection{Abstract:}

Accelerating anthropogenic climate change threatens to destroy coral reefs worldwide through the processes of bleaching and disease. These major contributors to coral mortality are both closely linked with thermal stress intensified by anthropogenic climate change. Disease outbreaks typically follow bleaching events, but a direct positive linkage 
between bleaching and disease has been debated. By tracking 152 individual coral ramets through the 2014 mass bleaching in a South Florida coral restoration nursery, we revealed a highly significant negative correlation between bleaching and disease in the Caribbean staghorn coral, Acropora cervicornis. To explain these results, we propose a mechanism for transient immunological protection through coral bleaching: Removal of Symbiodinium during bleaching may also temporarily eliminate suppressive symbiont modulation of host immunological function. We contextualize this hypothesis within an ecological perspective in order to generate testable predictions for future investigation.

\subsection{Introduction:}

Anthropogenic climate change threatens to destroy coral reefs globally before the end of the century (Hoegh-Guldberg et al., 2007; Hoegh-Guldberg, 2014). Increasing frequency, severity, and duration of thermal anomalies have caused increased coral bleaching and disease outbreaks (Harvell et al., 1999, 2002; Bruno et al., 2007; Hoegh-Guldberg \& Bruno, 2010; Ruiz-Moreno et al., 2012; Randall \& van Woesik, 2015). Coral bleaching represents the breakdown of the obligate mutualism between dinoflagellates of the genus Symbiodinium and reef building corals. This breakdown results in decreased coral growth, fecundity, and survivorship, as the loss of photosynthetic Symbiodinium deprives corals of up to 95\% of their energetic budget (Muscatine \& Porter, 1977; Glynn, 1983; Harriott, 1985; Goreau \& Macfarlane, 1990; Szmant \& Gassman, 1990; Baird \& Marshall, 2002). Coral tissue-loss disease outbreaks frequently follow bleaching events (Harvell et al., 2001; Muller et al., 2008; Brandt \& Mcmanus, 2009; Cróquer \& Weil, 
2009; Miller et al., 2009; Precht et al., 2016; Lewis et al., 2017) and, like bleaching, are linked to thermal anomalies (Selig et al., 2006; Bruno et al., 2007; Brandt \& McManus, 2009; Cróquer \& Weil, 2009; Ban, Graham \& Connolly, 2012; Ruiz-Moreno et al., 2012) as well as poor water quality (Haapkylä et al., 2011; Vega Thurber et al., 2014). Many of these diseases remain poorly characterized and may represent the invasion of one or more opportunistic microbes or viruses (see Lesser et al. 2007 and Bourne et al. 2009). Koch's postulates have been fulfilled for several coral diseases, but some of these same diseases have later been induced by alternative etiological agents, indicating that signs of coral maladies may constitute syndromes with many potential pathologies rather than a singular pathology (Denner et al., 2003; Lesser et al., 2007; Sunagawa et al., 2009; Sutherland et al., 2011; Lesser \& Jarett, 2014). Like bleaching, coral tissue loss diseases can cause coral mortality, reduce coral growth and fecundity, and are recognized as major drivers of coral reef decline (Richardson et al., 1998; Harvell et al., 2001; Patterson et al., 2002; Miller et al., 2006, 2009; Weil, Cróquer \& Urreiztieta, 2009) Coral tissue loss diseases (as opposed to diseases resultant in discoloration or abnormal growth form) are the focus of this study.

Whether tissue loss disease outbreaks follow bleaching events on a correlational or causal basis is a topic of debate (Bruno et al., 2007; Muller et al., 2008; Brandt \& McManus, 2009; Cróquer \& Weil, 2009; Ban, Graham \& Connolly, 2012). A causal relationship between the two conditions is intuitive as starvation induced by bleaching could lead towards increased coral host susceptibility. Muller et al. (2008) and others demonstrated that a relationship between temperature and disease prevalence could be found during a bleaching year as opposed to non-bleaching years and further correlated that mortality 
due to disease was correlated to temperature in bleached, but not unbleached corals. Furthermore, there is a relationship between mean percentage of bleached corals and prevalence of several diseases in numerous Caribbean scleractinian genera (Brandt \& McManus, 2009; Cróquer \& Weil, 2009). These relationships correlate bleaching and disease, but do not necessarily link them mechanistically. The co-occurrence of bleaching and tissue loss diseases is expected even if the two conditions are mechanistically independent, because bleaching and tissue loss diseases are both enhanced by thermal stress (Glynn \& D’Croz, 1990; Bruno et al., 2007; Lesser, 2011). Monitoring at the population level can indicate correlation between bleaching and disease, but cannot be used to prove a mechanistic link. A causal relationship between bleaching and disease would leave a pattern of co-occurrence when monitored at the individual level (i.e., bleached individuals should have significantly greater rates of disease). As such, monitoring efforts which perform repeated transects without tracking individuals may be unable to differentiate a causal or correlational relationship (Cróquer \& Weil, 2009). Population and community level co-observation between bleaching and disease linked by a common environmental driver should not be construed as a dependency between them. Contrary to this expected pattern of correlation, white band disease on the Great Barrier Reef has had a negative spatial correlation to bleaching events, even though the disease was correlated with thermal anomaly (Bruno et al., 2007). Further, geographically predictive models for white syndrome outbreaks are not improved by the incorporation of information known to accurately predict coral bleaching (Ban, Graham \& Connolly, 2012). This work suggests a correlational rather than causal relationship, because these disease outbreaks are not enhanced by prior bleaching. 
At a physiological level, immunological markers respond to bleaching conflictingly; prophenol oxidase and peroxidase activity may increase during bleaching, while phenol oxidase, lysozyme-like, and microbial antibacterial activity decline (Ritchie, 2006; Mydlarz et al., 2009; Palmer, Bythell \& Willis, 2011). The coral mucus layer acts both as a physical barrier to infection and a point of first contact/adhesion for an infectious agent (Banin et al., 2001; Brown \& Bythell, 2005). It is largely produced with resources from Symbiodinium, and its production is therefore dependent upon the mutualism between Symbiodinium and coral host(Brown \& Bythell, 2005).

In the present study, monitoring for bleaching and tissue loss disease was carried out in restoration nursery. Coral nurseries provide a unique opportunity for monitoring, because histories of environmental conditions and genetic backgrounds is known in these common gardens(Lirman \& Schopmeyer, 2016). Mother colonies are often fragmented many times, resulting in clonal individual colonies known as ramets ideal for replication. The collection of all these clonal ramets descendant from a single mother colony are known as a genet, although this is frequently referred to as a genotype in the restoration literature (Baums, 2008).

Individual Acropora cervicornis ramets were monitored during a bleaching event and subsequent recovery in an in situ coral nursery located near Miami, Florida, USA to elucidate patterns of correlation between bleaching and disease (Lirman et al., 2014). All of the ramets tracked had been at the nursery (common garden) for at least 3 years prior to the onset of bleaching. 
We hypothesized that bleached ramets should be more susceptible to disease than their unbleached counterparts and that certain coral genets would have genetic pre-dispositions towards disease and bleaching resistance or susceptibility. Our results confirmed our hypothesis regarding the effect of genet. However, to our surprise, results revealed a significant negative correlation between bleaching and disease. These findings lead us to postulate a model whereby Symbiodinium may suppress host immunity. According to this theoretical framework, bleaching events may be associated with a transient increase in host immunological capacity, despite the nutritionally detrimental loss of Symbiodinium.

\subsection{Materials and Methods:}

The strong El Niño Southern Oscillation (ENSO) event that occurred in 2014 triggered mass coral bleaching events and subsequent disease outbreaks in the Greater Caribbean and the Florida Reef Tract (Manzello, 2015; Precht et al., 2016; Lewis et al., 2017). Ramets of A. cervicornis propagated since 2007 within the in situ University of Miami "North Nursery" at N 25.488; W 80.109 were monitored by the same observer using SCUBA at four time points (September and November 2014, January, and March 2015) under permits SAL-14-1086-SCRP, BISC-2014-SCI-0018, and BISC-2015-SCI-0018.

. Within the nursery, multiple ramets belonging to the same genet grow on individual pedestals raised off of a common cement block. Each block containing clonal ramets belonging to the same genet rests on a sand bottom all within approximately 100 meters of each other at an approximate depth of 7 meters. No ramets were in physical contact for the duration of the study. During the bleaching event and subsequent recovery, lasting 
from September 2014 through March 2015, 152 ramets representing 21 A. cervicornis genets were tracked. These genets were previously genotyped and identified as genetically distinct using microsatellite markers (Baums, Miller \& Hellberg, 2005; Baums et al., 2009; Lirman et al., 2014). During every time point, each ramet was photographed and scored for presence or absence of bleaching using a calibrated colorimetric card as a reference (Siebeck et al., 2006). Any visible presence of disease was also recorded when an easily discernible linear boundary between apparently normally pigmented (tan to brown) tissue and transparent tissue and visible skeleton was observed. Each ramet was then assigned to one of the following categories based upon observations: "bleaching without disease", "bleaching with disease", "no bleaching without disease", or "no bleaching with disease". Manifestation of a tissue loss condition was noted as disease, because it followed a linear progression of tissue loss from the base progressing towards the tips in a manner similar to white band disease. However, our study did not fully explore the pathogenesis of this phenomenon and it should properly be referred to as a tissue loss disease. The individual history of one ramet throughout the entire duration of the study was considered the experimental unit, so that if a ramet bleached, recovered, and later experienced disease, it was grouped as "bleaching with disease" even though bleaching and tissue-loss conditions never co-occurred.

A Fisher's exact test was employed to detect significant effect of genet on likelihood of bleaching or disease. To determine which genets were significantly different from each other, a Bonferroni corrected pair wise Fisher's exact test was performed. A Chi squared test for independence was carried out to determine whether bleaching and disease were correlated or independent. Expected values were calculated for each 
category based upon the null hypothesis that bleaching and disease were fully independent as follows:

$\mathrm{O} \% \mathrm{~B}=$ observed $\%$ of ramets bleached

$\mathrm{O} \% \mathrm{D}=$ observed $\%$ of ramets with disease

$\mathrm{O} \% \mathrm{~B} \& \mathrm{D}=$ observed $\%$ of ramets bleached and diseased

Bleaching without disease $=(\mathrm{O} \% \mathrm{~B}-\mathrm{O} \% \mathrm{~B} \& \mathrm{D}) \mathrm{X}$ total ramets

Disease without bleaching $=\left(\mathrm{O}_{\%} \mathrm{D}-\mathrm{O} \% \mathrm{~B} \& \mathrm{D}\right) \mathrm{X}$ total ramets

Bleaching with disease $=\mathrm{O} \% \mathrm{~B}$ X O $\%_{\mathrm{D}} \mathrm{X}$ total ramets

No Bleaching or disease $=(1-(\mathrm{O} \% \mathrm{~B} \& \mathrm{D}+\mathrm{O} \% \mathrm{D}+\mathrm{O} \% \mathrm{~B})) \mathrm{X}$ total ramets

Genets ( 9 of 21) that contained neither a bleached nor a diseased ramet over the entire duration of the study were removed from statistical analyses. We reasoned that these genets lacking vulnerability to both bleaching and disease are unsuitable for studying the interaction of bleaching and disease(Vollmer \& Kline, 2008). Expected values for each test were calculated based upon the pool of observations inclusive of all those genets analyzed by each respective test. Only genets which showed neither bleaching nor disease in all of their ramets were removed from analyses. 


\subsection{Results:}

In September 2014, nine ramets were bleached while fourteen ramets were affected by a white band-like tissue loss disease. In November 2014, four ramets were bleached, while one experienced tissue loss. In January 2014, two ramets were bleached and an additional two were afflicted by tissue loss. In March 2015, both bleaching and tissue loss disease increased in prevalence to eight and eleven cases, respectively (Fig. 4.1). During the entire period, 19 of the $152(12.5 \%)$ A. cervicornis ramets showed signs of bleaching, while 28 ramets $(18.4 \%)$ showed signs of this tissue loss disease. Only one ramet $(0.7 \%)$ showed signs of both bleaching in Sept 2014 and disease recorded in March 2015, though pigmentation had recovered prior to the onset of disease. No ramet with simultaneous bleaching and disease was ever observed.

The tissue loss disease appeared to follow a linear progression from the base towards the apical tips of ramets in a manner reminiscent of white band disease (Fig. 4.2). However, molecular analyses necessary to confirm the identity of the disease were not conducted and the disease we observed is henceforth referred to as a "tissue loss disease". Furthermore, preliminary transmission trials bringing unaffected ramets into contact with the active lesions were unable to induce transmission although a linear progression of tissue loss was apparent. A highly significant negative correlation was detected between the presence of bleaching and disease $\left(\chi^{2}=7.14, p=0.0075\right)$. In total, nine of the 21 genets did not contain a single ramet suffering from either bleaching or disease during the monitoring period. There were significant differences between genets' proportion of ramets bleached, diseased, neither bleached nor diseased, or both bleached and diseased 
despite limited statistical power to detect a medium sized effect $(\mathrm{p}<0.0001,1-\beta=0.31$, Fig. 4.3)(Cohen, 1992).

\subsection{Discussion:}

Focusing on a ramet by ramet basis, our study revealed a negative correlation between bleaching and tissue loss disease during the thermal event in 2014 while simultaneously documenting a positive temporal relationship between bleaching and disease at a population scale (Fig. 4.1). While negative correlation between bleaching and a tissue loss disease has been previously documented (Bruno et al., 2007), ours is the first report that shows a negative correlation between bleaching and a tissue loss disease in individually tracked ramets.

Previous work has indicated that coral genet identity influences diverse host phenotypes such as bleaching susceptibility, disease resistance, growth rate, and morphology (Willis \& Ayre, 1985; Vollmer \& Kline, 2008; Bowden-Kerby \& Carne, 2012; Lirman et al., 2014). Our study further contributes to the body of genotypic response literature, suggesting that host genotype is a significant factor to consider for effective conservation and restoration. Unfortunately, the limited statistical power of our analyses may have contributed to our detection of relatively few significant comparisons (figure 4.3). A much larger analysis including 443 ramets equally distributed amongst genets would have provided a much greater statistical power of 0.90 , but was beyond the scope of the current study. 
Despite the great importance of coral host genetics in determining both bleaching and disease resistance, presence of genets susceptible to only one of the two conditions and resistant to the other does not appear to have solely driven the negative correlation between bleaching and disease. This is evident especially in genets A,J,R, and W (Fig. 4.3) which contain both ramets that suffered from disease and other ramets that suffered from bleaching, although never at the same time (recall that the ramet classified as bleached and diseased in genet $\mathrm{W}$ first bleached and became diseased only after recovering from bleaching). Such a pattern suggests that unbleached ramets within these genets later suffered increased disease susceptibility relative to their clones.

The role of Symbiodinium identity has also been strongly implicated in physiological response to bleaching and disease (Baker, 2004; Tchernov et al., 2004; LaJeunesse et al., 2009; Silverstein, Cunning \& Baker, 2014; Rouzé et al., 2016). Results from a representative subset of samples taken from diverse genets indicates that no ramet had greater than a minimal $(<2 \%)$ variance from exclusively hosting type A3 Symbiodinium (Merselis et al., in prep). Therefore, we suggest that host genetics, not Symbiodinium identity is responsible for observed significant differences between genets. Not only do genet dependent differences in physiology inform which genets will do best in response to one or two focal stressors, but more importantly, which genets we are likely to lose. Given the precipitous decline of Caribbean reefs, and Acropora cervicornis in particular, we suggest that surviving genets likely posses anthropogenically robust traits, even if a study on any one given stressor indicates susceptibility. These differential responses should motivate not only the crossing of very bleaching or disease 
resistant genets, but also the inclusion of genets clearly at risk, but likely possessing unknown resistances to other anthropogenic stressors.

While increased sample size would have benefited analysis at the genet level and probably allowed for the detection of more significant differences $(1-\beta=0.31)$, physiology must be studied at the level of the individual (in this case ramet). Without knowledge of the history of an individual gathered over multiple time points, it is not possible to ascertain whether an individual was not affected by bleaching or disease, suffered only bleaching, suffered only disease, or was afflicted by both bleaching and disease. When individuals are not tracked, but the prevalence of bleaching and tissue loss diseases are followed, it is clear that disease and bleaching are linked through time during temperature anomalies. (Fig. 4.1 of this study; and Muller et al. 2008). However, because both bleaching and many tissue loss diseases are dependent upon temperature as a common stressor, it is expected that they should co-occur along spatial and temporal scales (Fig. 4.1), sharing high incidence where thermal stress has been severe and low incidence where thermal stress is mild (Muller et al., 2008). Without data to show that individuals and not just populations are first affected by bleaching and then disease, a physiological link cannot be supported. As exemplified here, when data is presented on an individual basis along a time series, it is possible that those individuals that bleach may be less prone to disease despite temporal co-occurrence within the population. We suggest it is possible that a negative correlation between bleaching and tissue loss diseases on an individual basis may have been overlooked by previous investigations, because individuals were not tracked across multiple time points (Cróquer \& Weil, 2009). Monitoring individual corals (ramets) within a common garden nursery allowed us to 
control against co-occurrence of bleaching and tissue loss diseases as a result of spatial variation in environmental conditions while enabling repeated assessment of individuals with known bleaching and disease history.

A possible explanatory mechanism for a negative correlation between bleaching and tissue loss diseases may hinge upon the immuno-suppressive nature of intracellular symbioses. Intracellular parasites and mutualists modulate host immunological defenses in order to facilitate their intracellular lifestyles (Oster, Kenyon \& Pedersen, 1978; Fytrou et al., 2006; Douglas, Bouvaine \& Russell, 2011; Ratzka, Gross \& Feldhaar, 2012; Zheng, Tan \& Xu, 2014). Examples are diverse including Rickettsea (Oster, Kenyon \& Pedersen, 1978), Walbachea (Fytrou et al. 2006), Buchnera (Douglas et al. 2011), Spiroplasma (Herren \& Lemaitre, 2011), Sodalis, Wigglesworthia (reviewed in Ratzka et al. 2012), and Plasmodium (reviewed in Zheng et al. 2014), a distant relative of Symbiodinium that interferes with cellular processes to prevent apoptosis (Kaushansky et al., 2013a,b).

Further evidence is apparent within Symbiodinium - Cnidarian symbioses. Cnidarians hosting Symbiodinium express an altered distribution and expression of Rab proteins when compared to their apo-symbiotic con-specifics. This alternative regulation of Rab proteins preserves the symbiosis by preventing the maturation of the symbiosome, the vacuole where the symbiont resides, into a lysosome (Chen et al., 2004; Riesgo et al., 2014). This same dysregulation mechanism possibly impairs the ability for phagosomal degradation of pathogens by cnidarians hosting Symbiodinium. Further, apoptosis, an important immune response, is down-regulated in symbiotic versus aposymbiotic sea anemones (Rodriguez-Lanetty, Phillips \& Weis, 2006; Oakley et al., 2016; Matthews et 
al., 2017)Medrano et al., in prep), while potential cell adhesion markers facilitating pathogen entry are upregulated (Rodriguez-Lanetty et al. 2006; Yuyama et al. 2010; Riesgo et al. 2014). This leads us to think that Symbiodinium containing host cells are immune-suppressed.

Symbiodinium may also promote immunological tolerance of their cnidarian hosts. Exogenous application of tolerogenic factors both decreases immune response of Exaiptasia pallida and prevents it from bleaching under elevated temperatures, while the treatment with an anti-tolerogenic factor prevents symbiosis establishment and stimulates host immune function (Detournay et al., 2012; Berthelier et al., 2017). Recently, anthozoan TGF $\beta$ receptor and other modulators of immune response were proven to be regulated by Symbiodinium produced miRNAs in hospite(Baumgarten et al., 2017). Likewise, many immunological processes lead to the generation of ROS, a primary trigger of coral bleaching (Lesser, 1996), suggesting that corals with high capacity for immunological response may be more susceptible to bleaching. Therefore, corals with the highest immunological activity at the onset of thermal stress may be at an elevated risk of bleaching (Brandt \& Mcmanus, 2009). A host previously lacking in Symbiodinium may be better prepared to confront invading pathogenic microbes. Conversely, corals better prepared to confront invading microbes may be more likely to expel their symbionts as a side effect of an immune response.

Under our proposed model (see Fig. 4.4), bleaching corals gain a transient immunological advantage as a result of shedding their symbionts. Despite disparate thermal bleaching thresholds both between and amongst species, genotypes, and geographic locations, little is known about the "trade-off" or ecological cost for increased bleaching resistance, 
although a slower growth rate for bleaching resistant genotypes has been supported for Acropora cervicornis (Ladd et al., 2017). We suggest that our proposed model is a tradeoff of decreased bleaching resistance in exchange for enhanced immunological function and vise versa.

It is important to note that immunological responses are metabolically costly. Bleaching reduces or completely stops the assimilation of Symbiodinium derived nutrition.

Therefore, the immunological capacity of a bleached coral would eventually be hindered by decreasing energetic reserves. The model, which assumes that Symbiodinium density is directly related to immune-suppression, illustrates that corals would have evolved to consider immunological capacity when setting a bleaching threshold, alongside tolerance for oxidative and thermal stress. By setting a high bleaching threshold, corals forego the putative immunological advantages of bleaching, but retain Symbiodinium until their antioxidant protections against thermal stress become overwhelmed. This strategy would maintain higher energetic reserves and may prove more successful under long term thermal stress scenarios where energetic reserves may become limiting to the maintenance of homeostatic processes and immunological capacity. Conversely, corals may set a low bleaching threshold to protect against infectious disease in the short term at the risk of susceptibility to starvation if thermal stress is long term and prevents the repopulation of Symbiodinium. Corals exploiting this latter strategy suffer ongoing pathogen exposures or thermal stress and may be forced to recover symbiont populations in order to prevent starvation. Resultantly, these corals simultaneously suffer the onset of Symbiodinium mediated immunological suppression and depleted energetic stores. In congruence with field observations, this is perhaps why disease outbreaks may intensify 
upon the onset of bleaching recovery (Brandt \& McManus, 2009). In further agreement with field observations, those corals which bleach and are still unable to prevent the onset of disease outbreaks would be expected to suffer the greatest tissue loss (Muller et al., 2008; Brandt \& McManus, 2009). These corals lack both the immunological competency to prevent infectious disease and the energetic stores to mount a sustained response. Also in agreement with field observations, Symbiodinium densities are greater on eutrophied reefs which also have greater tissue loss disease prevalence (Muscatine et al., 1989; Shantz \& Burkepile, 2014; Vega Thurber et al., 2014). It is worth noting that reefs with more frequent thermal anomaly are known both for their bleaching resistance and white syndrome susceptibility, although it should also be noted that they are more susceptible to brown spot disease (Hume et al., 2013; Fine, Gildor \& Genin, 2013; Palumbi et al., 2014; Randall et al., 2014).

Here, in addition to proposing a new model for infectious disease susceptibility in the context of coral bleaching, we establish a testable hypothesis: Coral bleaching confers a transient immunological advantage to the coral host. While the present study's sample size is limited and canonical logic has historically supported a causal and positive relationship between bleaching and tissue loss diseases, our proposed hypothesis is supported by molecular work and alternative interpretations of several field studies. Further testing is warranted, especially as reefs are exposed to increasingly frequent and intense thermal anomalies. Beyond our proposed hypothesis, this study adds further support to numerous works demonstrating the importance of coral host genotype in determination of diverse physiological traits. 


\subsection{Acknowledgements:}

The authors thank Dr. Kuulei Rodgers, Dr. Tanya Brown, Dr. Anthony Bellantuono, Ms. Ellen Dow, Ms. Cindy Lewis, Mr. Daniel Quintero, and two anonymous reviewers, whose comments improved this manuscript, Stephanie Schopmeyer, Crawford Drury, Dalton Hesley, and Patricia Waikel for diving logistical support, and Dr. Wensong Wu for statistical advice. 


\subsection{Figures:}

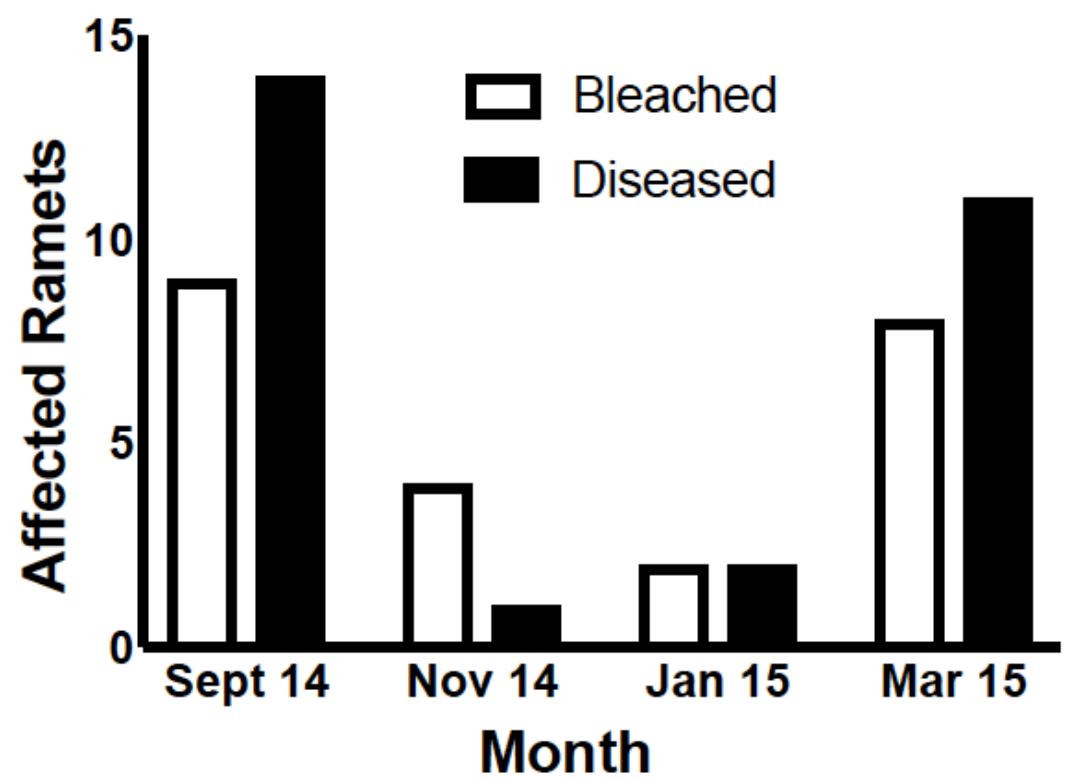

Fig. 4.1: Monthly prevalence of bleached and diseased coral ramets of Acropora cervicornis between September 2014 and March 2015 in the "North Nursery" at Biscayne Bay (N 25.488;W80.109) 


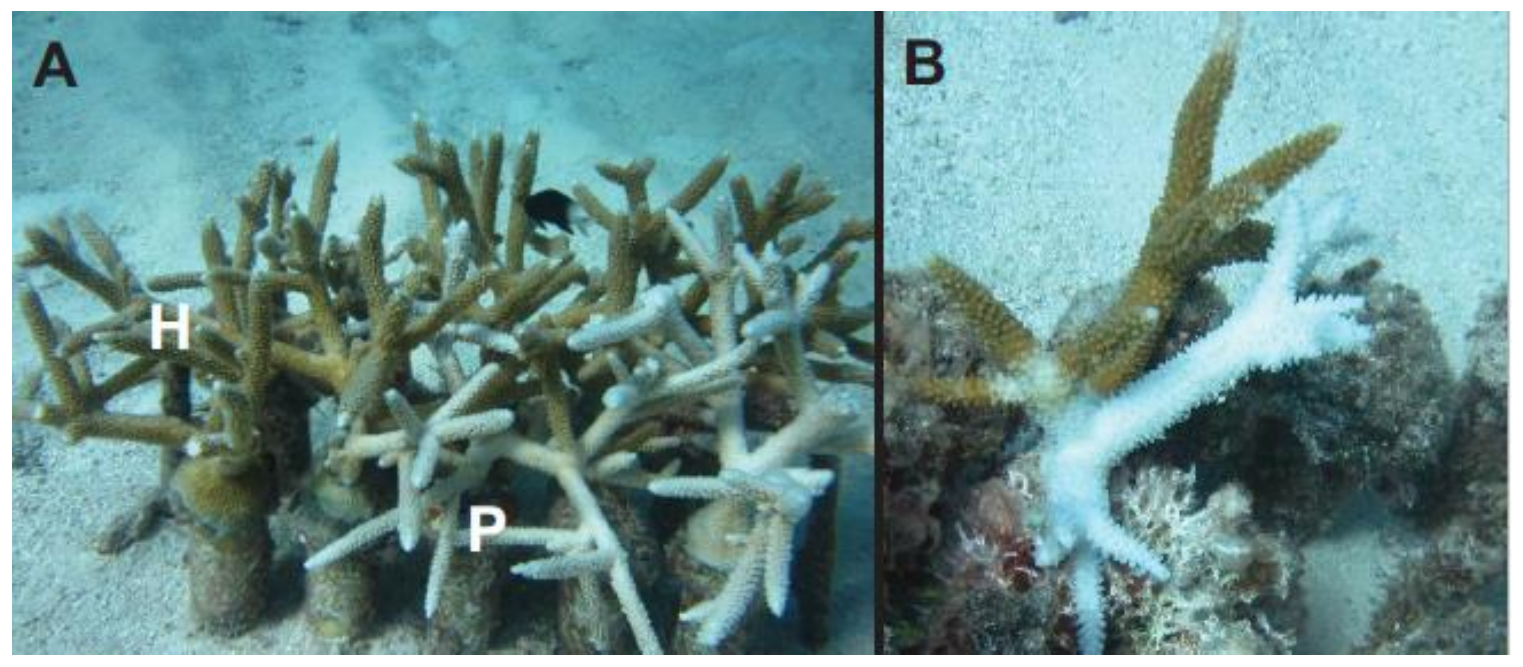

Fig. 4.2: Images of bleaching and diseased colonies of Acropora cervicornis within the North Nursery. Examples of bleaching and diseased colonies of Acropora cervicornis within the North Nursery. (A) Several ramets, some of which show normal, healthy pigmentation $(\mathrm{H})$, while others are bleached pale $(\mathrm{P})$. (B) One ramet showing signs of white band-like white syndrome. Photographs taken by Stephanie Schopmeyer.

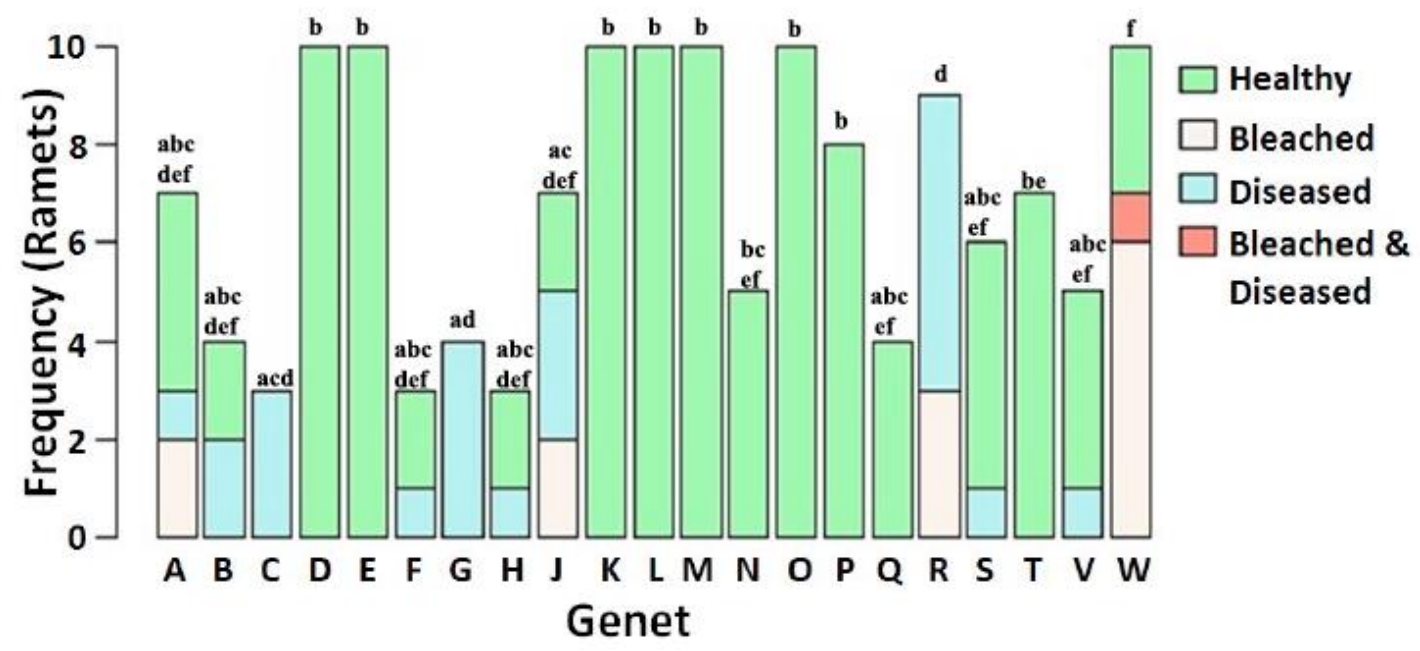

Fig. 4.3: Frequency of health status in Acropora cervicornis corals as a function of genet identity. Genet identity has a significant effect on the probability for each studied health status ( $p<0: 0001)$. Shared letters between genets indicate no significant difference. Both the trend for fewer significant comparisons for those genets with few ramets and low overall statistical power $1-\beta=0: 31$ suggest that more significant differences could have been detected with a larger sample size. 


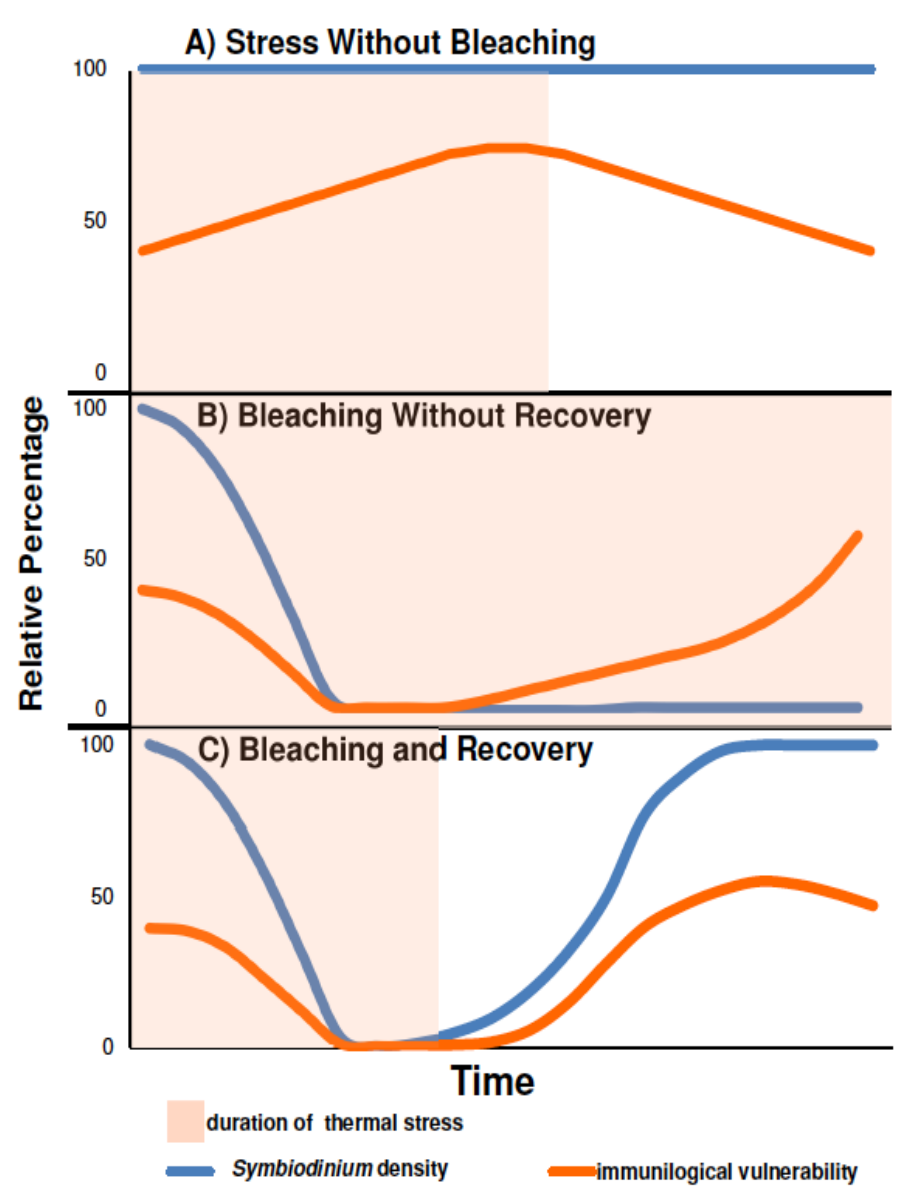

Fig. 4.4: Predicted relative immunological vulnerability assuming Symbiodinium have an immunosuppressive effect on the coral host. (A) A coral which does not bleach in response to a stress event may see immunological vulnerability increase until the stress event subsides. (B) A coral which bleaches and does not recover is free from symbiont immunosuppression, but eventually becomes immunologically vulnerable because of energy store deprivation. (C) A coral which bleaches and recovers may minimize Symbiodinium immunosuppression in the short term, but suffer from reduced energy stores and immunosuppression of returning Symbiodinium upon recovery. 


\subsection{References}

Baird a., Marshall P. 2002. Mortality, growth and reproduction in scleractinian corals following bleaching on the Great Barrier Reef. Marine Ecology Progress Series 237:133-141. DOI: 10.3354/meps237133.

Baker AC. 2004. Corals' adaptive response to climate change. Nature 430:2004.

Ban SS., Graham NAJ., Connolly SR. 2012. Relationships between temperature, bleaching and white syndrome on the Great Barrier Reef. Coral Reefs 32:1-12. DOI: 10.1007/s00338-012-0944-6.

Banin E., Israely T., Fine M., Loya Y., Rosenberg E. 2001. Role of endosymbiotic zooxanthellae and coral mucus in the adhesion of the coral-bleaching pathogen Vibrio shiloi to its host. FEMS Microbiology Letters 199:33-37. DOI: 10.1016/S0378-1097(01)00162-8.

Baumgarten S., Cziesielski MJ., Thomas L., Michell CT., Esherick LY., Pringle JR., Aranda M., Voolstra CR. 2017. Evidence for miRNA-mediated modulation of the host transcriptome in cnidarian-dinoflagellate symbiosis. Molecular Ecology. DOI: 10.1111/mec.14452.

Baums IB. 2008. A synopsis of coral restoration genetics. In: Advances in Coral Husbandry in Public Aquariums. Public Aquarium Husbandry Series. 335-338.

Baums I., Devlin-Durante K., Brown L., Pinzon JH. 2009. Nine novel, polymorphic microsatellite markers for the study of threatened Caribbean acroporid corals. Molecular ecology resources 9:1155-1158. DOI: 10.1111/j.17550998.2009.02588.x.

Baums IB., Miller MW., Hellberg ME. 2005. Regionally isolated populations of an imperiled Caribbean coral, Acropora palmata. Molecular Ecology 14:1377-1390. DOI: 10.1111/j.1365-294X.2005.02489.x.

Berthelier J., Schnitzler CE., Wood-Charlson EM., Poole AZ., Weis VM., Detournay O. 2017. Implication of the host TGF $\beta$ pathway in the onset of symbiosis between larvae of the coral Fungia scutaria and the dinoflagellate Symbiodinium sp. (clade C1f). Coral Reefs 36:1263-1268. DOI: 10.1007/s00338-017-1621-6.

Bourne DG., Garren M., Work TM., Rosenberg E., Smith GW., Harvell CD. 2009. Microbial disease and the coral holobiont. Trends in Microbiology 17:554-562. DOI: $10.1016 /$ j.tim.2009.09.004.

Bowden-Kerby A., Carne L. 2012. Thermal Tolerance as a factor in Caribbean Acropora Restoration. In: Proceedings of the 12th International Coral Reef Symposium. 9-13.

Brandt ME., Mcmanus JW. 2009. Disease incidence is related to bleaching extent in reefbuilding corals. Ecology 90:2859-2867. DOI: 10.1890/08-0445.1. 
Brandt M., McManus J. 2009. Disease incidence is related to bleaching extent in reefbuilding corals. Ecology 90:2859-2867.

Brown BE., Bythell JC. 2005. Perspectives on mucus secretion in reef corals. Marine Ecology Progress Series 296:291-309. DOI: 10.3354/meps296291.

Bruno JF., Selig ER., Casey KS., Page C a., Willis BL., Harvell CD., Sweatman H., Melendy AM. 2007. Thermal stress and coral cover as drivers of coral disease outbreaks. PLoS biology 5:e124. DOI: 10.1371/journal.pbio.0050124.

Chen MC., Cheng YM., Hong MC., Fang LS. 2004. Molecular cloning of Rab5 (ApRab5) in Aiptasia pulchella and its retention in phagosomes harboring live zooxanthellae. Biochemical and Biophysical Research Communications 324:10241033. DOI: 10.1016/j.bbrc.2004.09.151.

Cohen J. 1992. A power primer. Psychological Bulletin 112:155-159. DOI: 10.1037/0033-2909.112.1.155.

Cróquer A., Weil E. 2009. Changes in Caribbean coral disease prevalence after the 2005 bleaching event. Diseases of Aquatic Organisms 87:33-43. DOI: 10.3354/dao02164.

Denner EBM., Smith GW., Busse HJ., Schumann P., Narzt T., Polson SW., Lubitz W., Richardson LL. 2003. Aurantimonas coralicida gen. nov., sp. nov., the causative agent of white plague type II on Caribbean scleractinian corals. International Journal of Systematic and Evolutionary Microbiology 53:1115-1122. DOI: 10.1099/ijs.0.02359-0.

Detournay O., Schnitzler CE., Poole A., Weis VM. 2012. Regulation of cnidariandinoflagellate mutualisms: Evidence that activation of a host TGF $\beta$ innate immune pathway promotes tolerance of the symbiont. Developmental and comparative immunology 38:525-37. DOI: 10.1016/j.dci.2012.08.008.

Douglas AE., Bouvaine S., Russell RR. 2011. How the insect immune system interacts with an obligate symbiotic bacterium. Proceedings. Biological sciences / The Royal Society 278:333-8. DOI: 10.1098/rspb.2010.1563.

Fine M., Gildor H., Genin A. 2013. A coral reef refuge in the Red Sea. Global change biology 19:3640-7. DOI: 10.1111/gcb.12356.

Fytrou A., Schofield PG., Kraaijeveld AR., Hubbard SF. 2006. Wolbachia infection suppresses both host defence and parasitoid counter-defence. Proceedings of the Royal Society B: Biological Sciences 273:791-796. DOI: 10.1098/rspb.2005.3383.

Glynn P. 1983. Extensive“ bleaching” and death of reef corals on the Pacific coast of Panama. Environmental Conservation 10:149-154.

Glynn PW., D'Croz L. 1990. Experimental evidence for high temperature stress as the cause of El Niño-coincident coral mortality. Coral Reefs 8:181-191. DOI: 10.1007/BF00265009. 
Goreau TJ., Macfarlane a. H. 1990. Coral Reefs following the 1987-1988 coralbleaching event. Coral Reefs 8:211-215. DOI: 10.1007/BF00265013.

Haapkylä J., Unsworth RKF., Flavell M., Bourne DG., Schaffelke B., Willis BL. 2011. Seasonal rainfall and runoff promote coral disease on an inshore reef. PLOS ONE 6:1-10. DOI: 10.1371/journal.pone.0016893.

Harriott V. 1985. Mortality rates of scleractinian corals before and during a mass bleaching event. Marine Ecology Progress Series 21:81-88. DOI: 10.3354/meps021081.

Harvell D., Kim K., Burkholder JM., Colwell RR., Epstein PR., Grimes DJ., Hoffman EE., Lipp EK., Osterhause ADME., Overstreet RM., Porter JW., Smith GW., Vasta GR. 1999. Emerging Marine Diseases: Climate Links and Anthropogenic Factors. Science:1505-1510.

Harvell D., Kim K., Quirolo C., Weir J., Smith G. 2001. Coral bleaching and disease: contributors to 1998 mass mortality in Briareum asbestinum (Octocorallia, Gorgonacea). The Ecology and Etiology of Newly Emerging Marine Diseases:97104.

Harvell CD., Mitchell CE., Ward JR., Altizer S., Dobson AP., Ostfeld RS., Samuel MD. 2002. Climate Warming and Disease Risks for Terrestrial and Marine Biota. Science 296:2158-2162. DOI: 10.1126/science.1063699.

Herren JK., Lemaitre B. 2011. Spiroplasma and host immunity: Activation of humoral immune responses increases endosymbiont load and susceptibility to certain Gramnegative bacterial pathogens in Drosophila melanogaster. Cellular Microbiology 13:1385-1396. DOI: 10.1111/j.1462-5822.2011.01627.x.

Hoegh-Guldberg O. 2014. Coral reef sustainability through adaptation: glimmer of hope or persistent mirage? Current Opinion in Environmental Sustainability 7:127-133. DOI: 10.1016/j.cosust.2014.01.005.

Hoegh-Guldberg O., Bruno JF. 2010. The impact of climate change on the world's marine ecosystems. Science (New York, N.Y.) 328:1523-8. DOI: 10.1126/science.1189930.

Hoegh-Guldberg O., Mumby PJ., Hooten a J., Steneck RS., Greenfield P., Gomez E., Harvell CD., Sale PF., Edwards a J., Caldeira K., Knowlton N., Eakin CM., Iglesias-Prieto R., Muthiga N., Bradbury RH., Dubi a., Hatziolos ME. 2007. Coral reefs under rapid climate change and ocean acidification. Science (New York, N.Y.) 318:1737-42. DOI: 10.1126/science.1152509.

Hume B., D’Angelo C., Burt J., Baker a C., Riegl B., Wiedenmann J. 2013. Corals from the Persian/Arabian Gulf as models for thermotolerant reef-builders: Prevalence of clade C3 Symbiodinium, host fluorescence and ex situ temperature tolerance. Marine pollution bulletin 72:313-22. DOI: 10.1016/j.marpolbul.2012.11.032. 
Kaushansky A., Metzger PG., Douglass AN., Mikolajczak SA., Lakshmanan V., Kain HS., Kappe SH. 2013a. Malaria parasite liver stages render host hepatocytes susceptible to mitochondria-initiated apoptosis. Cell death \& disease 4. DOI: 10.1038/cddis.2013.286.

Kaushansky A., Ye AS., Austin LS., Mikolajczak SA., Vaughan AM., Camargo N., Metzger PG., Douglass AN., MacBeath G., Kappe SHI. 2013b. Suppression of Host p53 Is Critical for Plasmodium Liver-Stage Infection. Cell Reports 3:630-637. DOI: 10.1016/j.celrep.2013.02.010.

Ladd M., Shantz A., Bartels E., Burkepile D. 2017. Thermal stress reveals a genotypespecific tradeoff between growth and tissue loss in restored Acropora cervicornis. Marine Ecology Progress Series 572.

LaJeunesse TC., Smith RT., Finney J., Oxenford H. 2009. Outbreak and persistence of opportunistic symbiotic dinoflagellates during the 2005 Caribbean mass coral "bleaching” event. Proceedings. Biological sciences / The Royal Society 276:4139_ 48. DOI: 10.1098/rspb.2009.1405.

Lesser MP. 1996. Elevated temperatures and ultraviolet radiation cause oxidative stress and inhibit photosynthesis in symbiotic dinoflagellates. Limnology and Oceanography 41:271-283. DOI: 10.4319/lo.1996.41.2.0271.

Lesser MP. 2011. Coral Bleaching: Causes and Mechanisms. In: Coral Reefs: An Ecosystem in Transition. Dordrecht: Springer Netherlands, 405-419. DOI: 10.1007/978-94-007-0114-4_23.

Lesser MP., Bythell JC., Gates RD., Johnstone RW., Hoegh-Guldberg O. 2007. Are infectious diseases really killing corals? Alternative interpretations of the experimental and ecological data. Journal of Experimental Marine Biology and Ecology 346:36-44. DOI: 10.1016/j.jembe.2007.02.015.

Lesser MP., Jarett JK. 2014. Culture-dependent and culture-independent analyses reveal no prokaryotic community shifts or recovery of Serratia marcescens in Acropora palmata with white pox disease. FEMS Microbiology Ecology 88:457-467. DOI: 10.1111/1574-6941.12311.

Lewis CL., Neely KL., Richardson LL., Rodriguez-Lanetty M. 2017. Temporal dynamics of black band disease affecting pillar coral (Dendrogyra cylindrus) following two consecutive hyperthermal events on the Florida Reef Tract. Coral Reefs 36:427-431. DOI: $10.1007 / \mathrm{s} 00338-017-1545-1$.

Lirman D., Schopmeyer S. 2016. Ecological solutions to reef degradation: optimizing coral reef restoration in the Caribbean and Western Atlantic. PeerJ 4:e2597. DOI: $10.7717 /$ peerj. 2597.

Lirman D., Schopmeyer S., Galvan V., Drury C., Baker AC., Baums IB. 2014. Growth dynamics of the threatened Caribbean staghorn coral Acropora cervicornis: influence of host genotype, symbiont identity, colony size, and environmental setting. PloS one 9:e107253. DOI: 10.1371/journal.pone.0107253. 
Manzello DP. 2015. Rapid recent warming of coral reefs in the Florida Keys. Scientific Reports 5:16762. DOI: 10.1038/srep16762.

Matthews JL., Crowder CM., Oakley CA., Lutz A., Roessner U., Meyer E., Grossman AR., Weis VM., Davy SK. 2017. Optimal nutrient exchange and immune responses operate in partner specificity in the cnidarian-dinoflagellate symbiosis. Proceedings of the National Academy of Sciences:201710733. DOI: 10.1073/pnas.1710733114.

Miller J., Muller E., Rogers C., Waara R., Atkinson a., Whelan KRT., Patterson M., Witcher B. 2009. Coral disease following massive bleaching in 2005 causes $60 \%$ decline in coral cover on reefs in the US Virgin Islands. Coral Reefs 28:925-937. DOI: 10.1007/s00338-009-0531-7.

Miller J., Waara R., Muller E., Rogers C. 2006. Coral bleaching and disease combine to cause extensive mortality on reefs in US Virgin Islands. Coral Reefs 25:418-418. DOI: 10.1007/s00338-006-0125-6.

Muller EM., Rogers CS., Spitzack a. S., van Woesik R. 2008. Bleaching increases likelihood of disease on Acropora palmata (Lamarck) in Hawksnest Bay, St John, US Virgin Islands. Coral Reefs 27:191-195. DOI: 10.1007/s00338-007-0310-2.

Muscatine L., Falkowski PG., Dubinsky Z., Cook P., McCloskey LR. 1989. The Effect of External Nutrient Resources on the Population Dynamics of Zooxanthellae in a Reef Coral. Proceedings. Biological sciences / The Royal Society 236:311-324.

Muscatine L., Porter J. 1977. Reef corals: mutualistic symbioses adapted to nutrient-poor environments. Bioscience 27:454-460.

Mydlarz LD., Couch CS., Weil E., Smith G., Harvell CD. 2009. Immune defenses of healthy, bleached and diseased Montastraea faveolata during a natural bleaching event. Diseases of Aquatic Organisms 87:67-78. DOI: 10.3354/dao02088.

Oakley CA., Ameismeier MF., Peng L., Weis VM., Grossman AR., Davy SK. 2016. Symbiosis induces widespread changes in the proteome of the model cnidarian Aiptasia. Cellular Microbiology 18:1009-1023. DOI: 10.1111/cmi.12564.

Oster CN., Kenyon RH., Pedersen CEJ. 1978. Suppression of cellular immune responses in guinea pigs infected with spotted fever group rickettsiae. Infection and immunity 22:411-417.

Palmer C V., Bythell JC., Willis BL. 2011. A comparative study of phenoloxidase activity in diseased and bleached colonies of the coral Acropora millepora. Developmental and Comparative Immunology 35:1098-1101. DOI: 10.1016/j.dci.2011.04.001.

Palumbi SR., Barshis DJ., Traylor-Knowles N., Bay RA. 2014. Mechanisms of Reef Coral Resistance to Future Climate Change. Science 344:895-898. DOI: 10.1071/MF99078. 
Patterson KL., Porter JW., Ritchie KB., Polson SW., Mueller E., Peters EC., Santavy DL., Smith GW. 2002. The etiology of white pox, a lethal disease of the Caribbean elkhorn coral, Acropora palmata. Proceedings of the National Academy of Sciences of the United States of America 99:8725-30. DOI: 10.1073/pnas.092260099.

Precht WF., Gintert BE., Robbart ML., Fura R., van Woesik R. 2016. Unprecedented Disease-Related Coral Mortality in Southeastern Florida. Scientific Reports 6:31374. DOI: $10.1038 /$ srep31374.

Randall CJ., Jordan-Garza AG., Muller EM., Van Woesik R. 2014. Relationships between the history of thermal stress and the relative risk of diseases of Caribbean corals. Ecology 95:1981-1994. DOI: 10.1890/13-0774.1.

Randall CJ., van Woesik R. 2015. Contemporary white-band disease in Caribbean corals driven by climate change. Nature Climate Change 5:DOI: 10.1038/NCLIMATE2530. DOI: 10.1038/nclimate2530.

Ratzka C., Gross R., Feldhaar H. 2012. Endosymbiont tolerance and control within insect hosts. Insects 3:553-572. DOI: 10.3390/insects3020553.

Richardson LL., Goldberg WM., Carlton R., Halas JC. 1998. Coral disease outbreak in the Florida Keys: Plague Type II. Rev. Biol. Trop. 46:187-198.

Riesgo A., Peterson K., Richardson C., Heist T., Strehlow B., McCauley M., Cotman C., Hill M., Hill A. 2014. Transcriptomic analysis of differential host gene expression upon uptake of symbionts: a case study with Symbiodinium and the major bioeroding sponge Cliona varians. BMC genomics 15:376. DOI: 10.1186/14712164-15-376.

Ritchie K. 2006. Regulation of microbial populations by coral surface mucus and mucusassociated bacteria. Marine Ecology Progress Series 322:1-14. DOI: 10.3354/meps322001.

Rodriguez-Lanetty M., Phillips WS., Weis VM. 2006. Transcriptome analysis of a cnidarian-dinoflagellate mutualism reveals complex modulation of host gene expression. BMC genomics 7:23. DOI: 10.1186/1471-2164-7-23.

Rouzé H., Lecellier G., Saulnier D., Berteaux-Lecellier V. 2016. Symbiodinium clades A and D differentially predispose Acropora cytherea to disease and Vibrio spp. colonization. Ecology and Evolution 6:560-572. DOI: 10.1002/ece3.1895.

Ruiz-Moreno D., Willis BL., Page a C., Weil E., Cróquer A., Vargas-Angel B., JordanGarza AG., Jordán-Dahlgren E., Raymundo L., Harvell CD. 2012. Global coral disease prevalence associated with sea temperature anomalies and local factors. Diseases of aquatic organisms 100:249-61. DOI: 10.3354/dao02488.

Selig ER., Harvell CD., Bruno JF., Willis BL., Page a C., Casey KA., Sweatman H. 2006. Analyzing the relationship between ocean temperature anomalies and coral disease outbreaks at broad spatial scales. In: Phinney J, Hoegh-Guldberg O, Kleypas 
J, Skirving W eds. Coral reefs and climate change: science and managemen. Washington, DC: American Geophysical Union, 111-128. DOI: 10.1029/61CE07.

Shantz AA., Burkepile DE. 2014. Context-dependent effects of nutrient loading on the coral-algal mutualism. Ecology 95:1995-2005. DOI: 10.1890/13-1407.1.

Siebeck UE., Marshall NJ., Klüter a., Hoegh-Guldberg O. 2006. Monitoring coral bleaching using a colour reference card. Coral Reefs 25:453-460. DOI: 10.1007/s00338-006-0123-8.

Silverstein RN., Cunning R., Baker AC. 2014. Change in algal symbiont communities after bleaching, not prior heat exposure, increases heat tolerance of reef corals. Global change biology:1-14. DOI: 10.1111/gcb.12706.

Sunagawa S., DeSantis TZ., Piceno YM., Brodie EL., DeSalvo MK., Voolstra CR., Weil E., Andersen GL., Medina M. 2009. Bacterial diversity and White Plague Diseaseassociated community changes in the Caribbean coral Montastraea faveolata. The ISME journal 3:512-521. DOI: 10.1038/ismej.2008.131.

Sutherland KP., Shaban S., Joyner JL., Porter JW., Lipp EK. 2011. Human pathogen shown to cause disease in the threatened eklhorn coral Acropora palmata. PLoS ONE 6. DOI: 10.1371/journal.pone.0023468.

Szmant A., Gassman N. 1990. The effects of prolonged "bleaching" on the tissue biomass and reproduction of the reef coral Montastrea annularis. Coral reefs 8:217224.

Tchernov D., Gorbunov MY., de Vargas C., Narayan Yadav S., Milligan AJ., Haggblom M., Falkowski PG. 2004. Membrane lipids of symbiotic algae are diagnostic of sensitivity to thermal bleaching in corals. Proceedings of the National Academy of Sciences 101:13531-13535. DOI: 10.1073/pnas.0402907101.

Vega Thurber RL., Burkepile DE., Fuchs C., Shantz AA., Mcminds R., Zaneveld JR. 2014. Chronic nutrient enrichment increases prevalence and severity of coral disease and bleaching. Global Change Biology 20:544-554. DOI: 10.1111/gcb.12450.

Vollmer S V., Kline DI. 2008. Natural disease resistance in threatened staghorn corals. PLoS ONE 3:1-5. DOI: 10.1371/journal.pone.0003718.

Weil E., Cróquer A., Urreiztieta I. 2009. Yellow band disease compromises the reproductive output of the Caribbean reef-building coral Montastraea faveolata (Anthozoa, Scleractinia). Diseases of Aquatic Organisms 87:45-55. DOI: 10.3354/dao02103.

Willis BL., Ayre DJ. 1985. Asexual reproduction and genetic determination of growth form in the coral Pavona cactus: biochemical genetic and immunogenic evidence. Oecologia:516-525.

Yuyama I., Watanabe T., Takei Y. 2010. Profiling Differential Gene Expression of Symbiotic and Aposymbiotic Corals Using a High Coverage Gene Expression 
Profiling (HiCEP) Analysis. Marine Biotechnology 13:32-40. DOI:

10.1007/s10126-010-9265-3.

Zheng H., Tan Z., Xu W. 2014. Immune evasion strategies of pre-erythrocytic malaria parasites. Mediators of Inflammation 2014. DOI: 10.1155/2014/362605. 


\subsection{Additional Analyses since Publication}

At the request of the dissertation committee, I contribute additional analyses to the otherwise previously published work in chapter four. Additional analyses recapitulate the interpretations reported by the chapter while considering alternative treatments of the data.

In particular, the committee suggested that disregarding ramets that bleached but did not endure the entire study may have selected against a demographic of the surveyed population. Ramets could not feasibly be monitored continuously so it was possible that ramets that bleached and died had died because of disease without ever being identified as diseased.

In order to address the committee's concern, I determined that only one ramet had been classified as bleached and then died before the end of the study, leading to the coral's exclusion from the original analysis. I then repeated the chi square test for independence counting the coral first as bleached and then diseased and second as bleached only giving significant results on both occasions $\left(X^{2}=9.79, \mathrm{p}<0.05\right.$ and $\mathrm{X}^{2}=$ $12.561, \mathrm{p}<0.05$, respectively). 


\section{Chapter 5: Overall Conclusions and Synthesis}

\subsection{Symbiodiniaceae Assemblage Structuring Factors}

My dissertation detected limited change in Symbiodiniaceae community structure of 21 different genets of repeatedly bleached Acropora cervicornis without detectable physiological significance. At the outset of my project, no deep sequencing approaches had yet been applied to Caribbean Acropora. Our work now adds to a building consensus that, even the level of cryptic Symbiodiniaceae, A. cervicornis is a symbiont specialist. Through unmeasured mechanisms, the A. cervicornis surveyed in my dissertation resisted colonization by exogenous Symbiodiniaceae. The fact that corals bleached visibly confirms that greater than $50 \%$ of Symbiodiniaceae were lost and yet, despite having a pre-bleaching cryptic presence in the summer of 2015, thermally tolerant Durusdinium trenchii species was unable to capitalize on the relative absence of competing "Symbiodinium fitti" (nomen novum) symbionts. Perhaps the proliferation of exogenous symbionts in coral holobionts is hampered not just by competitive interactions with native symbionts, but also by host mechanisms biased against hosting exogenous colonizers.

However, Acropora cervicornis occasionally hosts Durusdinium trenchii or even Cladocopium as its dominant symbiont (Baums et al. 2010; Lirman et al. 2014). Can these alternative symbionts be explained by their environment? Durusdinium trenchii hosts were found in constitutively warmer turbid locations (Baums et al. 2010) or could certain developmental stages of even symbiont specialists be susceptible to colonization by alternative symbionts? The cellular mechanisms for host-symbiont specificity require 
further exploration in model systems such as Exaiptasia which has a similar bias against Durusdinium trenchii even when bleached (Gabay et al. 2019; Medrano et al. 2019).

My dissertation further finds no evidence supporting environmental selection acting upon Symbiodiniaceae communities associated with ten genets for each of two Orbicella species. These species have been identified as symbiont generalists since even before the emergence of deep sequencing, owing to great variance even amongst their most dominant symbiont species amongst and within colonies. Even in generalist hosts, Symbiodiniaceae communities do not substantially restructure to facilitate environmental adaptation with a year in the absence of bleaching.

By exploring the Symbiodiniaceae community of Orbicella species using high throughput sequencing, our work further extends the repertoire of symbionts known to engage with these symbiotically flexible coral species including Gerakladium spongiolum. By identifying the presence of G. spongiolum, chapter three adds an additional support to a small, but growing literature hinting that Gerakladium symbionts could be coral symbionts (Kimes et al. 2013; Stat et al. 2013; Thomas et al. 2014; Bonthond et al. 2018) in addition to their associations with sponges (Hill et al. 2011). Further work is needed to determine if cryptic Gerakladium reported here as Gerakladium spongiolum is indeed part of the same species that typically associates with Clionid sponges or if speciation has occurred to allow adaptation to specific hosts. Comparative studies to determine how Gerakladium symbionts have speciated to specialize in specific hosts or how it associates with multiple host phyla would be enlightening to the ongoing hunt to identify mechanisms of host-symbiont specificity and communication. 


\subsection{Adaptive Mechanisms: Conclusions, Limitations, and Future Directions}

My dissertation aimed to ascertain whether bleaching experience could foster the development of an inter-annual memory that would increase bleaching resistance but did not produce any evidence supporting such a mechanism. Despite the possibility of acclimatization influencing, interacting with, and mediating all organismal functions through epigenetic underpinnings, very little is understood in non-model organisms under forecasted environmental scenarios (Torda et al. 2017; Eirin-Lopez and Putnam 2018). Whether epigenetic programs set in place by prior bleaching or thermal experience will even have a net positive or negative effect requires experimental attention (Torda et al. 2017).

Chapter two is one of just three studies investigating the potential for prior bleaching to influence bleaching response in a subsequent year while tracking the Symbiodiniaceae community and it is the only study working with corals grown in a common garden. In three coral species investigated, Grottolli et al. (2014) only identified an improved bleaching response for Porites divaricata, but it also experienced substantial symbiont community change. Orbicella faveolata showed improvements in some metrics of performance, but losses in others also had substantial Symbiodiniaceae change. Porites astreoides fared significantly worse upon the second bleaching exposure and was the only coral species without substantial Symbiodiniaceae community change. Manzello et al., (2019) identified one of ten sites with improved response to a second bleaching event. The lone acclimatizing site was one of several inshore sites, all of which outperformed the offshore sites. Inshore Orbicella was dominated by thermally tolerant Durusdinium trenchii, and temperatures remained warmer on inshore reefs, so it is unclear whether 
better bleaching performance in the second year would have been possible without consistently warmer conditions. The authors conclude that they are not able to disentangle acclimatization vs possible local adaptation explaining differential performance on inshore vs offshore reefs.

Together these three studies agree that the role for innate acclimatization appears limited, but they are far from conclusive. For example, these three studies all consider bleaching as a priming event, rather than using a sub-bleaching thermal stress for priming. Perhaps the thermal damage or metabolic losses suffered by corals in all three studies outweigh the benefits of acquiring a thermally resistant epigenetic program. Consequently, perhaps corals pre-exposed to stressful but sub-bleaching summers prior to bleaching inducing summer temperatures would develop thermally resistant phenotypes. The punctuated record of thermal mass bleaching up to the present date suggests that such a scenario would be a departure from the pattern of warming that has been observed. On local scales, acclimatization facilitated through sub-bleaching thermal exposure may play a substantial role at inshore reefs where temperatures remain high and thermally tolerant epigenetic programs may be more consistently reinforced.

Besides the possibility for acclimatization of mature corals, susceptibility to epigenetic imprinting is different in germ line cells and at different stages of metazoan development. These three studies did not explore the possibility that offspring of these surveyed corals or developing larvae and/or recruits experiencing these same thermal challenges could not acclimatize to a substantial extent (e.g., Cumbo et al. 2013; Putnam and Gates 2015). A critical knowledge-gap remains the longevity of acclimatization and 
whether it is predictive of better performance in trans-annual thermal or disease challenges and thusly a source of hope under annual hyperthermal stress scenarios.

My dissertation did not add further hope for the potential role of Symbiodiniaceae community change to facilitate the persistence of coral reefs. However, the project did provide further evidence that the cryptic Symbiodiniaceae community is not physiologically consequential. Symbiodiniaceae community change clearly structures physiology (Ruiz-Moreno et al. 2012; Hume et al. 2013; Manzello et al. 2019), but by circumstance, the dissertation did not have an opportunity to measure the full physiological potential of Symbiodiniaceae community change because substantial community change was not observed.

The true novelty brought forth in these chapters was the lack of observed community change in response to bleaching, disease, and a critically important environmental variable: depth. My data challenge the likelihood that Symbiodiniaceae community change is likely to occur under A) repetitive bleaching or disease scenarios of symbiont specialist corals or B) transplantation across depths- even in symbiont generalists. Future work is needed to determine whether symbiont generalists would continue to resist changes in community without a bleaching event or whether the time scales explored here were insufficient. Trade-offs associated with hosting alternative symbionts require continued attention as do a mechanism for how coral holobionts are able to accommodate changes in Symbiodiniaceae community.

Finally, all data chapters of my dissertation identify coral genetic identity as a source of variability in every measurement of performance taken. The prominent influence of genetic identity suggests that coral evolution has substantial physiological 
potential. Despite hopeful results, my dissertation does not appraise the likelihood for adaptation to occur and so it remains a major knowledge-gap. Evolutionary models suggest that corals will evolve, but without much regard for the possibility of continuing mass mortality and overall reduction in successful coral reproduction (Matz et al. 2018). One study considering a rapidly growing species that quickly reaches sexual maturity ( $\sim 5$ years) estimated that adaptation could be achieved in 100-250 years in the Great Barrier Reef, where thermally tolerant populations are well-connected across the reef tract, though the authors keenly note that intervention through coral transplantation may accelerate adaptation (Matz et al. 2018). Annual bleaching for virtually all global reefs will set in prior to the end of the century (Van Hooidonk et al. 2013). In Florida, coral cover is scarce, and reproduction amongst rapidly growing species appears to have collapsed a decade before annual bleaching is predicted. It seems dubious that the admittedly rapid rate of adaptation can protect the ecological and economic value of coral reefs as provided by even the most rapidly growing and reproducing species. Assuming the same connectivity, availability of thermally tolerant alleles, and unhindered reproductive success, coral species commonly reaching sexual maturity at 10,15 , or 20 years might expect to adapt in 200-1,000 years.

To build on the foundation of Matz et al. (2018) future efforts should focus on modelling the likelihood of adaptation in species that are less well-connected and/or slower growing with additional consideration for the effects of thermal stress, disease, and other synergistic stressors that may greatly reduce population sizes, and reproductive potential. 


\subsection{Applications in Restoration and Conservation}

Unlike other mechanisms of acclimatization and adaptation discussed in here, our understanding of innate acclimatization without partner change is in its nascent stages. Despite uncertainty, further exploration of acclimatization may reveal stress hardening protocols for facilitating the emergence of anthropogenically robust phenotypes. Therefore, a role for acclimatization by simulating thermal or light stress en masse in restoration programs cannot be advised, though small trials must be attempted. Coral nurseries should, however, be positioned as close as possible (in-situ) to the reefs that they aim to restore, or restoration corals should be brought to a protected in-situ staging site for an acclimatization period prior to final out planting to minimize stress at the time of out planting (Page et al. 2018).

Taken together, Chapters two and three suggest Symbiodiniaceae community selection may represent a challenge which adult corals may not be able to overcome on their own. If the mosaicism of ramets within genets of symbiont generalist species is determined to be temporally stable, restoration nurseries should track not just genet, but also symbiont identity. Such prior knowledge could facilitate outplanting strategies with niche partitioning amongst by ramets of the same genet. Regarding symbiont specialist coral species, nurseries should be constructed in locations in order to foster long term culture, sexual reproduction, and recruit grow-out in environments known to increase the likelihood of anthropogenically robust symbiont colonization of juvenile corals.

In order to facilitate adaptation, coral restorationists must make sexual reproduction a central part of their programs. The loss of some coral genets to events like 
warming temperature and increased disease prevalence is predictable. Their genomic content must be protected within thermal and disease resistant phenotypes of other genets.

As climate change intensifies, even thermally resistant genets will no longer resist bleaching. Besides selective breeding for thermal tolerance and other desirable traits, managers and restorationists must seriously entertain assisted gene flow from corals from warmer locations to higher latitudes. Assisted gene flow integrates thermally selected alleles into local populations and may also extend the lifetime of corals from the warmest areas of the world. A restoration model incorporating sexual reproduction might still rely largely upon asexual propagation of ramets for out-planting but could include dedicated nursery space for the grow-out of sexually mature colonies. For local $\mathrm{x}$ foreign cross genets to be incorporated into nursery brood stock, ramets should perform well on local reefs for a minimum period to prevent genetic swamping and loss of locally adaptive alleles.

Attempting to leverage acclimatization, Symbiodiniaceae community change, or coral evolution all converge on an increased role for sexual reproduction in restoration strategy and proximity of nurseries to the reefs they hope to restore. 


\subsection{References}

Baums IB, Johnson ME, Devlin-Durante MK, Miller MW (2010) Host population genetic structure and zooxanthellae diversity of two reef-building coral species along the Florida Reef Tract and wider Caribbean. Coral Reefs 29:835-842. doi: 10.1007/s00338-010-0645-y

Bonthond G, Merselis DG, Dougan KE, et al. (2018) Inter-domain microbial diversity within the coral holobiont Siderastrea siderea from two depth habitats. PeerJ 6:e4323. doi: 10.7717/peerj.4323

Cumbo VR, Edmunds PJ, Wall CB, Fan TY (2013) Brooded coral larvae differ in their response to high temperature and elevated $\mathrm{pCO} 2$ depending on the day of release. Mar Biol 160:2903-2917. doi: 10.1007/s00227-013-2280-y

Eirin-Lopez JM, Putnam HM (2018) Marine Environmental Epigenetics. Ann Rev Mar Sci 11:335-368. doi: 10.1146/annurev-marine-010318-095114

Gabay Y, Parkinson JE, Wilkinson SP, et al. (2019) Inter-partner specificity limits the acquisition of thermotolerant symbionts in a model cnidarian-dinoflagellate symbiosis. ISME J 1.

Hill M, Allenby A, Ramsby B, et al. (2011) Symbiodinium diversity among host clionaid sponges from Caribbean and Pacific reefs: Evidence of heteroplasmy and putative host-specific symbiont lineages. Mol Phylogenet Evol 59:81-8. doi: 10.1016/j.ympev.2011.01.006

Hume B, D'Angelo C, Burt J, et al. (2013) Corals from the Persian/Arabian Gulf as models for thermotolerant reef-builders: Prevalence of clade C3 Symbiodinium, host fluorescence and ex situ temperature tolerance. Mar Pollut Bull 72:313-22. doi: 10.1016/j.marpolbul.2012.11.032

Kimes NE, Johnson WR, Torralba M, et al. (2013) The Montastraea faveolata microbiome: Ecological and temporal influences on a Caribbean reef-building coral in decline. Environ Microbiol 15:2082-2094. doi: 10.1111/1462-2920.12130

Lirman D, Schopmeyer S, Galvan V, et al. (2014) Growth dynamics of the threatened Caribbean staghorn coral Acropora cervicornis: influence of host genotype, symbiont identity, colony size, and environmental setting. PLoS One 9:e107253. doi: 10.1371/journal.pone.0107253

Manzello DP, Jankulak M, Matz M V, et al. (2019) Role of host genetics and heat tolerant algal symbionts in sustaining populations of the endangered coral Orbicella faveolata in the Florida Keys with ocean warming. Glob Chang Biol 1016-1031. doi: $10.1111 / \mathrm{gcb} .14545$

Matz M V, Treml EA, Aglyamova G V, Bay LK (2018) Potential and limits for rapid genetic adaptation to warming in a Great Barrier Reef coral. PLOS Genet 1-19. 
Medrano E, Merselis DG, Bellantuono AJ, Rodriguez-Lanetty M (2019) Proteomic basis of symbiosis: A heterologous partner fails to duplicate homologous colonization in a novel Cnidarian-Symbiodiniaceae mutualism. Front Microbiol 10:1-15. doi: 10.3389/fmicb.2019.01153

Page CA, Muller EM, Vaughan DE (2018) Microfragmenting for the successful restoration of slow growing massive corals. Ecol Eng 123:86-94. doi: 10.1016/j.ecoleng.2018.08.017

Putnam HM, Gates RD (2015) Preconditioning in the reef-building coral Pocillopora damicornis and the potential for trans-generational acclimatization in coral larvae under future climate change conditions. J Exp Biol 218:2365-2372. doi: $10.1242 /$ jeb. 123018

Ruiz-Moreno D, Willis BL, Page a C, et al. (2012) Global coral disease prevalence associated with sea temperature anomalies and local factors. Dis Aquat Organ 100:249-61. doi: 10.3354/dao02488

Stat M, Pochon X, Franklin EC, et al. (2013) The distribution of the thermally tolerant symbiont lineage (Symbiodinium clade D) in corals from Hawaii: Correlations with host and the history of ocean thermal stress. Ecol Evol 3:1317-1329. doi: $10.1002 /$ ece 3.556

Thomas L, Kendrick G a., Kennington WJ, et al. (2014) Exploring Symbiodinium diversity and host specificity in Acropora corals from geographical extremes of Western Australia with 454 amplicon pyrosequencing. Mol Ecol 23:3113-3126. doi: 10.1111/mec. 12801

Torda G, Donelson JM, Aranda M, et al. (2017) Rapid adaptive responses to climate change in corals. Nat Clim Chang 7:627-636. doi: 10.1038/nclimate3374

Van Hooidonk R, Maynard JA, Planes S (2013) Temporary refugia for coral reefs in a warming world. Nat Clim Chang 3:508-511. doi: 10.1038/nclimate1829 
VITA

\section{DANIEL GARRET MERSELIS}

Born Ridgewood, New Jersey

2007-2011

B.Sc. Molecular Biology

University of New Hampshire

Durham, NH

2011-2013

Manufacturing Associate II

Lonza Biologics

Portsmouth, NH

2013

Research Associate

Mote Marine Laboratory

Sarasota, Fl

2013-2019

Doctoral Candidate

Florida International University

Miami, Fl

\section{PUBLICATIONS AND PRESENTATIONS}

$\uparrow$ denotes mentored student $\mathrm{F}$ denotes equal contributor

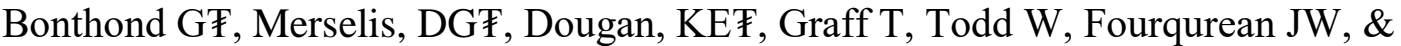
Rodriguez-Lanetty M (2018). Inter-domain microbial diversity within the coral holobiont Siderastrea siderea from two depth habitats. PeerJ, 6, e4323.

Lesser, MP, Bailey, MA, Merselis, DG, \& Morrison, JR (2010), Physiological response of the blue mussel Mytilus edulis to differences in food and temperature in the Gulf of Maine. Comparative Biochemistry and Physiology Part A: Molecular \& Integrative Physiology, 156(4), 541-551.

Medrano EM†, Merselis DG, Bellantuono AJ, and Rodriguez-Lanetty M (2019) Proteomic Basis: A Heterologous Partner Fails to Duplicate Homologous Colonization in a Novel Cnidarian - Symbiodiniaceae Mutualism. Frontiers in Microbiology, 10, 1153.

Merselis DG*, Lirman D, and Rodriguez-Lanetty M, Fostering Lasting Acropora cervicornis Restoration: Potential for Selective Breeding, Thermal Priming, and Symbiodiniaceae Inoculation, Reef Futures Symposium, Key Largo, Fl December 2018 
Merselis DG, Lirman D, and Rodriguez-Lanetty M (2018). Symbiotic immunosuppression: Is disease susceptibility the price of bleaching resistance? International Symbiosis Society Congress, June, 2018

Merselis DG, Lirman D, and Rodriguez-Lanetty M (2018). Symbiotic immunosuppression: Is disease susceptibility the price of bleaching resistance? PeerJ 6, e4494.

Merselis DG*, Anthony Bellantuono AJ, Dougan KE, Thinesh T,Nedimeyer K, NEEMO consortium, and Rodriguez-Lanetty M, Effects of Genotype and Environmental History on Coral Nursery Bleaching Resistance, Florida International University Biosymposium, February, 2018

Merselis DG*, Bellantuono AJ*, Rodriguez-Lanetty, M.: Engineering the Coral Reefs of the Future, Fort Lauterdale International Boat Show, October, 2017

Merselis DG*, Rodriguez-Lanetty M.: Facilitating Coral Adaptation During a Mass Extinction Event, Gumbo Limbo Nature Center, April, 2017

Merselis DG*; Dougan KE; Bellantuono AJ*; and Rodriguez-Lanetty M.: How Low Can You Go: Restoration and coral holobiont composition across depths on Conch Reef, Keys Marine Laboratory Winter Science Seminar, February, 2017

Merselis DG*; Drury CR; Schopmeyer SA, Lirman D, Rodriguez-Lanetty M: Evaluating the Contribution of Host Genotype, Symbiodinium Community, and Bleaching History in Repeatedly Bleached Acropora cervicornis Nurseries, International Coral Reef Symposium, June, 2016

Merselis DG* and Rodriguez-Lanetty M: Coral restoration: importance of genotype in thermal stress, Florida International University Biological Symposium, January, 2015

Merselis DG* and Lesser MP: Presence of Superoxide Dismutase Metalloproteins in Symbiodinium spp., the photosynthetic dinoflagellate symbionts of Cnidarians Honors Senior Thesis Seminar, University of New Hampshire, May, 2011

Ritchie KB, Schwarz M, Mueller J†, Lapacek V.A, Merselis DG., Walsh CJ, Luer, CA (2017). Survey of antibiotic-producing bacteria associated with the epidermal mucus layers of rays and skates. Frontiers in Microbiology, 8, 1050. 